INSTITUTO DE PESQUISAS ENERGÉTICAS E NUCLEARES

Autarquia Associada à Universidade de São Paulo

SÍNTESE DE ELETROCATALISADORES DE PdRu/C PELO MÉTODO DE REDUÇÃO POR BOROHIDRETO DE SÓDIO PARA ELETROOXIDAÇÃO DO ETANOL E GLICEROL EM MEIO ALCALINO

CARLOS EDUARDO DOMINGUES RAMOS

Dissertação apresentada como parte dos requisitos para obtenção do Grau de Mestre em Ciências na Área de Tecnologia Nuclear - Materiais

Orientador:

Prof. Dr. Almir Oliveira Neto

São Paulo 


\section{INSTITUTO DE PESQUISAS ENERGÉTICAS E NUCLEARES \\ Autarquia Associada à Universidade de São Paulo}

SíNTESE DE ELETROCATALISADORES DE PdRu/C PELO MÉTODO DE REDUÇÃO POR BOROHIDRETO DE SÓDIO PARA ELETROOXIDAÇÃO DO ETANOL E GLICEROL EM MEIO ALCALINO

Versão Corrigida

Versão Original disponível no IPEN

CARLOS EDUARDO DOMINGUES RAMOS

Dissertação apresentada como parte dos requisitos para obtenção do Grau de Mestre em Ciências na Área de Tecnologia Nuclear - Materiais

Orientador:

Prof. Dr. Almir Oliveira Neto

\section{São Paulo}


Fonte de Financiamento: CNPq

Autorizo a reprodução e divulgação total ou parcial deste trabalho, para fins de estudo e pesquisa, desde que citada a fonte

Como citar:

DOMINGUES RAMOS, C. E. . SÍNTESE DE ELETROCATALISADORES DE PdRu/C PELO MÉTODO DE REDUÇÃO POR BOROHIDRETO DE SÓDIO PARA ELETROOXIDAÇÃO DO ETANOL E GLICEROL EM MEIO ALCALINO . 2020. 83 p. Dissertação (Mestrado em Tecnologia Nuclear), Instituto de Pesquisas Energéticas e Nucleares, IPEN-CNEN/SP, São Paulo. Disponível em: (data de consulta no formato: $\mathrm{dd} / \mathrm{mm} / \mathrm{aaaa})$

Ficha catalográfica elaborada pelo Sistema de geração automática da Biblioteca IPEN/USP, com os dados fornecidos pelo(a) autor(a)

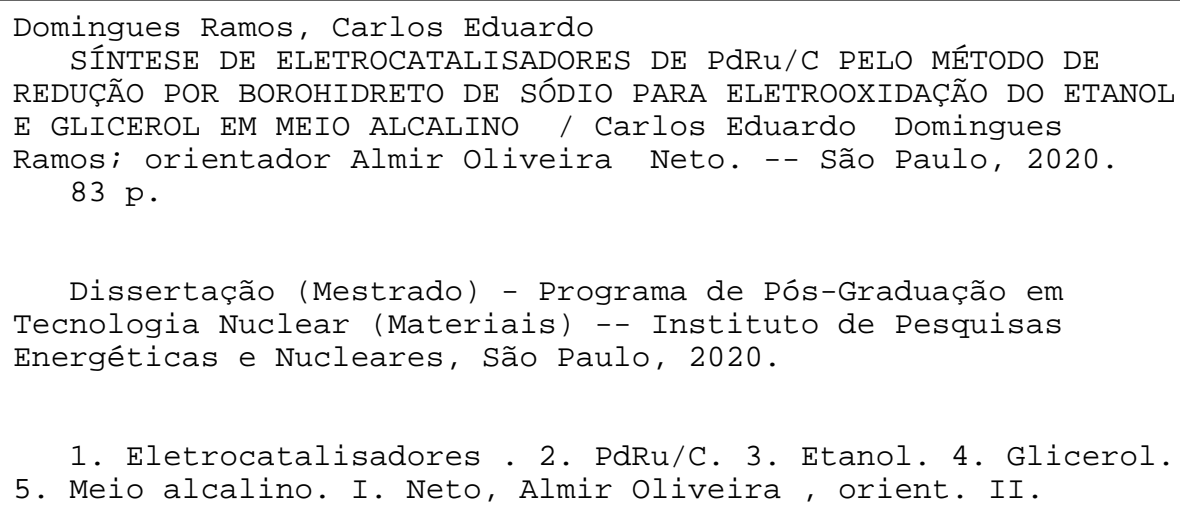




\section{AGRADECIMENTOS}

Agradeço a Deus, por me abençoar e fortalecer todos os dias, graças ao Senhor entrego mais um trabalho.

Aos meus pais, que mesmo em poucas condições me criaram e me fizeram um homem honesto. Agradeço também a minha irmã que sempre acreditou que eu conseguiria muitas conquistas na vida.

Ao meu orientador Prof. Dr. Almir Oliveira Neto e a Prof. Dra. Cristiane Ottoni pela amizade, conhecimento transmitido e por sempre acreditar em mim e não deixar eu desistir no decorrer do trabalho.

Aos meus amigos do laboratório, Eric, Conrado, Vitor, Nandenha, Robinson, Luís, Sirlane, Nivaldo, Vivi, Julian, Rodiney, Aninha, Jamil e Rodrigo. Meus amigos, todos vocês contribuíram para meu sucesso, nunca me esquecerei de vocês.

E por fim ao IPEN pela infraestrutura e ao CNPq pelo auxílio financeiro, muitíssimo obrigado. 
"O fracasso jamais me surpreenderá, se a minha decisão de vencer for suficientemente forte."

Og Mandino 


\title{
SÍNTESE DE ELETROCATALISADORES DE PdRu/C PELO MÉTODO DE REDUÇÃO POR BOROHIDRETO DE SÓDIO PARA ELETROOXIDAÇÃO DO ETANOL E GLICEROL EM MEIO ALCALINO
}

\section{Carlos Eduardo Domingues Ramos}

\begin{abstract}
RESUMO
Os eletrocatalisadores de $\mathrm{PdRu} / \mathrm{C}$ foram sintetizados pelo método de redução via borohidreto de sódio com uma carga metálica de $20 \%$ em massa suportados em carbono Vulcan XC-72 em diferentes proporções mássicas. Os eletrocatalisadores obtidos neste trabalho foram caracterizados por espectroscopia de energia dispersiva de raios $X(E D X)$, difração de raios $X(D R X)$, microscopia eletrônica de transmissão (MET), espectroscopia de fotoelétrons excitados por raios X (XPS), espectroscopia na região do infravermelho (ATR-FTIR), voltametria cíclica e cronoamperometria. Também se aplicou a experimentos em uma célula a combustível de etanol e glicerol direto (DEFC e DGFC). A caracterização por EDX permitiu obter informações a respeito da composição atômica do material em estudo. Espectros de DRX para todos os eletrocatalisadores de $\mathrm{PdRu} / \mathrm{C}$ indicaram um deslocamento do pico do $\mathrm{Pd}(\mathrm{fcc})$ relativo ao plano (220) para maiores valores de $2 \theta$. Histogramas gerados pela contagem das nanopartículas obtidas por MET para PdRu/C mostraram nanopartículas homogêneas e distribuídas sobre o suporte com tamanhos entre 2,9 a $6,5 \mathrm{~nm}$. Os resultados de XPS revelaram diferentes estados de oxidação $\left(\mathrm{Ru}^{0}\right.$ e $\left.\mathrm{RuO}_{2}\right)$ nos quais favorecem as oxidações das espécies intermediárias adsorvidas, por meio do mecanismo bifuncional. O eletrocatalisador PdRu/C (90:10) demonstrou-se ter o melhor desempenho para oxidação eletrocatalítica do etanol e glicerol observado pelas análises de voltametria linear e cronoamperometria, entretanto, nos ensaios em célula a combustível de álcool direto (DEFC e DGFC) o eletrocatalisador PdRu/C (70:30) exibiu o maior valor de densidade de potência em comparação aos demais eletrocatalisadores tanto para eletro-oxidação do etanol quanto a do glicerol em meio alcalino.
\end{abstract}

Palavras-chave: Eletrocatalisadores de PdRu/C, Etanol, Glicerol, meio alcalino. 


\title{
SYNTHESIS OF PdRU/C ELECTROCATALYSTS PREPARED WITH SODIUM BOROHYDRIDE REDUCTION METHOD FOR ETHANOL AND GLYCEROL ELECTROOXIDATION IN ALKALINE MEDIA
}

\section{Carlos Eduardo Domingues Ramos}

\begin{abstract}
The PdRu/C electrocatalysts were synthesized by the sodium borohydride reduction method, with $20 \%$ of the metallic load. The metal nanoparticles were supported on Carbo Vulcan XC-72, loading to different Pd:Ru mass proportions. The electrocatalysts obtained in this work were characterized by $X$-ray dispersive energy spectroscopy (EDX), X-ray diffraction (DRX), transmission electron microscopy (TEM), X-ray excited photoelectron spectroscopy (XPS), Fourier- transform infrared spectroscopy (ATRFTIR), cyclic voltammetry and chronoamperometry. It also applied to direct-ethanol and glycerol fuel cells (DEFC and DGFC). The characterization by EDX allowed us to obtain information about the respect of the atomic composition of the material under study. XRD spectra for all PdRu / C electrocatalysts indicate a shift from the Pd peak (fcc) relative to the plane (220) to higher $2 \theta$ values. Histograms achieved by counting nanoparticles recorded by TEM for PdRu/C showing homogeneous nanoparticles and distributed on the support with sizes between 2.9 and $6.5 \mathrm{~nm}$. The XPS results revealed different oxidation states $\left(\mathrm{Ru}^{0}\right.$ and $\left.\mathrm{RuO}_{2}\right)$ in which they favor oxidation of adsorbed intermediate species, through the bifunctional mechanism. The PdRu/C electrocatalyst $(90: 10)$ demonstrated the best performance for the electrocatalytic oxidation of ethanol and glycerol, observing the analyzes of linear voltammetry and chronoamperometry, however, in the tests using direct-ethanol and glycerol fuel (DEFC and DGFC) PdRu/C (70:30) electrocatalyst exhibited the highest power density value compared to other electrocatalysts.
\end{abstract}

Keywords: PdRu/C Electrocatalysts, Ethanol, Glycerol, alkaline medium. 


\section{LISTA DE TABELAS}

Tabela 1 - Composição atômica nominal e experimental obtidas por EDX dos eletrocatalisadores de Pd/C, PdRu/C (90:10; 70:30; 50:50) e Ru/C

Tabela 2 - Tamanho médio das nanopartículas dos eletrocatalisadores $\mathrm{Pd} / \mathrm{C}$ e $\mathrm{PdRu} / \mathrm{C}$ (90:10; 70:30 e 50:50) sintetizados pelo método de redução via borohidreto de sódio

Tabela 3 - Determinação da composição atômica dos eletrocatalisadores considerando os diferentes estados de oxidação formados na superfície dos eletrocatalisadores $\mathrm{Ru} / \mathrm{C}, \mathrm{Pd} / \mathrm{C}$ e $\mathrm{PdRu} / \mathrm{C}$ (50:50; 70:30 e 90:10) sintetizados pelo método de redução via borohidreto de sódio

Tabela 4 - Experimentos em DEFC utilizando eletrocatalisadores $\mathrm{Ru} / \mathrm{C}, \mathrm{Pd} / \mathrm{C}$ e $\mathrm{PdRu} / \mathrm{C}$ (50:50; 70:30 e 90:10), destaque para o potencial de circuito aberto em $\mathrm{V}$ e densidade de potência em $\mathrm{mW}$.

Tabela 5 - Potenciais de início de oxidação eletroquímica do glicerol e densidades de corrente de pico para os eletrocatalisadores $\mathrm{Pd} / \mathrm{C}$ e PdRu/C (90:10) .70 Tabela 6 - Experimentos em DGFC utilizando eletrocatalisadores $\mathrm{Ru} / \mathrm{C}, \mathrm{Pd} / \mathrm{C}$ e $\mathrm{PdRu} / \mathrm{C}$ (50:50; 70:30 e 90:10), destaque para o potencial de circuito aberto em $\mathrm{V}$ e densidade de potência em $\mathrm{mW}$ 


\section{LISTA DE FIGURAS}

FIGURA 1 - Representação esquemática de uma célula a combustível do tipo

PEMFC.

FIGURA 2 - Rota da eletro-oxidação do etanol em meio alcalino sobre paládio.........21

FIGURA 3 - Fluxograma para preparar eletrocatalisadores via redução borohidreto de sódio.

FIGURA 4 - Espectros da composição dos elementos constituintes da amostra: (a) $\mathrm{PdRu} / \mathrm{C}$ preparado pelo método de redução por borohidreto de sódio.

FIGURA 5 - Micrografias obtidas por MEV: (a) PdRu/C (50:50) e (b) PdRu/C (70:30)

(c) $\mathrm{PdRu} / \mathrm{C}(90: 10)$ preparado pelo método de redução via borohidreto de sódio........39

FIGURA 6 - Padrões de difração de raios $X$ obtidos em um intervalo de medida $2 \theta=20^{\circ}$ a $90^{\circ}$, incrementos de $0,05^{\circ}$ e com uma velocidade de varredura de $2^{\circ} \mathrm{min}^{-1}$ dos eletrocatalisadores de $\mathrm{Pd} / \mathrm{C}, \mathrm{Ru} / \mathrm{C}$ e PdRu/C (90:10, 70:30 e 50:50) em forma de pó.

FIGURA 7 - Micrografia obtida por microscopia eletrônica de transmissão e histograma da distribuição de tamanho médio de nanopartícula metálica (a) $\mathrm{Pd} / \mathrm{C}$. (b) $\mathrm{PdRu} / \mathrm{C}$ (90:10) (c) PdRu/C (70:30) (d) PdRu/C (50:50) (e) Ru/C.

FIGURA 8 - Espectros de XPS C1s da superfície dos eletrocatalisadores de (a) $\mathrm{PdRu} / \mathrm{C}$ 90:10, (b) PdRu/C 70:30 e (c) PdRu/C 50:50

FIGURA 9 - Espectros de XPS O1s da superfície do eletrocatalisadores (a) PdRu/C 90:10. (b) PdRu/C (70:30) e (c) PdRu/C (50:50)

FIGURA 10 - Espectros de XPS Pd3d da superfície do eletrocatalisador (a) PdRu/C 90:10 (b) PdRu/C (70:30) e (c) PdRu/C (50:50)

FIGURA 11 - Espectros de XPS Ru3p da superfície do eletrocatalisador (a) PdRu/C 90:10, (b) PdRu/C (70:30) e (c) PdRu/C (50:50)

FIGURA 12 - Voltamogramas cíclicos dos eletrocatalisadores $\mathrm{Ru} / \mathrm{C}, \mathrm{Pd} / \mathrm{C}$ e PdRu/C (50:50; 70:30 e 90:10) em solução de $\mathrm{KOH} 1,0 \mathrm{M}$ na ausência de etanol com uma velocidade de varredura de $10 \mathrm{mV} \mathrm{s}^{-1}$.....

FIGURA 13 - Voltamogramas linear obtidos a temperatura ambiente dos eletrocatalisadores Ru/C, Pd/C e PdRu/C (50:50; 70:30 e 90:10) em solução de KOH $1,0 \mathrm{M}$ na presença de 1,0 M EtOH com uma taxa de varredura de $10 \mathrm{mV} \mathrm{s}^{-1}$.....

FIGURA 14 - Curvas de cronoamperometria obtidos a temperatura ambiente dos eletrocatalisadores $\mathrm{Ru} / \mathrm{C}, \mathrm{Pd} / \mathrm{C}$ e PdRu/C (50:50; 70:30 e 90:10) em solução de $\mathrm{KOH}$ $1,0 \mathrm{M}$ na presença de $1,0 \mathrm{M} \mathrm{EtOH}$. Potencial aplicado de $-0,35 \mathrm{~V}$ durante 1800 segundos.

FIGURA 15 - Espectros no infravermelho obtidos durante a reação de oxidação de etanol $\left(1 \mathrm{~mol} \mathrm{~L}^{-1}\right)$ em diferentes potenciais, com eletrólito de $\mathrm{KOH} 1 \mathrm{~mol} \mathrm{~L}^{-1}$ sobre eletrocatalisadores baseados em $\mathrm{PdRu} / \mathrm{C}$.

FIGURA 16 - Produção de espécies oriundas da oxidação do etanol, as bandas relativas a $\mathrm{CO}_{2}$, carbonato e acetato.

Figura 17 - Curvas de polarização de uma DEFC utilizando eletrocatalisadores $R u / C$, $\mathrm{Pd} / \mathrm{C}$ e PdRu/C (50:50; 70:30 e 90:10) no ânodo, com uma carga metálica de $1 \mathrm{mg} \mathrm{Pd}$ $\mathrm{cm}^{-2}$, em temperatura de operação de $80 \stackrel{\circ}{\circ}$, com fluxo contínuo de etanol de $2 \mathrm{M} \mathrm{KOH}+\mathrm{EtOH}$ 
FIGURA 18 - Curvas de densidade de potência de uma DEFC utilizando eletrocatalisadores $\mathrm{Ru} / \mathrm{C}, \mathrm{Pd} / \mathrm{C}$ e PdRu/C (50:50; 70:30 e 90:10) no anodo, com uma carga metálica de $1 \mathrm{mg} \mathrm{Pd} \mathrm{cm}{ }^{-2}$, em temperatura de operação de $80^{\circ} \mathrm{C}$, com fluxo contínuo de etanol de $2 \mathrm{M} \mathrm{KOH}+\mathrm{EtOH}$.

FIGURA 19 - Voltamogramas cíclicos dos eletrocatalisadores Ru/C, Pd/C e PdRu/C (50:50; 70:30 e 90:10) em solução de $\mathrm{KOH} \mathrm{1,0} \mathrm{M} \mathrm{na} \mathrm{ausência} \mathrm{de} \mathrm{glicerol} \mathrm{com} \mathrm{uma}$ taxa de varredura de $10 \mathrm{mV} \mathrm{s}^{-1}$

FIGURA 20 - Voltamogramas lineares obtidos a temperatura ambiente dos eletrocatalisadores $\mathrm{Ru} / \mathrm{C}, \mathrm{Pd} / \mathrm{C}$ e PdRu/C (50:50; 70:30 e 90:10) em solução de KOH $1,0 \mathrm{M}$ na presença de $1,0 \mathrm{M}$ Glicerol com uma taxa de varredura de $10 \mathrm{mV} \mathrm{s}^{-1}$ .70 FIGURA 21 - Curvas de cronoamperometria obtidos a temperatura ambiente dos eletrocatalisadores Ru/C, Pd/C e PdRu/C (50:50; 70:30 e 90:10) em solução de KOH 1,0 M na presença de 1,0 M de glicerol. Potencial aplicado de $-0,35 \mathrm{~V}$ no período de 1800 segundos.

FIGURA 22 - Espectros no infravermelho obtidos durante a reação de oxidação de etanol (1 mol L-1) em diferentes potenciais, com eletrólito de $\mathrm{KOH} 1 \mathrm{~mol} \mathrm{~L}^{-1}$ sobre eletrocatalisadores $\mathrm{PdRu} / \mathrm{C}$ 74

FIGURA 23 - Produtos de oxidação do glicerol como a $1411 \mathrm{~cm}^{-1}$ correspondente ao carbonato, $1377 \mathrm{~cm}^{-1}$ atribuída ao glicerato, $1355 \mathrm{~cm}^{-1}$ para hidroxipiruvato, $1339 \mathrm{~cm}^{-1}$ para tartronato e $1225 \mathrm{~cm}^{-1}$ para formiato. 76

Figura 24 - Curvas de polarização de uma DEFC utilizando eletrocatalisadores $\mathrm{Ru} / \mathrm{C}$, $\mathrm{Pd} / \mathrm{C}$ e PdRu/C (50:50; 70:30 e 90:10) no ânodo, com uma carga metálica de 1mg Pd $\mathrm{cm}^{-2}$, em temperatura de operação de $80 \stackrel{\circ}{\circ}$, com fluxo contínuo de etanol de $2 \mathrm{M} \mathrm{KOH}+\mathrm{EtOH}$

FIGURA 25 - Curvas de densidade de potência de uma DEFC utilizando eletrocatalisadores $\mathrm{Ru} / \mathrm{C}, \mathrm{Pd} / \mathrm{C}$ e PdRu/C (50:50; 70:30 e 90:10) no ânodo, com uma carga metálica de $1 \mathrm{mg} \mathrm{Pd} \mathrm{cm}{ }^{-2}$, em temperatura de operação de $80 \stackrel{\circ}{\circ}$, com fluxo contínuo de etanol de $2 \mathrm{M} \mathrm{KOH}+\mathrm{EtOH}$. 


\section{LISTA DE ABREVIAÇÕES}

CaC - Célula a Combustível

DAFC - Célula a combustível de álcool direto

DEFC - Célula a combustível de etanol direto

DGFC - Célula a combustível de glicerol direto

DRX - Difração de raios $X$

EDX - Espectroscopia de energia dispersiva de raios $X$

MEA - Conjunto eletrodo-membrana

MET - Microscopia eletrônica de transmissão

XPS - Espectroscopia de fotoelétrons excitados por raios $X$

$\mathrm{EtOH}$ - Etanol 


\section{SUMÁRIO}

1. INTRODUÇÃO

2. OBJETIVOS

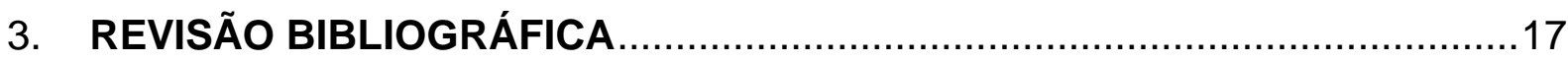

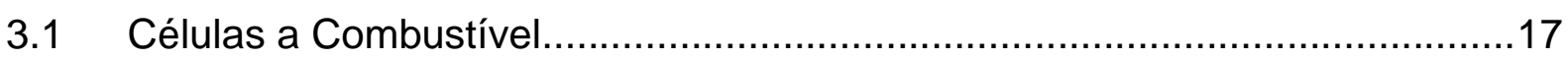

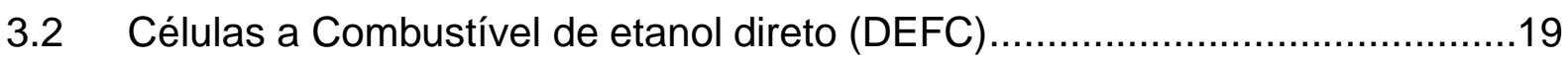

3.2.1 Eletro-oxidação do etanol em células (DEFC)..............................................

3.3 Células a combustível de glicerol direto (DGFC) .........................................22

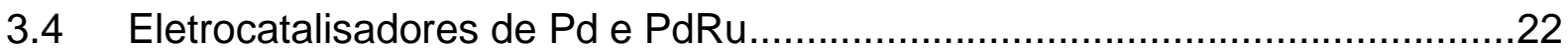

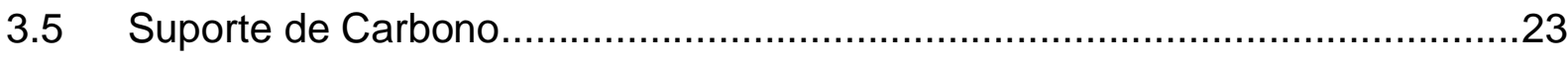

3.6 Métodos de preparação de eletrocatalisadores...........................................24

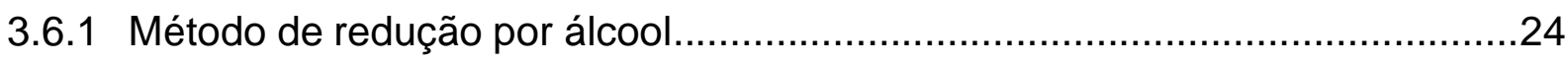

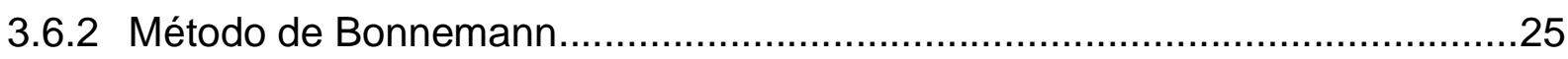

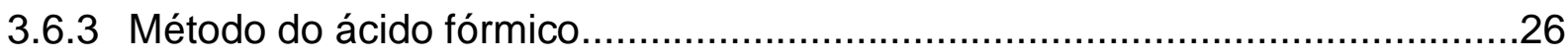

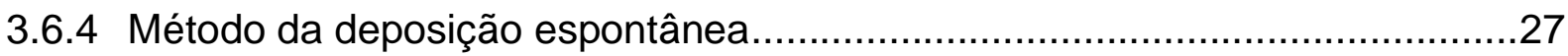

3.6.5 Método de redução por Borohidreto de sódio $\left(\mathrm{NaBH}_{4}\right) \ldots \ldots \ldots \ldots \ldots \ldots \ldots \ldots \ldots \ldots \ldots . . .27$

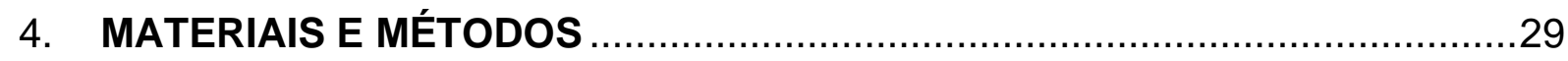

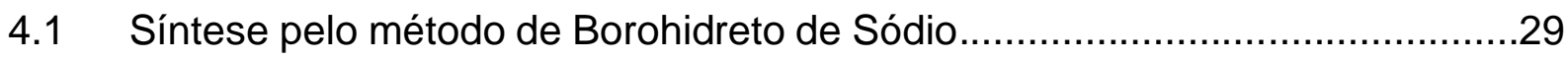

4.2 Caracterização físico-química dos eletrocatalisadores....................................30

4.3 Espectroscopia de energia dispersiva de raios X (EDX) ..............................30

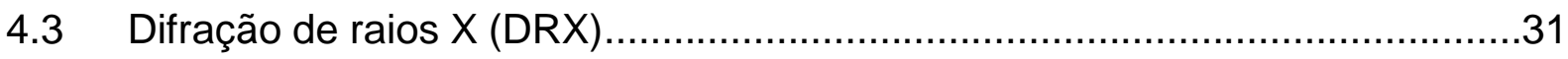

4.5 Microscopia eletrônica de transmissão (MET) ...........................................32

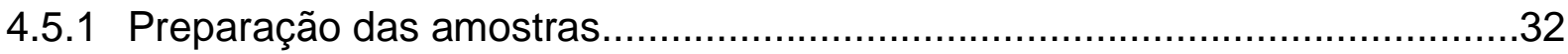

4.6 Espectroscopia de Fotoelétrons de raios X (XPS) ........................................33

4.7 Espectroscopia no infravermelho com reflectância total atenuada

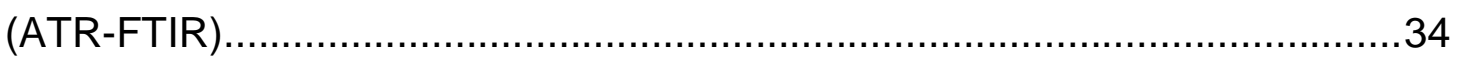

4.8 Caracterização eletroquímica dos eletrocatalisadores...................................34

4.9 Experimento em célula a combustível do tipo DEFC e DGFC..........................35

4.9.1 Preparação do conjunto membrana-eletrodo (MEA) ......................................35

4.9.2 Experimento em célula a combustível.......................................................36

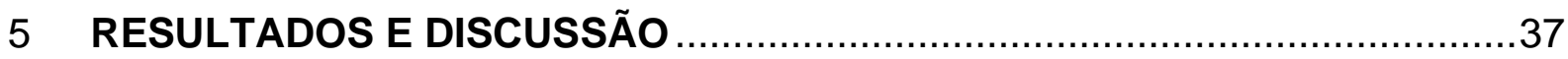

5.1 Espectroscopia por energia dispersiva de raios X (EDX) ..............................37 


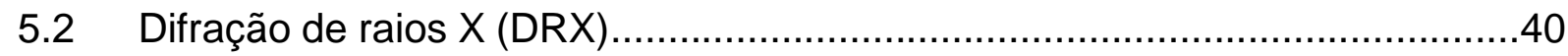

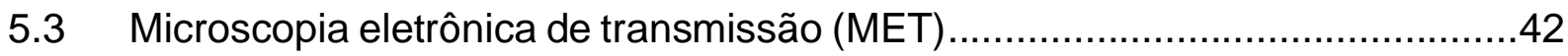

5.4 Espectroscopia de Fotoelétrons de raios X (XPS) .....................................45

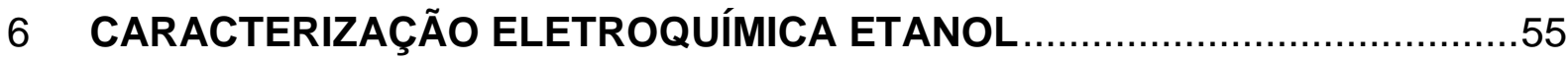

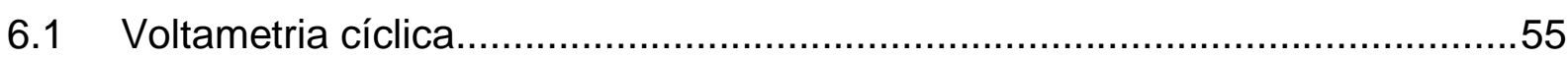

6.2 Desempenho Eletrocatalítico para a Oxidação Eletroquímica do Etanol..........56

6.3 Espectroscopia no infravermelho com reflectância total atenuada

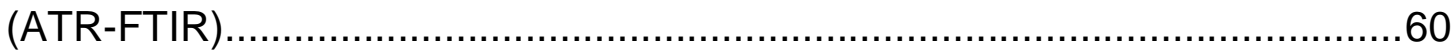

6.4 Experimento em Célula a Combustível de etanol direto..................................64

7 CARACTERIZAÇÃO ELETROQUÍMICA GLICEROL …................................67

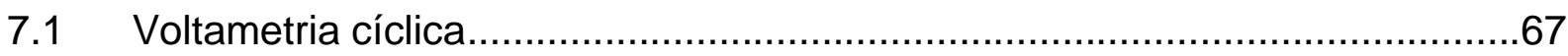

7.2 Desempenho eletrocatalítico para a oxidação eletroquímica do glicerol.........69

7.3 Espectroscopia no infravermelho com reflectância total atenuada

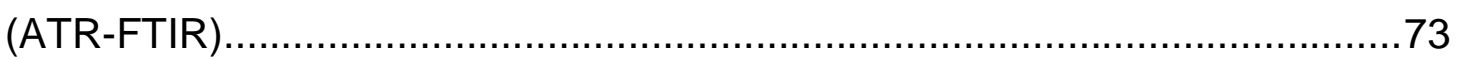

7.4 Experimento em Célula a Combustível.....................................................77

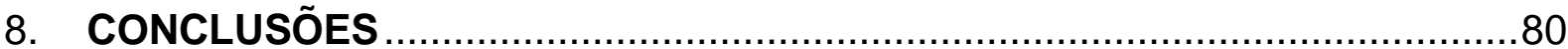

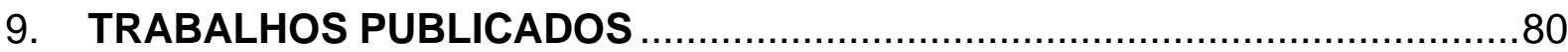

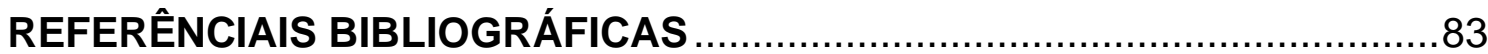




\section{INTRODUÇÃO}

Meio ambiente e sustentabilidade são temas amplamente discutidos no século XXI nos mais diversos setores que compõem a sociedade contemporânea. Com relação a obtenção de energia, esta discussão é mais intensa, uma vez que, existe o aumento progressivo do consumo mundial de energia associado ao crescimento populacional, expansão industrial e inovações tecnológicas [1].

Os principais recursos para produção de energia nos dias atuais, ainda são por meio de fontes não renováveis. Tais fontes além de serem finitas promovem impactos nocivos no meio ambientais [2]. Com o intuito de preservar o meio ambiente e, concomitantemente, a espécie humana, desde 1970, foram continuamente desenvolvidos tratados, entre diversos países, com o objetivo é atenuar o nível de poluição mundial [3-4].

Com o intuito de preservar os recursos naturais e concomitantemente promover o avanço econômico e social é imprescindível o desenvolvimento tecnológico sustentável [5-6] o qual atenda às necessidades da sociedade e, também das gerações futuras. Existem diversas tecnologias de energias renováveis em desenvolvimento e que são alternativas às fontes fósseis, tais como, energia solar, energia eólica, energia maremotriz entre outras [7], todavia, cada tipo de energia atende contextos específicos para sua utilização. Tornam-se necessários novos engenhos tecnológicos desafiadores para um bom desenvolvimento sustentável [5-7], e uma alternativa ao conjunto de energias renováveis apresentadas acima, tem sido o uso de células a combustível $(\mathrm{CaC})$.

As $\mathrm{CaC}$ são constituídas por dois eletrodos (ânodo e cátodo) e um eletrólito. Dentre os diversos tipos de $\mathrm{CaC}$, a mais estudada é a de Membrana Polimérica de Troca Protônica (PEMFC - Proton Exchange Membrane Fuel Cell) [8], a qual utiliza hidrogênio como combustível no ânodo. $O$ hidrogênio como combustível tem o benefício de ser abundante, por exemplo presente em moléculas de água, este gás possui alta densidade energética, podendo ser obtido por eletrólise da água ou por reforma de um outro composto químico, contudo, demanda um alto custo de armazenamento e produção via eletrolise da água. A obtenção por meio de reforma de um composto químico resulta em um hidrogênio com impurezas, tais como o monóxido de carbono (CO), que age como um veneno catalítico desativando os sítios 
catalíticos dos metais que compõe a $\mathrm{CaC}$, além disso, em diversos países, assim como o Brasil, ainda não se possui uma infraestrutura para utilização do hidrogênio em veículos ou como fonte estacionária, portanto, a utilização deste combustível está para um futuro próximo.

Nos últimos anos, as células PEMFC foram modificadas para empregar combustíveis líquidos, tornando-se Células à Combustível de Álcool Direto (DAFC Direct Alchool Fuel Cell). As células DAFC têm atraindo enorme atenção por apresentarem alta densidade energética, simples operação à temperatura ambiente e os combustíveis utilizados apresentam fácil armazenamento [9-10], como o metanol, etanol, etileno glicol e o glicerol [11-12].

O etanol apresenta vantagens em comparação ao metanol por ser proveniente de fonte renovável, apresentar menor toxicidade e alta densidade energética teórica [13-15], e no Brasil, a tecnologia de fabricação e distribuição do etanol já está consolidada em comparação a outros combustíveis. De acordo com a literatura, o glicerol também tem recebido atenção especial nos últimos anos para utilização nas DAFC [16-18], tornando-se interessante o estudo em célula a combustível de glicerol direto (DGFC), por ser um resíduo de baixo interesse comercial proveniente da fabricação do biodiesel, apresentar um alto potencial teórico, exibir baixa toxidade e por ser menos inflamável em comparação aos outros combustíveis líquidos, além de ser possível a formação de produtos de maior valor agregado de interesse em diferentes operações industriais [18-19].

Um dos pontos mais críticos no desempenho das DAFC está associado ao emprego dos eletrocatalisadores, em que a oxidação do combustível (etanol ou glicerol) requer maiores potenciais para atingir uma corrente adequada [20-21]. Para superar esse problema, muito esforço vem sendo dedicado no desenvolvimento de novos materiais para preparação de eletrocatalisadores mais eficientes para serem utilizados nas DAFC [22]. Os eletrocatalisadores mais empregados nas DGFC e DEFC são constituídos a base de platina $(\mathrm{Pt})$ por apresentarem alta atividade catalítica e estabilidade química [22-23].

No entanto, esses eletrocatalisadores de platina apresentam um alto custo por ser um metal nobre e raro na natureza, também sofre envenenamento pelos intermediários fortemente adsorvidos provenientes da reação de oxidação do álcool empregado [22; 24-25] diminuindo sua atividade catalítica. Dessa forma, torna-se necessário o desenvolvimento de novos eletrocatalisadores eficientes, no qual 
apresente, uma melhora da cinética na reação de oxidação do combustível [26]. Ottoni e colaboradores [22] menciona que a cinética de oxidação do álcool aprimorada no eletrólito pode ser favorecida em meio alcalino. Diferentes composições de eletrocatalisadores foram propostos para melhorar o desempenho das DEFC e DGFC em condições alcalinas [27-28]. Uma alternativa aos eletrocatalisadores de Pt e que favoreça a reação no meio reacional alcalino são eletrocatalisadores a base de paládio $(P d)$, esses apresentam boa atividade e estabilidade em células alcalinas em comparação as células de meio ácido, além de apresentar maior abundancia na crosta terrestre em comparação a Pt [29-30], também os eletrocatalisadores de Pd apresenta maior atividade na eletro-oxidação do glicerol quando comparados aos eletrocatalisadores de Pt [18], além disso exibe maior atividade na eletro-oxidação do etanol e apresenta maior tolerância ao CO [31-33].

Ottoni e colaboradores [34] relata que eletrocatalisadores binários a base de paládio, apresentam maior atividade para oxidação de álcoois em meio alcalino comparados com eletrocatalisador Pd puro. Diversos metais de transição $M(M=R u$, $\mathrm{Ni}, \mathrm{Au}, \mathrm{Sn}, \mathrm{Ag}, \mathrm{Cu}$, etc.) [35-39] foram empregados para melhorar a atividade e estabilidade catalítica dos eletrocatalisadores à base de $\mathrm{Pd}$. Entre os metais de transição citados, o $\mathrm{Ru}$ tem recebido grande atenção por causa de sua atividade catalítica para reação de oxidação do etanol [40-41]. Qinggang e colaboradores [37] descrevem que a adição de Ru no catalisador de Pd melhora a cinética de reação de oxidação do etanol em meio alcalino. Dash e colaboradores [42] relatam que a introdução de $\mathrm{Ru}$ em catalisadores a base de Pd aumenta a atividade catalítica na oxidação do glicerol em meio alcalino.

Nesse contexto, com base nas informações apresentadas, buscou-se desenvolver neste trabalho eletrocatalisadores binários constituídos de $\mathrm{PdRu}$ suportados em carbono (C), preparados pelo método de redução via borohidreto de sódio, estudando a oxidação eletroquímica do etanol, glicerol e sua atividade eletrocatalítica. 


\section{OBJETIVOS}

O objetivo deste trabalho consiste na preparação e caracterização de eletrocatalisadores $\mathrm{PdRu} / \mathrm{C}$ em diferentes composições atômicas, preparados pelo método de redução via borohidreto de sódio para o estudo da oxidação do etanol e glicerol em meio alcalino 


\section{REVISÃO BIBLIOGRÁFICA}

\subsection{Células a Combustível}

Células a combustível são dispositivos de energia eletroquímica, que convertem a energia química do combustível, normalmente o hidrogênio, diretamente em energia elétrica [43], podendo ser utilizados combustíveis provenientes da biomassa. E as aplicações podem ser portáteis, móveis ou estacionárias [44], também podem ser empregadas em áreas remotas ou lugares que sofreram por catástrofes naturais levando energia rapidamente para estas regiões.

Em comparação às pilhas alcalinas de Daniell, as células a combustível apresentam vantagens por serem modulares, ter operação prolongada, carga compacta e eficiência de recarga [45], é importante ressaltar que o combustível é introduzido na célula externamente, enquanto que nas pilhas de Daniel os eletrodos são consumidos. As células a combustível são classificadas de acordo com o eletrólito empregado e sua temperatura de operação [46], as que operam a baixas temperaturas, estando entre 20 a $200{ }^{\circ} \mathrm{C}$, são: Células a Combustível de Membrana Polimérica de Troca Protônica (PEMFC - Proton Exchange Membrane Fuel Cell), Células a Combustível Alcalina (AFC - Alkaline Fuel Cell) e Células a Combustível de Álcool Direto (DAFC - Direct Alchohol Fuel Cell). Enquanto que, as células de altas temperaturas de operação, encontrando-se na faixa de operação de 650 a $1000{ }^{\circ} \mathrm{C}$ [47-48], essas células são: Células a Combustível de Carbonato Fundido (MCFC Molten Carbonate Fuel Cell) e Células a Combustível de Óxido Sólido (SOFC - Solid Oxide Fuel Cell).

As PEMFC apresentam-se como fontes promissoras de energia para transporte, dispositivos portáteis e estacionários devido à sua elevada eficiência, fácil transporte e por serem modulares, baixa temperatura de operação e reduzida emissão de poluentes [49-52]. A constituição da PEMFC consiste em três partes importantes, sendo elas: o ânodo, o cátodo e a membrana [52], na região do cátodo, o oxigênio é reduzido enquanto que na região do ânodo o hidrogênio (combustível) é oxidado [53].

A região do ânodo e do cátodo são compostas por eletrodos de platina, esses eletrodos são constituídos de uma camada difusora composta por tecido ou papel de 
carbono misturado com politetrafluoretileno (PTFE) contendo a camada catalítica (platina) e a membrana utilizada é de troca protônica, sendo uma folha permeável fina de aproximadamente 20 a $250 \mu \mathrm{m}$, feita de ionômeros e projetada para conduzir prótons, atuando como barreira para reagentes e isolador de elétrons [44], e o conjunto eletrodos membrana forma o MEA. A figura 1 apresenta o esquema de uma célula a combustível do tipo PEMFC.

FIGURA 1: Representação esquemática de uma célula a combustível do tipo PEMFC

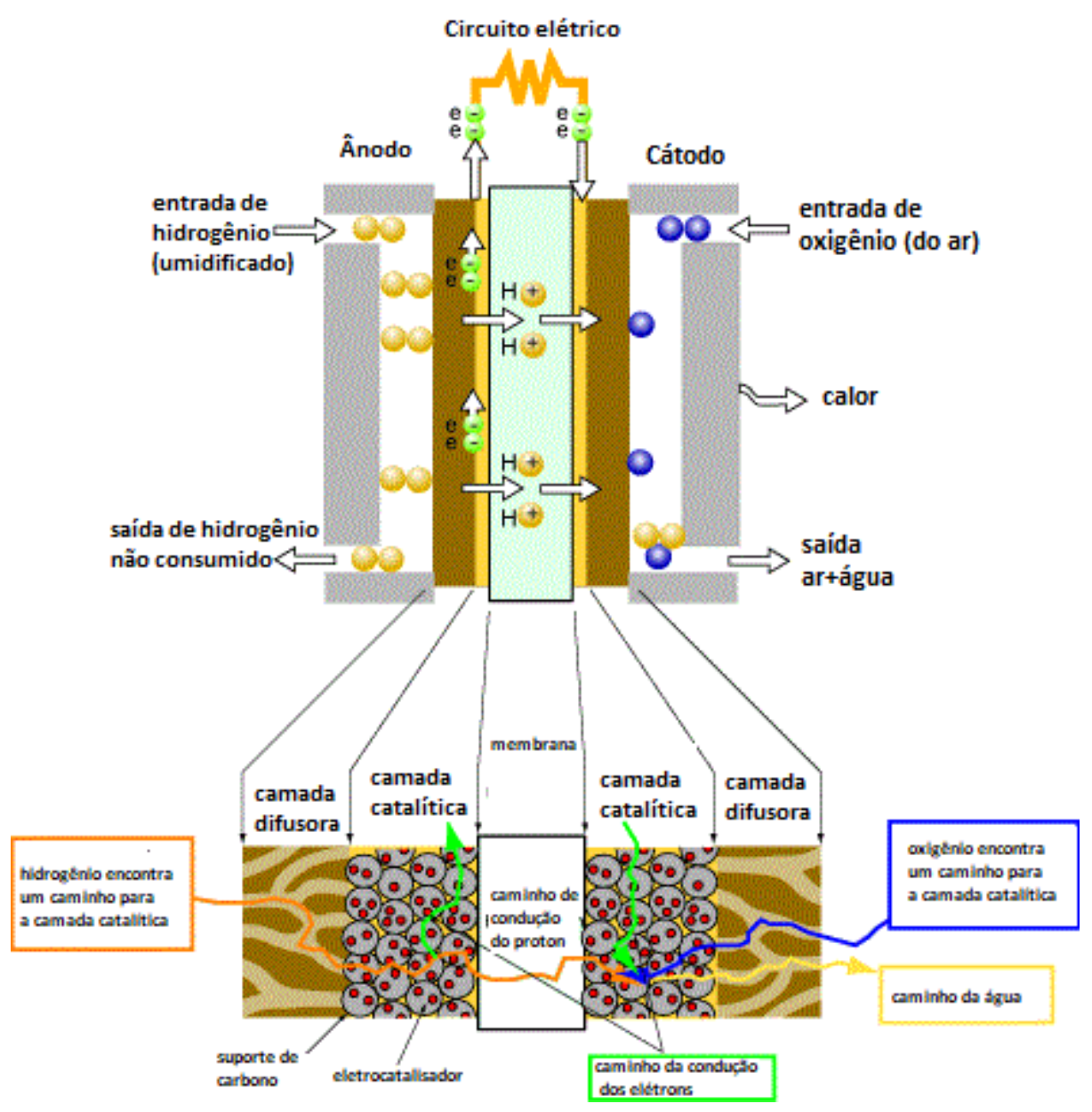

Fonte: Disponível em <https://physics.nist.gov/MajResFac/NIF/pemFuelCells.html>. Acesso em: 25 fev. 2020.

Na região do ânodo, as moléculas de hidrogênio são transferidas da camada difusora para a camada catalítica, onde se separam em $\mathrm{H}^{+}$e elétrons [52]. Os elétrons percorrem o circuito externo fornecendo trabalho elétrico e no cátodo o oxigênio passa 
através da camada difusora reagindo na camada catalítica, posteriormente combinase com os prótons e elétrons para formar água e gerando calor [52]. Sua reação química é exibida pelas equações 1-3 [55-56].

Ânodo: $2 \mathrm{H}_{2(\mathrm{~g})}+4 \mathrm{H}_{2} \mathrm{O}_{(\mathrm{l})} \rightarrow \quad 4 \mathrm{H}_{3} \mathrm{O}_{(\mathrm{l})}^{+}+4 \mathrm{e}^{-}$

Cátodo: $\mathrm{O}_{2(\mathrm{~g})}+4 \mathrm{H}_{3} \mathrm{O}_{(\mathrm{l})}^{+}+4 \mathrm{e}^{-} \quad \rightarrow \quad \mathrm{H}_{2} \mathrm{O}_{(\mathrm{l})}$

Global: $\quad 2 \mathrm{H}_{2(\mathrm{~g})}+\mathrm{O}_{2(\mathrm{~g})} \quad \rightarrow \quad 2 \mathrm{H}_{2} \mathrm{O}_{(\mathrm{l})}$

A eficiência teórica de uma célula PEMFC chega aproximadamente a 60\% em conversão de energia elétrica, reduzindo aproximadamente $90 \%$ de poluentes emitidos [57-58] apresentando eficiência superior às máquinas térmicas [58] em que sua eficiência teórica é estabelecida pelo quociente entre a energia livre da reação $\Delta \mathrm{G}$ e a entalpia da reação $\Delta \mathrm{H}$ [59]. A PEMFC encontra-se em um estágio avançado de desenvolvimento, contudo, existe uma baixa demanda comercial devido ao seu alto custo de produção, associado aos metais nobres e ao hidrogênio, no qual é um gás inflamável e, por esse motivo, precisa de cuidados especiais para transporte e manuseio [61-62], assim como outros fatores já discutidos.

Nesse contexto, a utilização de outros tipos de combustíveis como substâncias líquidas ricas em hidrogênio tais como glicerol [10] e etanol [63-67] tiveram grande impulso nas pesquisas de DAFC, visto que tais combustíveis apresentam como vantagens o baixo custo de obtenção, facilidade em transporte e armazenamento, altas densidades de energia, configuração compacta e operação simples [67-68].

\subsection{Células a Combustível de etanol direto (DEFC)}

O metanol pode ser considerado o combustível líquido mais empregado nas DAFC por ser relativamente barato e de simples oxidação [69]. No entanto, a produção do metanol é realizada por via química a partir de fontes não renováveis, sendo volátil, 
inflamável, apresenta alta toxicidade e quando utilizados nas DMFC o combustível passa por meio da membrana polimérica do anodo para o cátodo (efeito crossover), reduzindo a eficiência da célula a combustível [69-70].

O uso do etanol como combustível para transporte tem sido pesquisado nas últimas décadas [71]. O etanol é um composto orgânico proveniente da biomassa, bem como, da fermentação da cana de açúcar. As pesquisas utilizando etanol como combustível iniciaram por volta de 1920 no Brasil, onde inicialmente era adicionado à gasolina para redução do custo [72].

Em meados de 1975, carros movidos a etanol tiveram grande incentivo a partir do programa Proálcool (Programa Nacional de Álcool), quando houve um aumento significativo de etanol no mercado e o desenvolvimento da infraestrutura para carros movidos a etanol [72]. Atualmente, o etanol é produzido em grandes quantidades no setor agrícola, permitindo disponibilidade contínua e menor custo, também apresenta baixa toxicidade e menor tendência a inflamar em comparação ao metanol $[71 ; 73]$ sendo de interesse tecnológico para aplicação em Células a Combustível de Etanol Direto.

O principal objetivo de uma DEFC é a oxidação do etanol a $\mathrm{CO}_{2}$ liberado 12 elétrons em uma única reação [71; 74]. A energia teórica produzida pela oxidação do etanol corresponde à $8,0 \mathrm{kWh} \cdot \mathrm{kg}^{-1}$, enquanto que a oxidação completa do metanol produz 6,1 kWh. $\mathrm{kg}^{-1},[71 ; 75-76]$ As reações químicas para uma DEFC são apresentadas nas equações 4, 5 e 6 [77]:

Ânodo: $\mathrm{C}_{2} \mathrm{H}_{5} \mathrm{OH}+3 \mathrm{H}_{2} \mathrm{O} \rightarrow 12 \mathrm{e}^{-}+12 \mathrm{H}^{+}+2 \mathrm{CO}_{2}\left(\mathrm{E}_{0}\right.$ ânodo $\left.=0,084 \mathrm{~V}\right)$

Cátodo: $12 \mathrm{e}^{-}+12 \mathrm{H}^{+}+3 \mathrm{O}_{2} \rightarrow 6 \mathrm{H}_{2} \mathrm{O}\left(\mathrm{E}_{0}\right.$ cátodo $\left.=1,229 \mathrm{~V}\right)$

Reação Global: $\mathrm{C}_{2} \mathrm{H}_{5} \mathrm{OH}+3 \mathrm{O}_{2} \rightarrow 3 \mathrm{H}_{2} \mathrm{O}+2 \mathrm{CO}_{2}\left(\mathrm{E}_{0}\right.$ global $\left.=1,145 \mathrm{~V}\right) \quad$ eq.6

O potencial teórico obtido na reação de oxidação de uma DEFC é 1,145 V. Contudo, em experimentos práticos, não ocorre a oxidação completa do etanol, resultando em subprodutos como acetaldeído e ácido acético em meio ácido [73] e acetato em meio alcalino [78-79], fornecendo apenas 2 a 4 elétrons por molécula de 
etanol. Isso se deve a dificuldade de quebrar a ligação C-C da molécula de etanol [69; 79-80], também, tem-se a formação de intermediários adsorvidos no qual desativam o eletrocatalisador levando a perda de eficiência [80]. Portanto, torna-se necessário combustíveis alternativos para DAFC e eletrocatalisadores de alto desempenho [69; 74].

\subsubsection{Eletro-oxidação do etanol em células DEFC}

A oxidação do etanol pode ocorrer em meio ácido ou alcalino, ambos ambientes têm o objetivo de favorecer a oxidação do etanol a $\mathrm{CO}_{2}$ produzindo 12 elétrons. No entanto, em meio ácido o pH é baixo, havendo menos variedades de catalisadores disponíveis para serem testados nas DEFC ácida [71].

As DEFC que operam em meio alcalino exibem um alto valor de $\mathrm{pH}$ para o ambiente de reação, fornecendo uma adsorção de íons $\mathrm{OH}^{-}$na superfície do catalisador, melhorando a reação de oxidação [68; 71; 81], favorecendo uma melhor cinética da reação em comparação as células ácidas.

Como mencionado, a eletro-oxidação do etanol ocorre em várias etapas complexas, alguns autores relatam que o produto formado em maior quantidade da oxidação de etanol em meio alcalino sobre paládio é o acetato [82-83].

FIGURA 2: Rota da eletro-oxidação do etanol em meio alcalino sobre paládio

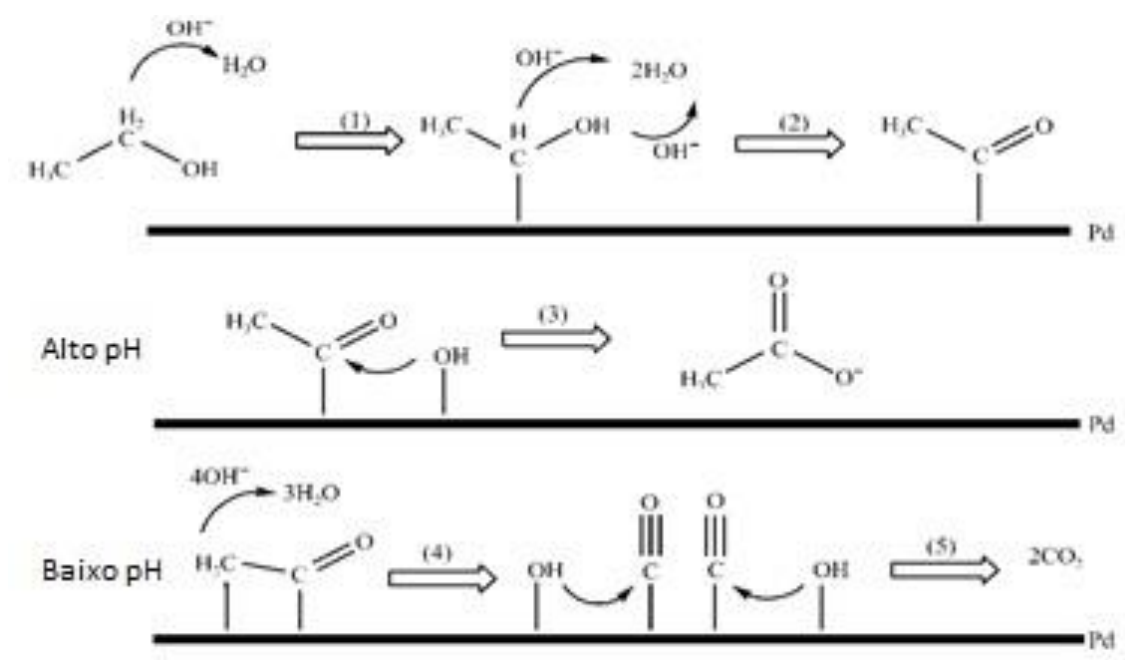

Fonte: Shen \& Fang (2009, p. 1936) [84] 


\subsection{Células a combustível de glicerol direto (DGFC)}

Recentemente, o uso do glicerol em aplicações como combustível em células a combustível a álcool direto tornou-se atraente, devido ao seu alto potencial teórico e por ser um coproduto gerado da fabricação do biodiesel [19]. Além disso, em meio alcalino a cinética de oxidação do glicerol pode ser aumentada [85-87].

O glicerol também apresenta as seguintes propriedades: não é tóxico, não é volátil assim como não é inflamável, apresentando uma densidade teórica de energia de 6,4 kWh.L-1 [88]. Seus subprodutos gerados por meio de reações químicas ou eletroquímicas (ácido glicérico, ácido tartônico ou ácido glicólico) os quais apresentam um alto valor agregado [89]. Não obstante, o glicerol é comercializado com menor preço em comparação com o etanol e metanol [89].

Benipal e colaboradores [89] sintetizaram nanopartículas de PdAg suportadas em nanotubos de carbono pelo método de redução de fase aquosa e observaram sua atividade catalítica para oxidação do glicerol em células a combustível de álcool direto onde os sistemas binários foram mais eficientes em relação ao paládio puro.

\subsection{Eletrocatalisadores de Pd e PdRu}

Um dos principais desafios encontrados nas células DAFC está relacionado a cinética lenta de oxidação do álcool assim como a atividade catalítica e estabilidade dos eletrocatalisadores usados no ânodo [90].

Diversos materiais foram pesquisados como eletrocatalisadores para o ânodo nas células a combustível a álcool direto, recentemente, os catalisadores mais estudados são os metais nobres a base de platina e paládio [71]. Entre a classe dos metais nobres e não-nobres, o paládio demonstra ser o eletrocatalisador mais ativo para a reação de oxidação do etanol em meio alcalino, exibindo uma atividade catalítica superior a platina [15; 91]. Também os eletrocatalisadores de Paládio apresentam maior resistência ao envenenamento por intermediários ( $\left.\mathrm{CO}_{\mathrm{ads}}\right)$ adsorvidos na sua superfície [32; 92]. 
Portanto, maior atenção tem sido direcionada ao uso de paládio e suas ligas metálicas como eletrocatalisadores na reação de eletro-oxidação do etanol [31]. A fim de melhorar a atividade catalítica e estabilidade dos eletrocatalisadores de paládio, trabalhos como $\mathrm{Pd}_{3} \mathrm{Au} / \mathrm{C}$ [93], PdTb/C [94], PdAg/C [95], PdRu [35], PdSn/C [96], PdCu [97] mencionam o emprego do co-catalisador ao paládio tornando-se mais estáveis e ativos para oxidação do etanol em meio alcalino em comparação ao $\mathrm{Pd} / \mathrm{C}$ [98], ou seja, aumentando a tolerância ao envenenamento de Pd e promovendo a oxidação do etanol [71]. A adição de um co-catalisador enfraquece a ligação formada com espécies intermediárias, além de fornecer superfície adicional para espécies oxigenadas para oxidação de produtos formados a partir da oxidação parcial do combustível [71].

Portanto, a presença de um co-catalisador assim como o suporte empregado podem afetar o desempenho catalítico em termos de estabilidade e atividade eletroquímica [40]. O Ru apresenta-se como um promotor para eletro-oxidação de álcoois em meios alcalinos, onde eletrocatalisadores bimetálicos de PdRu exibem alta atividade na reação de oxidação do álcool [40]. Roh e colaboradores [99] relata que o $\mathrm{Ru}$ contribui para a ocorrência do mecanismo bifuncional, assim como pelo efeito eletrônico. Os eletrodos modificados com $\mathrm{RuO}_{2}$ catalisam a reação de eletro oxidação do álcool por meio do par redox $\mathrm{Ru}(\mathrm{VI})$ e Ru (VII) [100-101]. Também é relatado que a presença de $\mathrm{Ru}$ pode produzir espécies $\mathrm{Ru}-\mathrm{OH}$ em sua superfície enquanto ativa moléculas de água para remover intermediários adsorvidos sobre sítios de Pt em baixos potenciais [102-104], o mesmo efeito poderia ocorrer utilizando Pd.

Não obstante, a eficiência catalítica dos eletrocatalisadores à base de $\mathrm{Pd}$ também depende crucialmente da morfologia, tamanho das nanopartículas e sua distribuição sobre o suporte [32;105]. Portanto, torna-se necessário novas rotas de sínteses dos eletrocatalisadores assim como diferentes composições químicas [106], a fim de se obter eletrocatalisadores com alta atividade catalítica [107-108].

\subsection{Suporte de Carbono}

O suporte empregado para ancoragem do metal é fundamental para a redução do custo dos eletrocatalisadores bem como o aumento da área ativa para catálise 
[109], sendo extremamente importante para que os eletrocatalisadores produzam alta atividade catalítica e tenham estabilidade [109-110].

Vários estudos relatam que o uso de diversos materiais utilizados como suporte para células a combustível [111-116], no entanto, alguns suportes apresentam pouca área superficial e baixa condutividade elétrica. $\mathrm{O}$ carbono Vulcan XC72 tornou-se atraente como suporte para ancoragem de nanopartículas metálicas para aplicações em células a combustível de baixa temperatura pelo fato de ser relativamente de baixo custo, apresentar boa condutividade elétrica e térmica [114;117], além de exibir alta área superficial $\left(\sim 250 \mathrm{~m}^{2} \cdot \mathrm{g}^{-1}\right)$ [109; 118]. Este suporte é fabricado por pirólise de hidrocarbonetos, como frações de gás natural ou óleo, provenientes do processamento de petróleo [119-120].

\subsection{Métodos de preparação de eletrocatalisadores}

Com o intuito de se obter eletrocatalisadores com tamanho de nanopartículas de tamanhos específicos ( 2 a $7 \mathrm{~nm}$ ) com distribuição homogênea sobre o suporte, além da alta atividade eletrocatalítica, vários métodos de sínteses têm sido desenvolvidos [107-108].

A literatura [121-122] descreve diversos métodos para preparação de eletrocatalisadores como: o método de Bonnemann, o método de redução por álcool, método de ácido fórmico e o método de redução por borohidreto de sódio. É importante ressaltar que o modo de preparação do eletrocatalisadores desempenha um papel fundamental em suas características.

\subsubsection{Método de redução por álcool}

O método de redução por álcool foi elaborado por Toshima e Yonezawa [123], para preparar dispersões coloidais com tamanho e distribuição de nanopartículas homogêneas. Este método também é conhecido como método de preparação livre de agente redutor químico para dispersão coloidal de nanopartículas metálicas [124-125]. 
O procedimento de preparação baseia-se no refluxo de uma solução alcoólica contendo os íons metálicos na presença de um agente estabilizante, geralmente um polímero, fornecendo dispersões coloidais de nanopartículas metálicas, sendo elas homogêneas [121]. Neste método, o álcool funciona como solvente e agente redutor, sendo oxidado a aldeídos e cetonas [121] conforme a equação 6 :

$\mathrm{H}_{2} \mathrm{PtCl}_{6}+2 \mathrm{CH}_{3} \mathrm{OH} \leftarrow \rightarrow \mathrm{Pt}^{0}+2 \mathrm{HCHO}+6 \mathrm{HCl}$

As vantagens deste método para preparação de nanopartículas são; procedimento de simples realização e reprodutível, as dispersões coloidais das nanopartículas apresentam alta atividade catalítica, o tamanho das nanopartículas pode ser controlado alterando as condições de preparação, como a escolha do álcool, temperatura de redução, quantidade e variedade do agente estabilizante, concentração do íon metálico e uso de aditivos [121]

Kim e colaboradores [124] prepararam nanopartículas de $\mathrm{Pt}-\mathrm{TiO}_{2}$ pelo método de redução de álcool, relatando que a taxa de redução dos íons metálicos é relativamente lenta, de modo que o tamanho das nanopartículas pode ser controlado e as mesmas, são revestidas sobre a superfície de $\mathrm{TiO}_{2}$ de modo uniforme.

Sarma e colaboradores [126] prepararam eletrocatalisadores de PtRu/C pelo método de redução a álcool modificado, no qual uma pequena quantidade de Nafion é introduzido durante a etapa de preparação, relatando que a atividade catalítica para oxidação eletroquímica do metanol foi aprimorada

\subsubsection{Método de Bonnemann}

O método de Bonnemann pode ser utilizado para a obtenção de catalisadores mistos ou sistemas de catalisadores, ternários e quaternários, sobre carvão ativo e carvão ativo grafiticado [121]. Este método, também conhecido como método coloidal apresenta alto desempenho catalítico e durabilidade a logo prazo [127-128]. Esta metodologia geralmente consiste na obtenção de eletrocatalisadores à base de platina 
e ligas metálicas e/ou óxidos metálicos, a partir dos elementos de transição, em particular, Sn, V, W, Mo, Cu e Ni [121].

A preparação baseia-se em um sistema coloidal em atmosfera inerte, utilizando-se solventes e sais desidratados, sua característica é a dissolução dos sais metálicos em uma solução de tetraidrofurano junto com brometo de tetraoctilamônio onde também é preparado o agente redutor e a fase final consiste em adicionar a dispersão coloidal vagarosamente a suspensão de pó de carbono em THF [121].

Beyhan e colaboradores [128] prepararam eletrocatalisadores de $\mathrm{PtSn} / \mathrm{C}$ pelo método de Bonnemann para eletro-oxidação do etanol em células a combustível, também adicionaram um terceiro metal no método empregado objetivando maior atividade catalítica, relatando que os resultados de estabilidade dos catalisadores foram satisfatórios. Neto e colaboradores [129] sintetizaram eletrocatalisadores $\mathrm{PtRu} / \mathrm{C}$ e PtRuMo/C pelo método de Bonnemann, avaliando a morfologia e a atividade catalítica dos eletrocatalisadores em estudo, o grupo relata que a metodologia em empregada mostrou-se eficaz para o desenvolvimento de ligas metálicas a base de platina, obtendo maior atividade catalítica para oxidação de metanol e etanol em PEMFC. No entanto, a principal desvantagem deste método está relacionada ao alto custo dos materiais e ao mantimento de uma atmosfera inerte.

\subsubsection{Método do ácido fórmico}

O ácido fórmico $(\mathrm{HCOOH})$ possui propriedades químicas de ácido carboxílico e de aldeído, de modo que pode reagir com uma ampla gama de produtos químicos orgânicos e inorgânicos, também apresenta baixo custo e sua evaporação é instantânea [130]. O método do ácido fórmico foi desenvolvido no Instituto de Química de São Carlos - USP com a finalidade de preparar eletrocatalisadores $\mathrm{Pt} / \mathrm{C}$ para estudos em células a combustível [121]. Sua metodologia consiste inicialmente em adicionar o suporte de carbono Vulcan XC72 a uma solução de ácido fórmico e a mistura é aquecida a $80^{\circ} \mathrm{C}$. Posteriormente é adicionado os sais metálicos em etapas, o controle do andamento da redução é feito com iodeto de potássio como reagente externo, com a finalidade de indicar a presença de platina em solução, após a redução total dos sais metálicos, o catalisador é filtrado, seco e triturado [121]. 


\subsubsection{Método da deposição espontânea}

Com o intuito de reduzir a quantidade de metal nobre e aumentar a atividade catalítica no desenvolvimento de novos eletrocatalisadores, desenvolveu-se o método de deposição espontânea. Este método visa a deposição espontânea do metal principal, geralmente platina sobre as nanopartículas do co-catalisador suportadas em carbono, sem a aplicação de um potencial externo [121].

Em sistemas de eletrocatalisadores $\mathrm{PtRu} / \mathrm{C}$, a preparação pelo método de deposição espontânea consiste inicialmente em tratar as nanopartículas de $\mathrm{Ru}$ suportadas em carbono Vulcan XC72 em atmosfera de hidrogênio a $300{ }^{\circ} \mathrm{C}$ por $2 \mathrm{~h}$. Após este período, são esfriadas à temperatura ambiente e imersas em uma solução contendo íons de platina, todo o procedimento é realizado em atmosfera de hidrogênio ou argônio [121]. A quantidade e a morfologia do depósito de Pt podem ser convenientemente controladas com o tempo de imersão do cristal e a concentração de $\left[\mathrm{PtCl}_{6}\right]^{2-}$ íons [131].

Tem sido mostrado [131-132], que os eletrocatalisadores de PtRu/C sintetizados pelo método de redução espontânea apresentaram maior tolerância ao $\mathrm{CO}$ em comparação aos eletrocatalisadores comercias $\mathrm{Pt} / \mathrm{Ru}$, assim como a camada de platina apresenta maior área ativa resultando em maior atividade eletrocatalítica.

\subsubsection{Método de redução por Borohidreto de sódio $\left(\mathrm{NaBH}_{4}\right)$}

O método de redução por borohidreto de sódio tem recebido atenção especial por ser um método simples para a preparação de nanopartículas metálicas de fácil reprodutividade [133]. $\mathrm{O} \mathrm{NaBH} 4$ é comercializado em forma sólida (pó ou grãos) ou em soluções alcalinas [134]. O borohidreto de sódio é um reagente leve e barato, com amplas aplicações na área da química quanto em escala industrial [135-136], sendo inestimável para aplicações de processos de redução [136]. $\mathrm{O} \mathrm{NaBH}_{4}$ também apresenta alta estabilidade em soluções alcalinas além de não ser inflamável e tóxico [137]. 
E o principal objetivo da utilização do $\mathrm{NaBH}_{4}$ para sintetizar eletrocatalisadores está relacionado por ser um agente redutor forte [134; 138], reduzindo os íons metálicos a carga 0 [138] e controlando satisfatoriamente o tamanho e dispersão das nanopartículas.

Assim, o método de redução por $\mathrm{NaBH}_{4}$ foi selecionado para ser utilizado neste trabalho para preparação dos eletrocatalisadores propostos. 


\section{MATERIAIS E MÉTODOS}

\subsection{Síntese pelo método de Borohidreto de Sódio}

Os eletrocatalisadores $\mathrm{Pd} / \mathrm{C}, \mathrm{Ru} / \mathrm{C}$ e $\mathrm{PdRu} / \mathrm{C}$ (90:10; 70:30 e 50:50) foram sintetizados pelo método de redução por borohidreto de sódio [20; 22], com carga metálica nominal de $20 \%$ em massa a partir dos sais de Paládio (nitrato de Paládio dihidratado), Rutênio (cloreto de Rutênio) e 80\% de suporte de Carbono Vulcan XC72.

De acordo com o método de síntese empregado, a etapa inicial na preparação dos eletrocatalisadores consistiu em utilizar $25 \mathrm{~mL}$ de água deionizada e $25 \mathrm{~mL}$ de álcool isopropílico imersos num béquer de $300 \mathrm{~mL}$, estando sobre agitação magnética (velocidade: $250 \mathrm{rpm}$ ) por 10 minutos a temperatura ambiente.

Posteriormente, adicionou-se ao béquer os precursores metálicos a serem reduzidos com a utilização de uma pipeta graduada, em seguida adicionou-se o suporte Carbono Vulcan XC72 e levou-se o conjunto em solução ao ultrassom de ponta no período de 10 minutos para a completa dissolução dos sais metálicos.

Após a solução tornar-se homogênea, foi acrescentado o agente redutor borohidreto de sódio em solução à $10 \mathrm{~mL}$ de hidróxido sódio, ainda em agitação, deixou-se a redução ocorrer por um período de 30 minutos. Ao final do processo, filtrou-se a solução com um kitasato a vácuo com pressão reduzida utilizando um filtro número 100. Posteriormente o sólido (eletrocatalisador) suspenso no filtro foi lavado com $4 \mathrm{~L}$ de água deionizada para remoção de impurezas. Após a lavagem, o sólido foi levado à estufa em $70 \stackrel{\circ}{\circ}$ para secagem num período mínimo de 2 horas [20]. $O$ fluxograma do método de preparação é apresentado na figura 3. 
FIGURA 3: Fluxograma para preparar eletrocatalisadores pelo método redução via borohidreto de sódio.

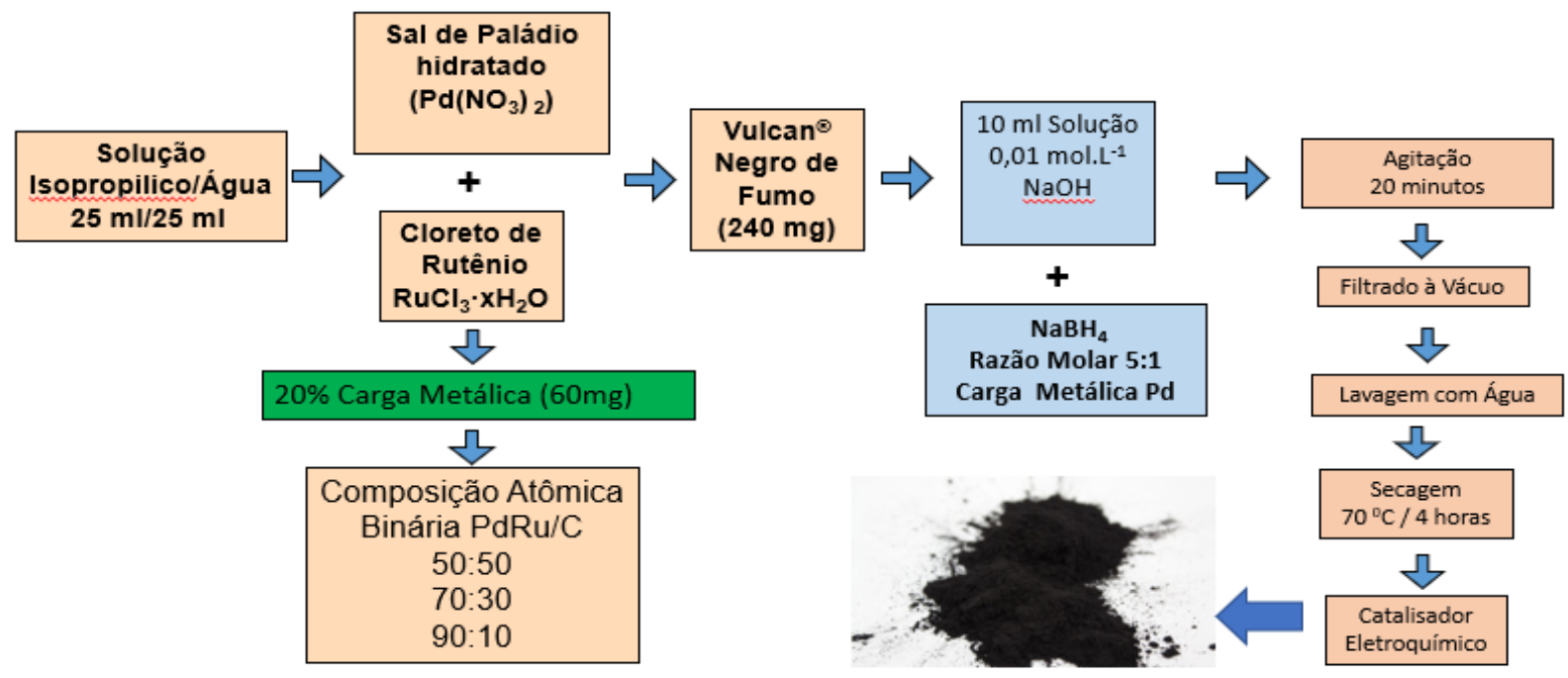

Fonte: Próprio autor

\subsection{Caracterização físico-química dos eletrocatalisadores}

Os eletrocatalisadores preparados foram caracterizados por Espectroscopia de Energia Dispersiva de Raios X (EDX), Difração de Raios X (DRX), Microscopia Eletrônica de Transmissão (MET), Espectroscopia de Fotoelétrons de raios X (XPS) e Espectroscopia no infravermelho com reflectância total atenuada (ATR-FTIR).

\subsection{Espectroscopia de energia dispersiva de raios X (EDX)}

A espectroscopia por energia de dispersão (Energy Dispersion Spectrometry EDS) é uma microanálise eletrônica semi-quantificativa baseada nos experimentos de raios $\mathrm{X}$ característicos, emitidos de uma amostra após o bombardeamento de elétrons, tento como finalidade identificar a composição elementar da amostra.

Esta técnica trabalha com o princípio de que a energia de um fóton está relacionada com a frequência de onda, segundo a relação de Planck. Assim, os fótons com suas energias correspondentes atingem o detector do EDX quase que 
simultaneamente e o processo de medida é realizado rapidamente, possibilitando analisar todos os comprimentos de onda também de modo simultâneo.

Para caracterização dos eletrocatalisadores por EDX foi utilizado um microscópio eletrônico de varredura, da marca Philips XL 30, com um feixe de elétrons de $20 \mathrm{keV}$, acoplado a um microanalisador EDAX modelo DX-4.

As amostras dos eletrocatalisadores foram fixadas em uma fita de cobre, sobrepostas em uma porta amostra confeccionado em bronze e introduzido ao Microscópio Eletrônico de Varredura. Foram coletados dados em três pontos aleatórios e distintos da amostra e o resultado final, apresentado neste trabalho, corresponde a uma média destes pontos.

\subsection{Difração de raios X (DRX)}

A Difração de raios $X$ obedece à lei de Bragg, sendo ela $n \lambda=2 d \sin \theta$, onde $d$, $\theta, \mathrm{n}$ e $\lambda$ representam o espaçamento interplanar, meio ângulo de difração, comprimento de onda inteiro positivo e comprimento de onda incidente, respectivamente [139-140].

A caracterização por difração de raios $X$ foi empregada para analisar a estrutura cristalina dos eletrocatalisadores e observar possíveis formações de ligas metálicas. As medidas de DRX foram realizadas pelo equipamento Rigaku modelo Miniflex II com fonte de radiação de CuKa $\left(\lambda=1,54056 \AA\right.$ ) com intervalo de medida $2 \theta$ de $20^{\circ}$ a $90^{\circ}$, incrementos de $0,05^{\circ}$ e velocidade de varredura de $2^{\circ} \mathrm{min}^{-1}$.

Para estes experimentos uma pequena quantidade do eletrocatalisador foi compactada utilizando uma pasta de silicone, posteriormente compactadas no suporte da amostra confeccionadas em vidro e introduzidas posteriormente na câmara de análise do equipamento. 


\subsection{Microscopia eletrônica de transmissão (MET)}

Para os estudos de microscopia eletrônica de transmissão foi utilizado um Microscópio Eletrônico de Transmissão JEOL modelo JEM-2100 no potencial de $200 \mathrm{kV}$.

A caracterização por MET permitiu obter informações referentes ao diâmetro médio das nanopartículas metálicas e sua distribuição sobre o suporte de carbono referente aos eletrocatalisadores $\mathrm{Pd} / \mathrm{C}, \mathrm{Ru} / \mathrm{C}$ e PdRu/C (90:10; 70:30 e 50:50). Consequentemente, foi possível avaliar se a rota de síntese proposta é efetiva ou não para a preparação dos eletrocatalisadores [141].

Para cada amostra foram obtidas aproximadamente 20 micrografias. Por intermédio das micrografias obtidas foi efetuada a contagem de aproximadamente 150 nanopartículas utilizando o Software ImageJ, após esse processo utilizou-se o Origin Pro 2018 para a construção dos histogramas e cálculo do tamanho médio de nanopartícula. De acordo com Gupta (2008) [142], a contagem ideal mínima para obter uma representatividade das amostras são aproximadamente cerca de 150 partículas.

\subsubsection{Preparação das amostras}

Uma das grandes dificuldades na microscopia eletrônica de transmissão encontra-se na preparação das amostras a serem observadas.

Neste estudo, utilizou-se uma porta amostra de cobre $(0,3 \mathrm{~cm}$ de diâmetro), no qual o mesmo foi tratado em solução de agua, álcool etílico e collodion, sendo necessário posteriormente um recobrimento com um filme de carbono.

As amostras foram preparadas dentro de um eppendorf contendo álcool isopropílico, posteriormente foram levadas ao ultrassom de banho até completa homogeneização. Uma alíquota da amostra foi depositada sobre a grade de cobre tradada e introduzido no microscópio para a obtenção das imagens de miscroscopia eletrônica de transmissão. 


\subsection{Espectroscopia de Fotoelétrons de raios X (XPS)}

A espectroscopia de fotoelétrons se baseia no efeito fotoelétrico descrito por Einstein no início do século XX. Quando um feixe de raios $X$ atinge a amostra, a energia do fóton incidente é absorvida por um elétron de uma camada mais interna do átomo. Se a energia do fóton, $h \backslash$ nu for suficientemente alta esse elétron escapará do átomo e sendo emitido da superfície do material. O elétron emitido com energia cinética $E_{k}$ é chamado de fotoelétron. A técnica de XPS utiliza fotoionização e análise da dispersão de energia do fotoelétron emitido para estudar a composição e o estado eletrônico da superfície de um material. Cada átomo da superfície tem um elétron de uma camada mais interna com sua energia de ligação característica que, não estritamente, é igual à energia de ionização desse elétron. A energia de ligação do elétron e dada pela relação [143]:

$$
E_{b}=h v-E_{k}-\phi
$$

onde $\Phi$ é a função trabalho do analisador.

O carregamento da superfície resulta em um deslocamento do pico para energias de ligação mais altas. Nesse caso, a energia de ligação deve ser calibrada com respeito a um pico interno de referência. Utilizamos nesta dissertação o pico do carbono 1s, elemento normalmente abundante na superfície no material analisado, com energia de ligação de 284,6 eV como referência para nossa calibração.

A caracterização por XPS dos eletrocatalisadores foi realizada com amostras na forma de pó, utilizando-se de um espectrômetro de fotoelétrons da ThermoFisher Scientific, modelo $\mathrm{K}$-alpha+, com radiação de Al-ka. Os ensaios foram realizados no laboratório $04 \mathrm{~S}$ na UFABC. 


\subsection{Espectroscopia no infravermelho com reflectância total atenuada (ATR-FTIR)}

As análises de espectroscopia in situ no infravermelho com transformada de Fourier (ATR-FTIR) foram realizadas utilizando um espectrômetro Nicolet 6700 , com um detector do tipo MCT refrigerado a nitrogênio líquido e o acessório ATR é da marca Miracle Pike. O intervalo de frequência para realização das medidas foi de 850 a $3000 \mathrm{~cm}^{-1}$, com resolução de $8 \mathrm{~cm}^{-1}$, computando uma média de 128 interferogramas.

Os experimentos foram realizados em uma célula eletroquímica de 3 eletrodos utilizando a técnica da camada fina porosa [14; 144], os eletrodos permaneceram imersos em solução de 1,0 mol.L-1 de combustível (etanol ou glicerol) e 1,0 mol.L-1 $\mathrm{KOH}$ saturados com nitrogênio.

O Espectrômetro foi acoplado a um potenciostato/galvanostato Metrohm Autolab PGSTAT 302N. Posteriormente, submeteu-se à célula eletroquímica um potencial de $-0,85 \mathrm{~V}$ por 15 minutos. Após esse período, para cada amostra foi retirado um espectro de background no potencial de $-0,85 \mathrm{~V}$. Após a extração do background, variou-se o potencial no intervalo de $-0,85 \mathrm{~V}$ a $0,05 \mathrm{~V}$ com incrementos de $100 \mathrm{mV}$. Os espectros foram coletados rapidamente para evitar que a produção excessiva da formação de subprodutos oriundos da oxidação eletroquímica do combustível (etanol ou glicerol) fosse exclusivamente ao potencial aplicado.

\subsection{Caracterização eletroquímica dos eletrocatalisadores}

Os estudos eletroquímicos foram realizados em célula eletroquímica de 3 eletrodos [144], utilizando o eletrocatalisador no eletrodo de trabalho de área geométrica de $0,3 \mathrm{~cm}^{2}$, com profundidade de $0,3 \mathrm{~mm}$. O eletrodo de $\mathrm{Ag} / \mathrm{AgCl}$ (3 mol. $\mathrm{L}^{-1} \mathrm{KCL}$ ) foi utilizado como eletrodo de referência e um fio de platina como contra eletrodo.

Os perfis eletroquímicos e as atividades eletrocatalíticas dos eletrocatalisadores foram avaliados por voltametria cíclica e cronoamperometria utilizando a técnica da camada fina porosa [14]. 
A técnica da camada fina porosa consiste na preparação de uma pasta, feita pela mistura de $20 \mathrm{mg}$ do eletrocatalisador, $50 \mathrm{~mL}$ de água deionizada e 3 gotas de uma dispersão 6\% deTeflon (Politetrafluoretileno - PTFE) [20]. A mistura resultante é levada a um sistema de ultrassom de ponta por 10 minutos. Posteriormente, essa mistura é filtrada a vácuo e a parte sólida aderida á cavidade do eletrodo de trabalho e compactada até a superfície ficar homogênea.

Estes experimentos foram executados em um potenciostato/galvanostato Metrohm Autolab PGSTAT 302N. As análises de voltametria cíclica foram realizadas no intervalo de potencial de $-0,85 \mathrm{~V}$ a 0,2 V com uma velocidade de varredura igual a $10 \mathrm{~m} \mathrm{V/s}$ utilizando como eletrólito suporte, solução 1,0 mol.L-1 de $\mathrm{KOH}$ na ausência e na presença de combustível, enquanto a cronoamperometria foi realizada no mesmo eletrólito contendo combustível no potencial de $-0,5 \mathrm{~V}$ por um período de $1800 \mathrm{~s}$. Todas as medidas foram realizadas em temperatura ambiente [20] e saturadas com $\mathrm{N}_{2}$ gasoso [145]. Os valores de corrente obtidos nestes estudos foram expressos em Ampéres $(A)$ e normalizados pela quantidade de paládio expresso em gramas $\left(A g^{-1} P d\right)$.

\subsection{Experimentos em célula a combustível do tipo DEFC e DGFC}

\subsubsection{Preparação do conjunto membrana-eletrodo (MEA)}

Foi empregado na confecção de todos os MEA um tecido de carbono teflonado (30\% PTFE) com $5 \mathrm{~cm}^{2}$ de área. A camada catalítica do anodo foi preparada usando uma solução de 30\% Nafion (dispersão 5\% DE520 da DuPont), álcool isopropílico e $1 \mathrm{mg}_{\mathrm{Pd}} \mathrm{cm}^{-2}$ dos eletrocatalisadores Pd/C, Ru/C e PdRu/C (90:10, 70:30 e 50:50). Em seguida, com o auxílio de um pincel, a camada catalítica preparada foi aplicada sobre o tecido de carbono até a total transferência da carga catalítica. Já para a preparação da camada catalítica do cátodo foi utilizado $1 \mathrm{mg} \mathrm{Pt} \mathrm{cm}^{-2}$ do catalisador comercial $\mathrm{Pt} / \mathrm{C}$ E-TEK (BASF - 20\% Pt em massa). Após a pintura, os eletrodos foram colocados na estufa a $70^{\circ} \mathrm{C}$ por um período de 24 horas para secagem. 
Para formação do MEA os dois eletrodos preparados foram prensados junto a membrana de Nafion 117 (DuPonTM), previamente tratadas com solução de KOH 6M, a $125^{\circ} \mathrm{C}$ por 10 minutos a $225 \mathrm{kgf} \mathrm{cm}^{-2}$.

\subsubsection{Experimento em célula a combustível}

Para se obter informações sobre a densidade de corrente em função do potencial, realizou-se curvas de polarização em uma célula a combustível unitária sendo possível comparar o desempenho entre o eletrocatalisadores por meio de suas respectivas curvas de densidade de potência [146].

Os ensaios em célula a combustível foram realizados com o uso de uma célula unitária (ElectroChem) com placas de grafite do tipo serpentina de $5 \mathrm{~cm}^{2}$ de área para distribuição do combustível e acomodação do MEA. Para realização dos experimentos, a célula foi acoplada a um potenciostato/galvanostato Metrohm Autolab PGSTAT 302N.

Após a montagem da célula, no cátodo o gás oxigênio foi umidificado externamente usando uma garrada umidificadora a uma temperatura de $85^{\circ} \mathrm{C}$ e no anodo, a temperatura ajustada para o etanol e glicerol foi de $80{ }^{\circ} \mathrm{C}$ e $90{ }^{\circ} \mathrm{C}$ respectivamente. 


\section{RESULTADOS E DISCUSSÃO}

\subsection{Espectroscopia por energia dispersiva de raios $X$ (EDX)}

Nesta seção, são apresentados os resultados da composição atômica experimental, seus respectivos espectros e as micrografias das regiões de varredura para a análise dos eletrocatalisadores PdRu/C (50:50), PdRu/C (70:30) e PdRu/C (90:10) preparados pelo método de redução por borohidreto de sódio. A figura 4 apresenta os espectros dos eletrocatalisadores em estudo, no qual é possível observar os espectros em forma de picos.

FIGURA 4: Espectros da composição dos elementos constituintes da amostra: (a) PdRu/C preparado pelo método de redução por borohidreto de sódio.

(a) Eletrocatalisador PdRu/C (50:50)

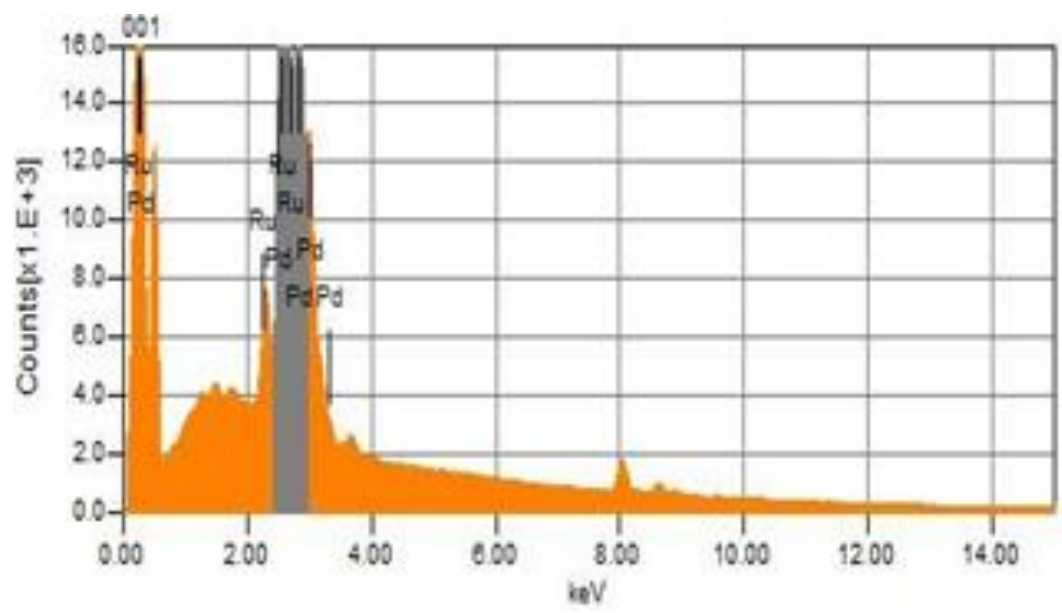

Fonte: Próprio autor 
FIGURA 4: Espectros da distribuição dos elementos constituintes da amostra: (b) $\mathrm{PdRu} / \mathrm{C}$ (70:30) e (c) PdRu/C (90:10) preparados pelo método de redução por borohidreto de sódio.

(b) Eletrocatalisador PdRu/C (70:30)

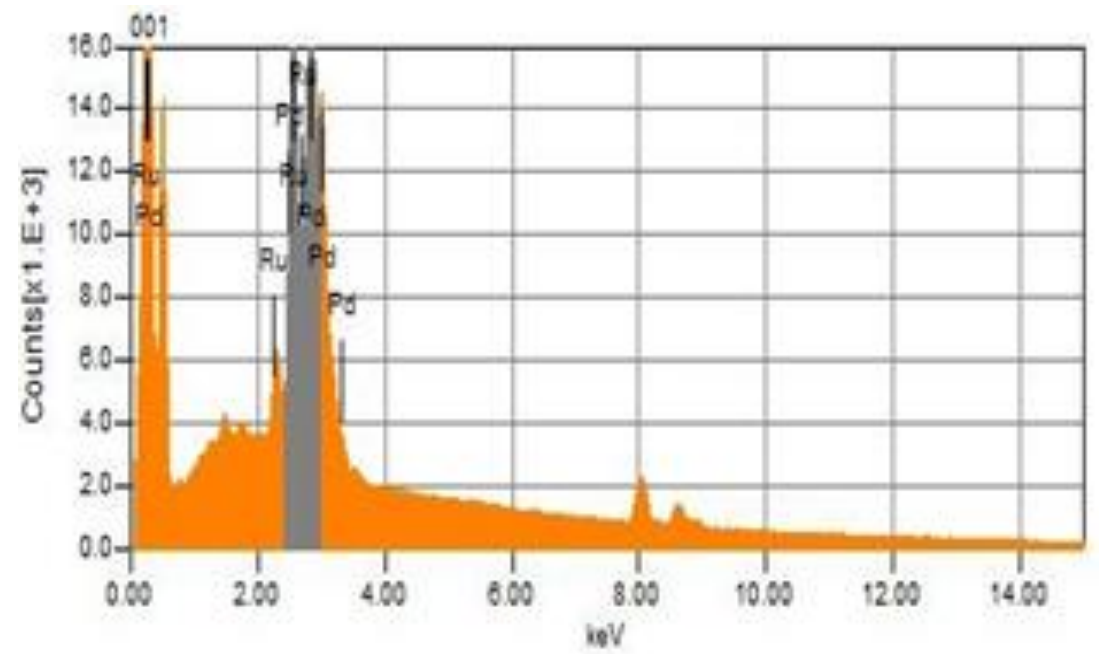

(c) Eletrocatalisador PdRu/C (90:10)

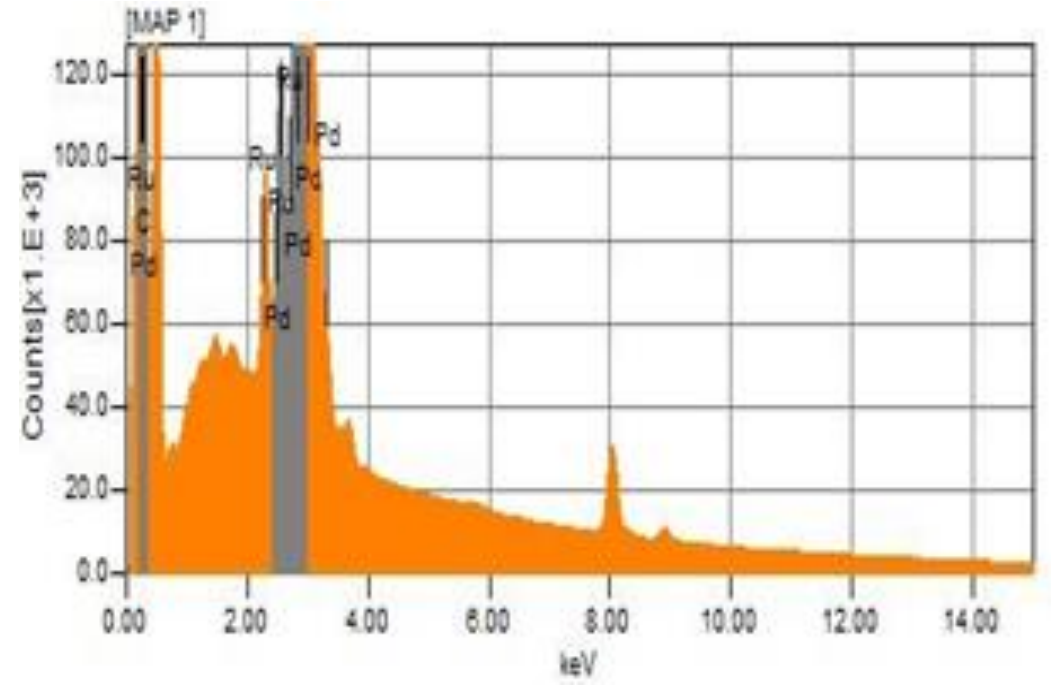

Fonte: Próprio Autor

Os picos observados para todos os espectros indicam os níveis de energia dos elementos que constituem a amostra onde foi verificado a presença de paládio e de rutênio. 
A figura 5 exibe as micrografias obtidas por MEV da região analisada para todos os eletrocatalisadores de $\mathrm{PdRu} / \mathrm{C}$ preparados.

FIGURA 5: Micrografias obtidas por MEV: (a) PdRu/C (50:50) e (b) PdRu/C (70:30) (c) $\mathrm{PdRu} / \mathrm{C}$ (90:10) preparado pelo método de redução via borohidreto de sódio.

(a) Eletrocatalisador PdRu/C (50:50)

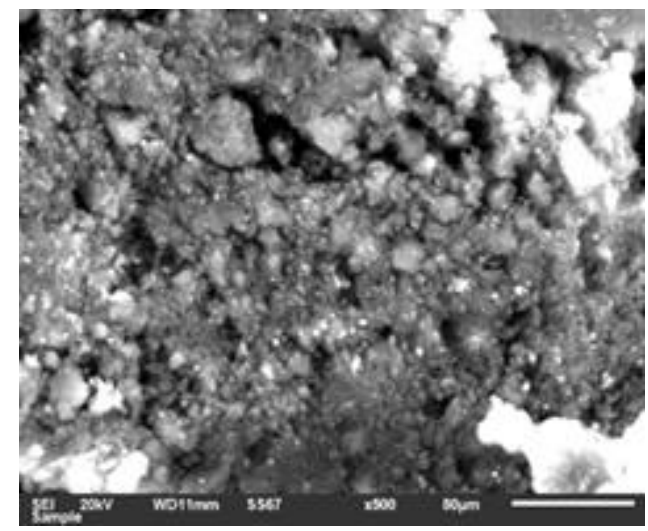

(b) Eletrocatalisador PdRu/C (70:30)

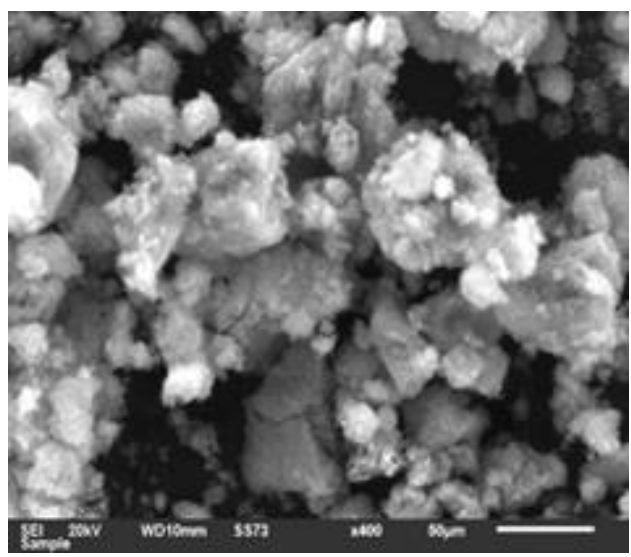

(c) Eletrocatalisador PdRu/C (90:10)

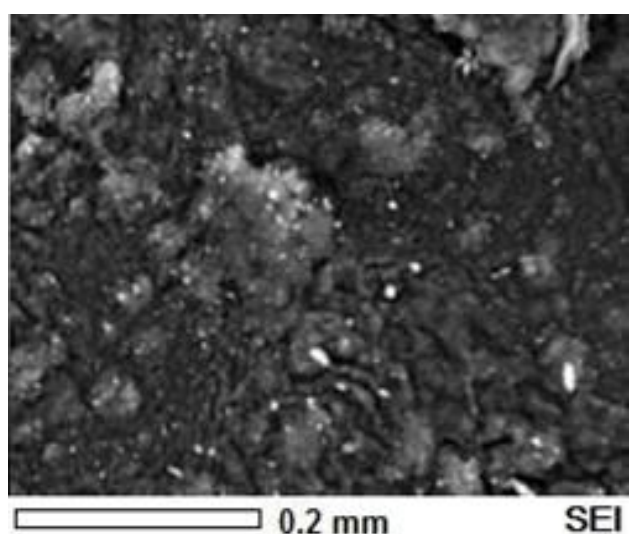

Fonte: Próprio Autor 
Os resultados das composições atômicas nominais e experimentais dos metais obtidos pela técnica de EDX para todos os eletrocatalisadores em estudo são apresentados na tabela 1 .

TABELA 1: Composição atômica nominal e experimental obtidas por EDX dos eletrocatalisadores de Pd/C, PdRu/C (90:10; 70:30; 50:50) e Ru/C.

\begin{tabular}{|c|c|c|c|c|}
\hline Eletrocatalisador & $\begin{array}{c}\text { Composição } \\
\text { experimental de } \\
\mathbf{P d}\end{array}$ & $\begin{array}{c}\text { Composição } \\
\text { experimental } \\
\text { de } \mathbf{R u}\end{array}$ & $\begin{array}{c}\text { Composição } \\
\text { nominal de } \\
\mathbf{P d}\end{array}$ & $\begin{array}{c}\text { Composição } \\
\text { nominal de Ru }\end{array}$ \\
\hline $\mathbf{P d} / \mathbf{C}$ & 100 & 0 & 100 & 0 \\
\hline $\mathbf{P d R u}(\mathbf{9 0}: \mathbf{1 0}) / \mathbf{C}$ & 91,13 & 8,87 & 90 & 10 \\
\hline $\mathbf{P d R u}(\mathbf{7 0}: \mathbf{3 0}) / \mathbf{C}$ & 70,21 & 29,79 & 70 & 30 \\
\hline $\mathbf{P d R u}(\mathbf{5 0}: 50) / \mathbf{C}$ & 50,95 & 49,05 & 50 & 50 \\
\hline $\mathbf{R u} / \mathbf{C}$ & 0 & 100 & 0 & 100 \\
\hline
\end{tabular}

Fonte: Próprio Autor

Os resultados de EDX apresentados na tabela 1 mostraram que os valores da composição atômica experimental são próximos aos nominais, respeitando os cálculos estequiométricos estabelecidos para preparação dos eletrocatalisadores em estudo, estes resultados mostraram que o método proposto é bastante eficiente na síntese de eletrocatalisadores de PdRu.

\subsection{Difração de raios X (DRX)}

Os difratogramas dos eletrocatalisadores de $\mathrm{Pd} / \mathrm{C}, \mathrm{Ru} / \mathrm{C}$ e $\mathrm{PdRu} / \mathrm{C}$ (90:10, 70:30 e 50:50) são apresentados na figura 6. 
FIGURA 6: Difratogramas obtidos em um intervalo de medida $2 \theta=20^{\circ}$ a $90^{\circ}$, incrementos de $0,05^{\circ}$ e com uma velocidade de varredura de $2^{\circ} \mathrm{min}^{-1}$ dos eletrocatalisadores de $\mathrm{Pd} / \mathrm{C}, \mathrm{Ru} / \mathrm{C}$ e PdRu/C (90:10, 70:30 e 50:50) em forma de pó.

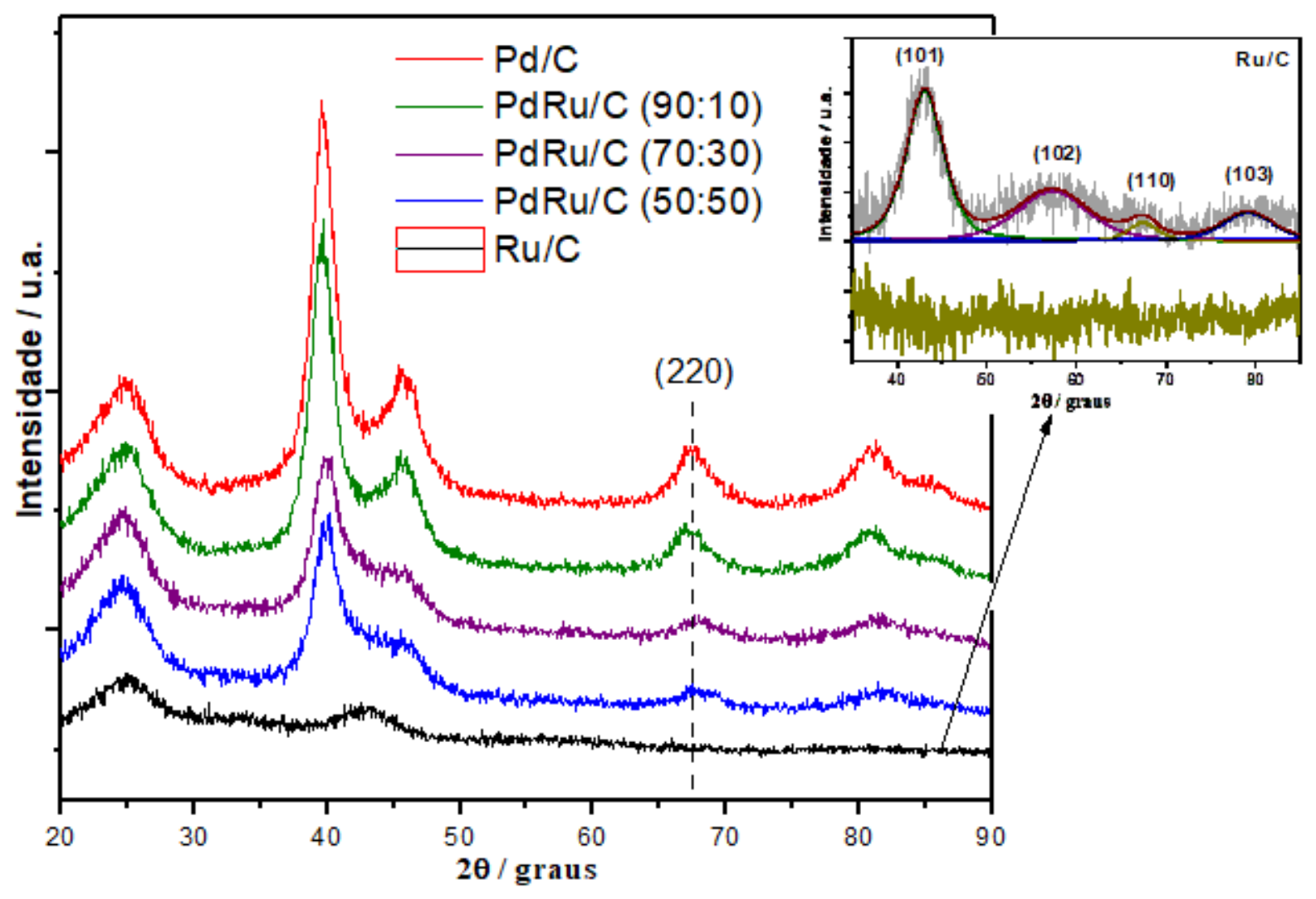

Fonte: Próprio Autor

De acordo com o difratograma apresentado na figura 6, para todos os eletrocatalisadores preparados, identificam-se os picos de difração de Bragg em aproximadamente $2 \theta=25^{\circ}$, referente ao suporte de carbono XC72 utilizado na síntese, correspondente ao plano (002) de estrutura hexagonal [147-150]. Os picos que aparecem em aproximadamente $2 \theta=40^{\circ}, 47^{\circ}, 68^{\circ}$ e $82^{\circ}$, são atribuídos aos planos de reflexão (111), (200), (220) e (311) correspondente a estrutura cúbica de face centrada do paládio [151-153].

É observado para os eletrocatalisadores binários (PdRu/C) uma sobreposição dos picos associados ao $\mathrm{Pd}$ e $\mathrm{Ru}$ em aproximadamente $2 \theta=40^{\circ}$ a $45^{\circ}$ devido da existência simultânea do plano cristalino de Ru (101) e de Pd (220) [33], e em 67,5은 foi observado um deslocamento do pico associado ao $\mathrm{Pd}$, possivelmente causado pela formação de liga metálica entre $\mathrm{Pd}$ e $\mathrm{Ru}$ [154-155]. Também é observado a predominância da estrutura cúbica de face centrada do $\mathrm{Pd}$, resultados estes de acordo 
com Liu e colaboradores [156]. O eletrocatalisador de $\mathrm{Ru} / \mathrm{C}$ apresenta 4 picos de baixa intensidade nos ângulos de Bragg $2 \theta=44^{\circ}, 58^{\circ}, 69^{\circ}$ e $78^{\circ}$ aproximadamente, associados aos planos (101), (102), (110) e (103) respectivamente, característico da estrutura hexagonal compacta (hcp) do rutênio [156-158].

\subsection{Microscopia eletrônica de transmissão (MET)}

Na figura 6 (a-e) são apresentados as micrografias obtidas por MET para todos os eletrocatalisadores em estudo, no qual é possível observar a distribuição das nanopartículas metálicas sobre o suporte de carbono, também é apresentado seus respectivos histogramas construídos a partir da contabilização digital de 100 nanopartículas, usados para construir a tabela 2.

TABELA 2: Tamanho médio das nanopartículas dos eletrocatalisadores $\mathrm{Pd} / \mathrm{C}$ e $\mathrm{PdRu} / \mathrm{C}$ (90:10; 70:30 e 50:50) sintetizados pelo método de redução via borohidreto de sódio.

\begin{tabular}{|c|c|c|c|}
\hline Eletrocatalisador & $\begin{array}{c}\text { Razão atômica } \\
\text { nominal } \\
\text { (Pd:Ru) }\end{array}$ & $\begin{array}{c}\text { Razão atômica } \\
\text { experimental / } \\
\text { EDS (Pd:Ru) }\end{array}$ & $\begin{array}{c}\text { Tamanho médio } \\
\text { de nanopartícula } \\
\mathbf{n m}\end{array}$ \\
\hline $\mathbf{P d} / \mathbf{C}$ & 100 & 100 & 6,5 \\
\hline $\mathbf{P d R u} / \mathbf{C}$ & $90: 10$ & $91,13: 8,87$ & 4,6 \\
\hline $\mathbf{P d R u} / \mathbf{C}$ & $70: 30$ & $70,21: 29,79$ & 2,6 \\
\hline $\mathbf{P d R u} / \mathbf{C}$ & $50: 50$ & $50,95: 49,05$ & 2,9 \\
\hline
\end{tabular}

Fonte: Próprio autor 
FIGURA 7: Micrografia obtida por microscopia eletrônica de transmissão e histograma da distribuição de tamanho médio de nanopartícula metálica (a) Pd/C. (b) PdRu/C (90:10) (c) PdRu/C (70:30) (d) PdRu/C (50:50).
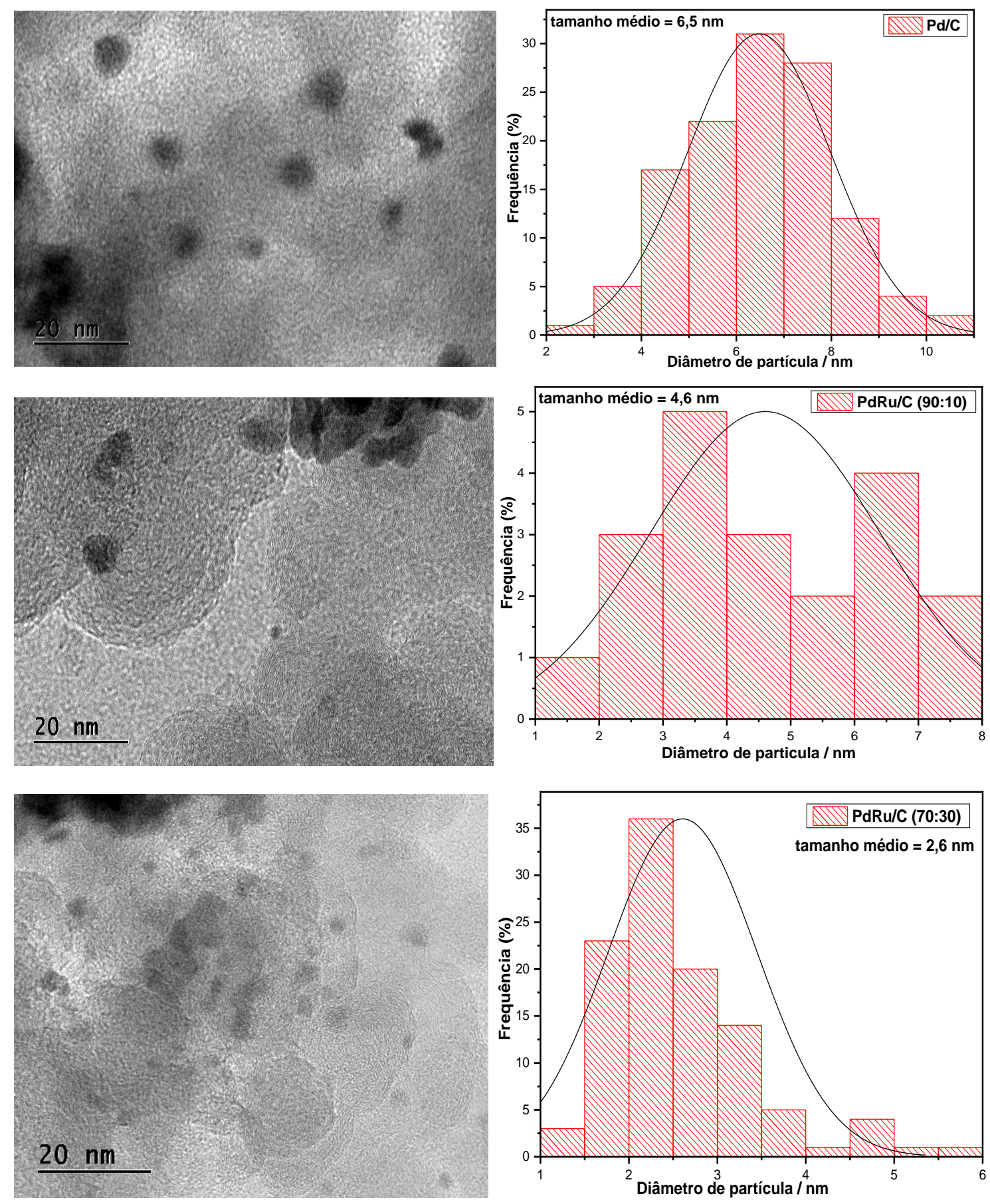

Fonte: Próprio autor 
FIGURA 7: Micrografia obtida por microscopia eletrônica de transmissão e histograma da distribuição de tamanho médio de partícula do eletrocatalisador (a) Pd/C. (b) PdRu/C (90:10) (c) PdRu/C (70:30). (d) PdRu/C (50:50).
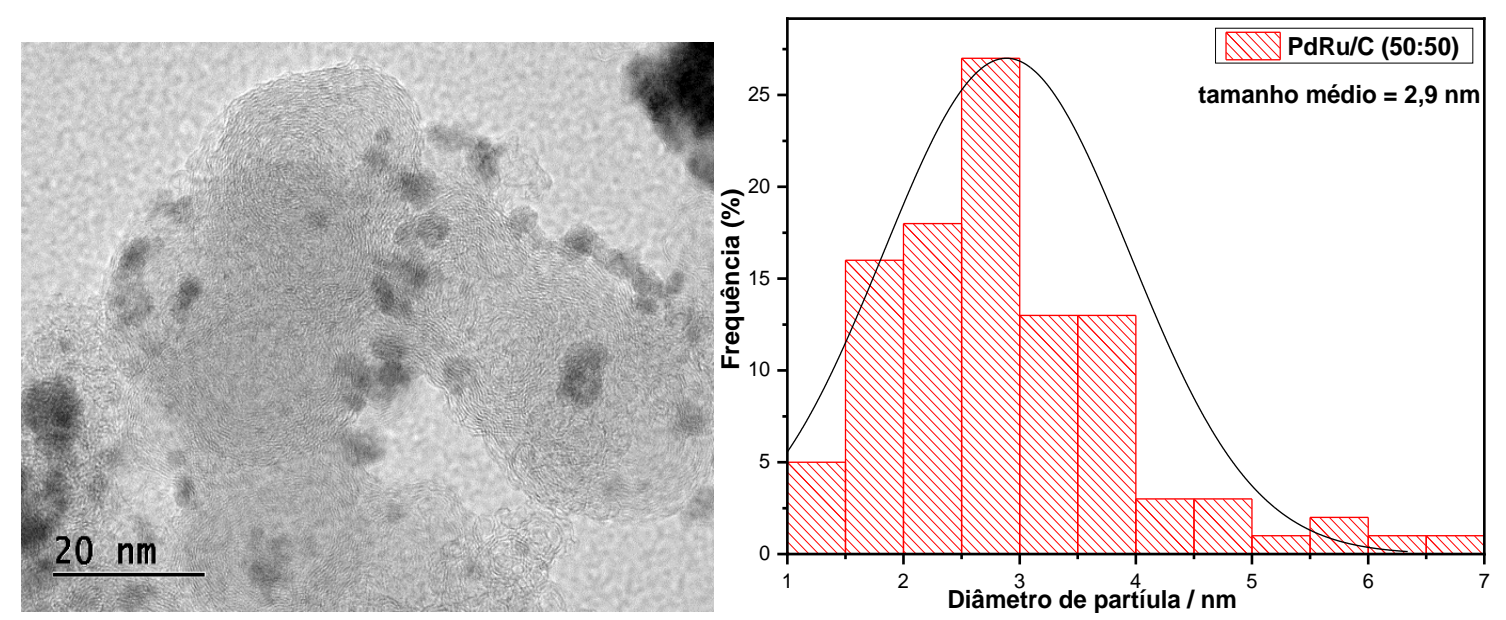

Fonte: Próprio autor.

Com base nas informações apresentadas na tabela 2, para o eletrocatalisador $\mathrm{Pd} / \mathrm{C}$, as nanopartículas exibiram um diâmetro médio de, aproximadamente, $6,5 \mathrm{~nm}$. Os eletrocatalisadores PdRu/C (90:10), PdRu/C (70:30) e PdRu/C (50:50) apresentaram tamanhos médios de partícula, aproximadamente, 4,6 nm, 2,6 nm e 2,9 $\mathrm{nm}$, respectivamente, estando em acordo com os resultados obtidos por Monyoncho e colaboradores [159]. Portanto, a adição de rutênio ao eletrocatalisador $\mathrm{Pd} / \mathrm{C}$ resultou em uma diminuição do tamanho médio de nanopartícula, este efeito pode ser decorrente de um efeito estabilizante do rutênio. Também foi observado nas micrografias que as nanopartículas metálicas foram razoavelmente distribuídas no suporte de carbono e também ocorreram algumas regiões de aglomerados, exceto para o catalisador $\mathrm{Ru} / \mathrm{C}$, que exibiu apenas regiões com aglomeração, não sendo capaz de realizar a contabilização para estimar o tamanho médio das partículas metálicas de rutênio. 


\subsection{Espectroscopia de Fotoelétrons de raios X (XPS)}

Pela técnica de XPS foi possível determinar a composição e os diferentes estados de oxidação da superfície dos eletrocatalisadores PdRu/C (90:10, 70:30 e 50:50). Além disso, foi possível realizar a quantificação desses diferentes estados de oxidação, não obstante, também foi possível verificar as ligações químicas entre as moléculas de $\mathrm{CO}$ com o suporte de carbono. Para isso, foi utilizado o software CASAXPS para a conversão dos arquivos .wvma para txt. O software OringinPro 2018 foi utilizado para a análise dos espectros, utilizando o método desenvolvido por (Shirley, 1965) para a elaboração das linhas bases.

A figura 8 (a-c) apresenta os espectros de XPS relativos aos estados $C 1 \mathrm{~s}$ do carbono para os eletrocatalisadores PdRu/C (90:10; 70:30 e 50:50).

FIGURA 8: Espectros de XPS C1s da superfície dos eletrocatalisadores de (a) PdRu/C 90:10, (b) PdRu/C 70:30 e (c) PdRu/C 50:50.

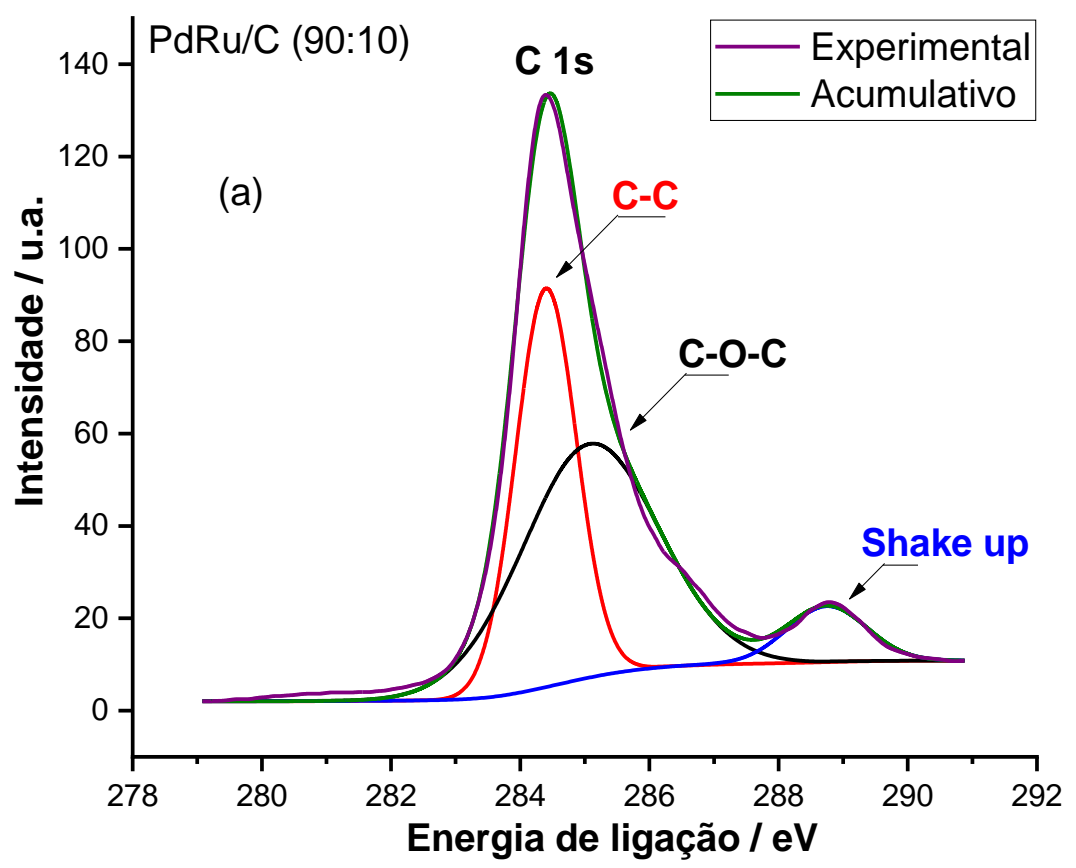

Fonte: Próprio autor 
FIGURA 8: Espectros de XPS C1s da superfície dos eletrocatalisadores de (a) PdRu/C 90:10, (b) PdRu/C 70:30 e (c) PdRu/C 50:50.
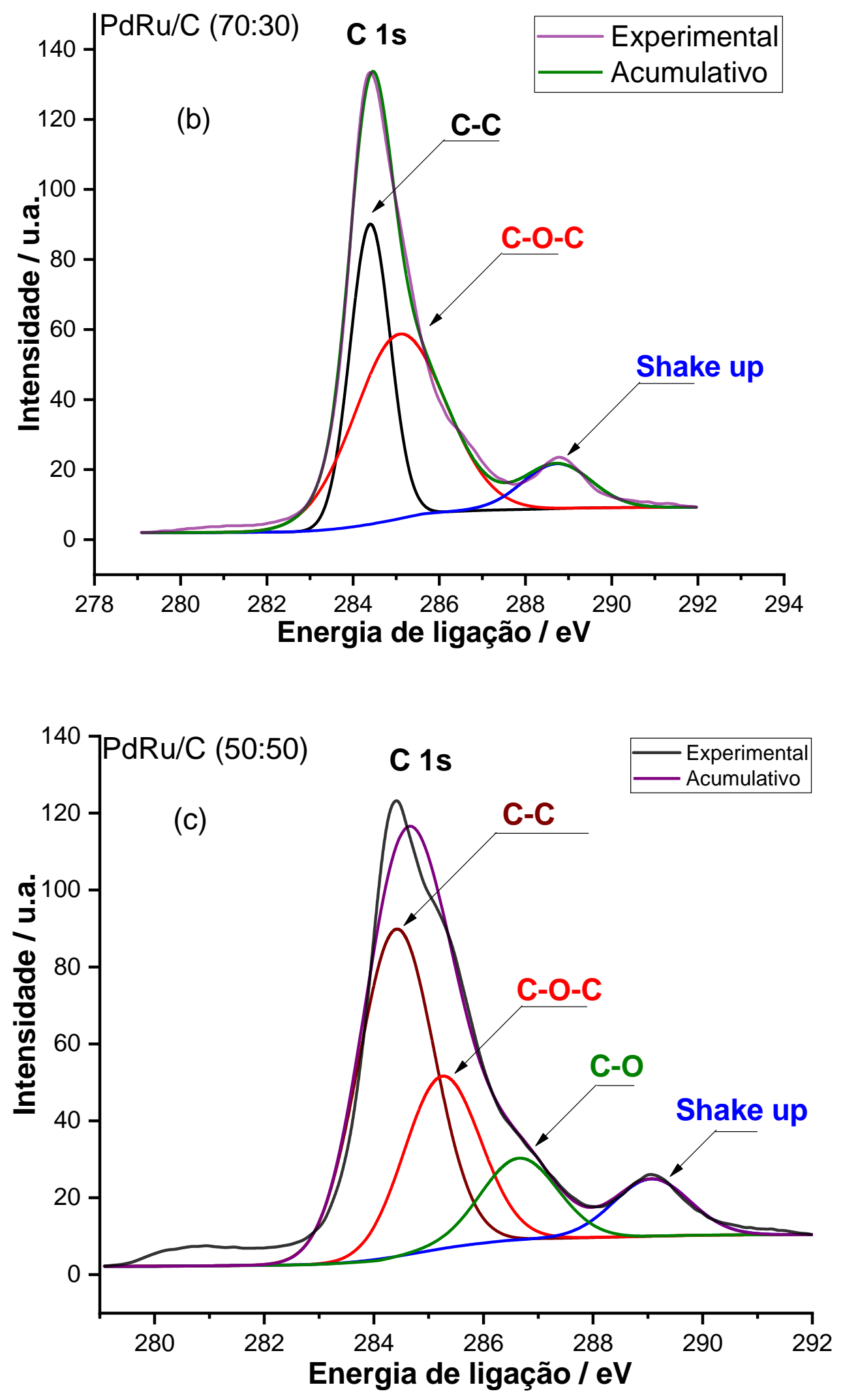

Fonte: Próprio autor 
Os espectros de carbono revelaram diferentes tipos de ligações químicas, sendo possível observar a ligação do tipo C-C com energia de ligação em aproximadamente $284,3 \mathrm{eV}$ [160], atribuído ao carbono grafítico, característico do suporte de carbono XC72 [161-162], também foi observado a energia de ligação em aproximadamente $285,1 \mathrm{eV}$, correspondente a hibridização $\mathrm{sp}^{2}$ do carbono, característico da ligação química C-O-C [151], o grupo funcional Éter é observado no suporte devido a interação dos átomos de oxigênio com os átomos de carbono. Essa interação é caracterizada pela reação química presente na síntese dos eletrocatalisadores [163].

Em aproximadamente $289 \mathrm{eV}$ foi observado um pico para todos os eletrocatalisadores em estudo, sendo característico de um efeito Shake up [151; 164], no qual os elétrons remanescentes da interação dos fótons com a amostra possuem energia de ligação ligeiramente maior. Para o eletrocatalisador $P d R u / C ~(50: 50)$, também foi observado um pico aproximadamente em 286,6 eV, associado a ligação C-O [165-166] atribuído à interação do ambiente com a superfície do eletrocatalisador [160; 167]. A figura 9 apresenta os espectros de XPS relativos aos estados O1s do oxigênio para os eletrocatalisadores PdRu/C (90:10; 70:30 e 50:50).

FIGURA 9: Espectros de XPS O1s da superfície do eletrocatalisadores (a) PdRu/C 90:10. (b) PdRu/C (70:30) e (c) PdRu/C (50:50).

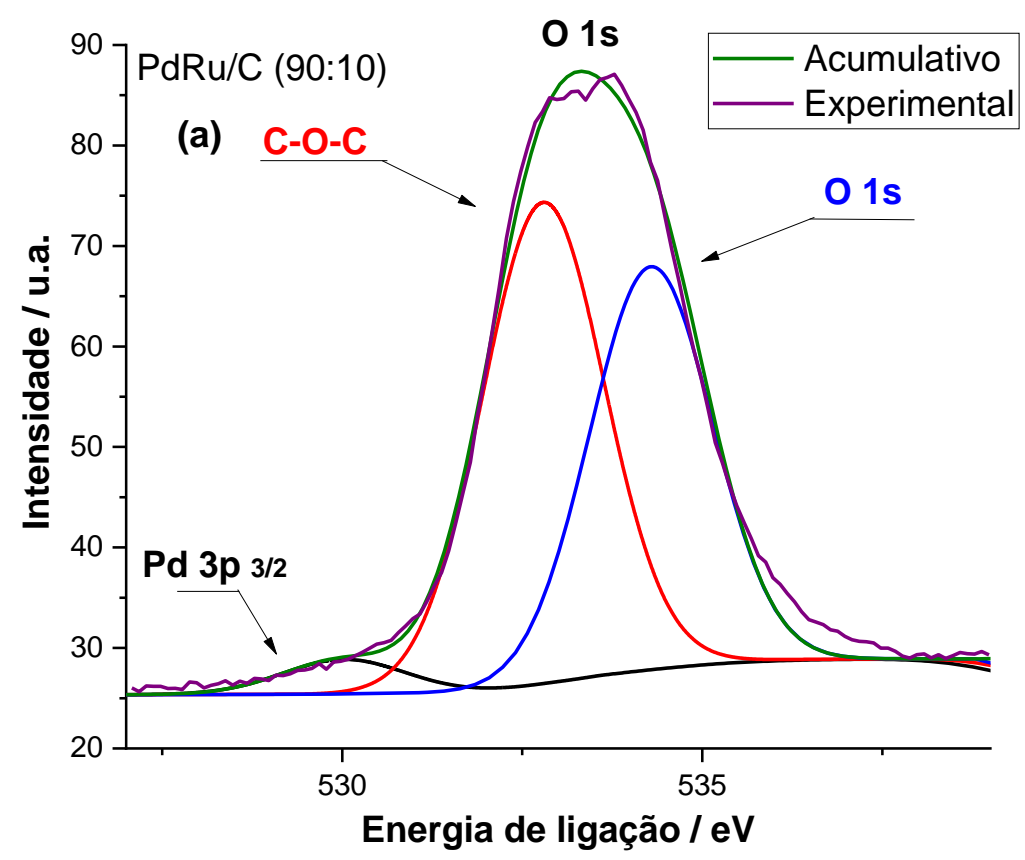

Fonte: Próprio autor 
FIGURA 9: Espectros de XPS O1s da superfície do eletrocatalisadores (a) PdRu/C 90:10. (b) $\mathrm{PdRu} / \mathrm{C}(70: 30)$ e (c) PdRu/C (50:50).
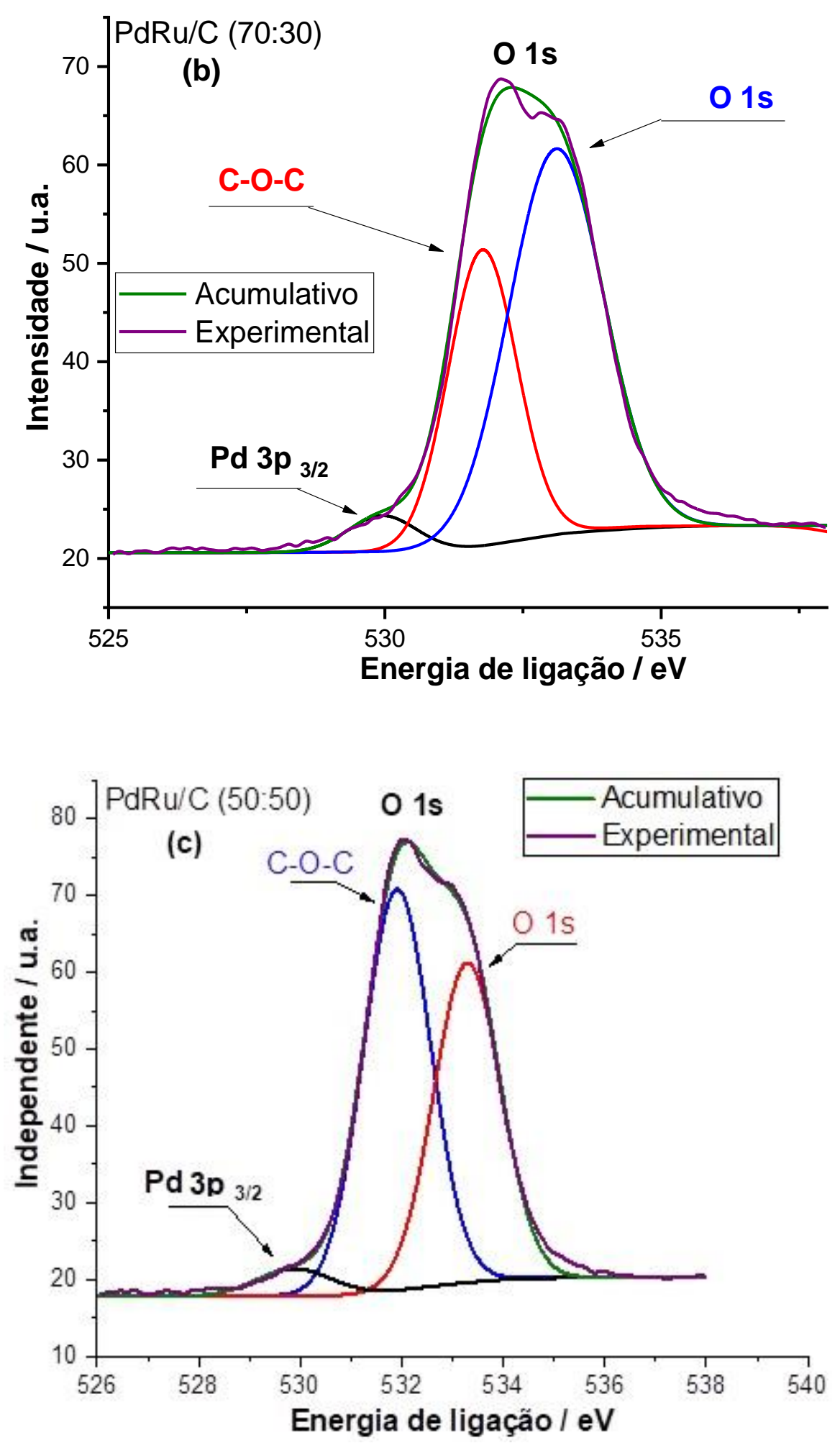

Fonte: Próprio autor 
Também foi observado uma banda O1s que representa a presença de oxigênio oriundo da reação de síntese dos eletrocatalisadores ou dos átomos de oxigênio presente no ambiente, discutidos nos espectros de carbono. $O$ pico exibido em $533 \mathrm{eV} \pm 0,7 \mathrm{eV}$ é associado ao oxigênio [151]. Também é observado a presença de

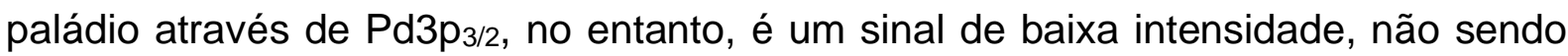
possível analisar os desvios químicos do paládio [151]. O pico em aproximadamente 531 eV \pm 0,6 eV corresponde ao grupo aldeído [162; 164; 168].

A figura 10 apresenta os espectros de XPS relativos aos estados Pd3d do paládio para os eletrocatalisadores PdRu/C (90:10; 70:30 e 50:50).

FIGURA 10: Espectros de XPS Pd3d da superfície do eletrocatalisador (a) PdRu/C 90:10 (b) $\mathrm{PdRu} / \mathrm{C}(70: 30)$ e (c) PdRu/C (50:50).

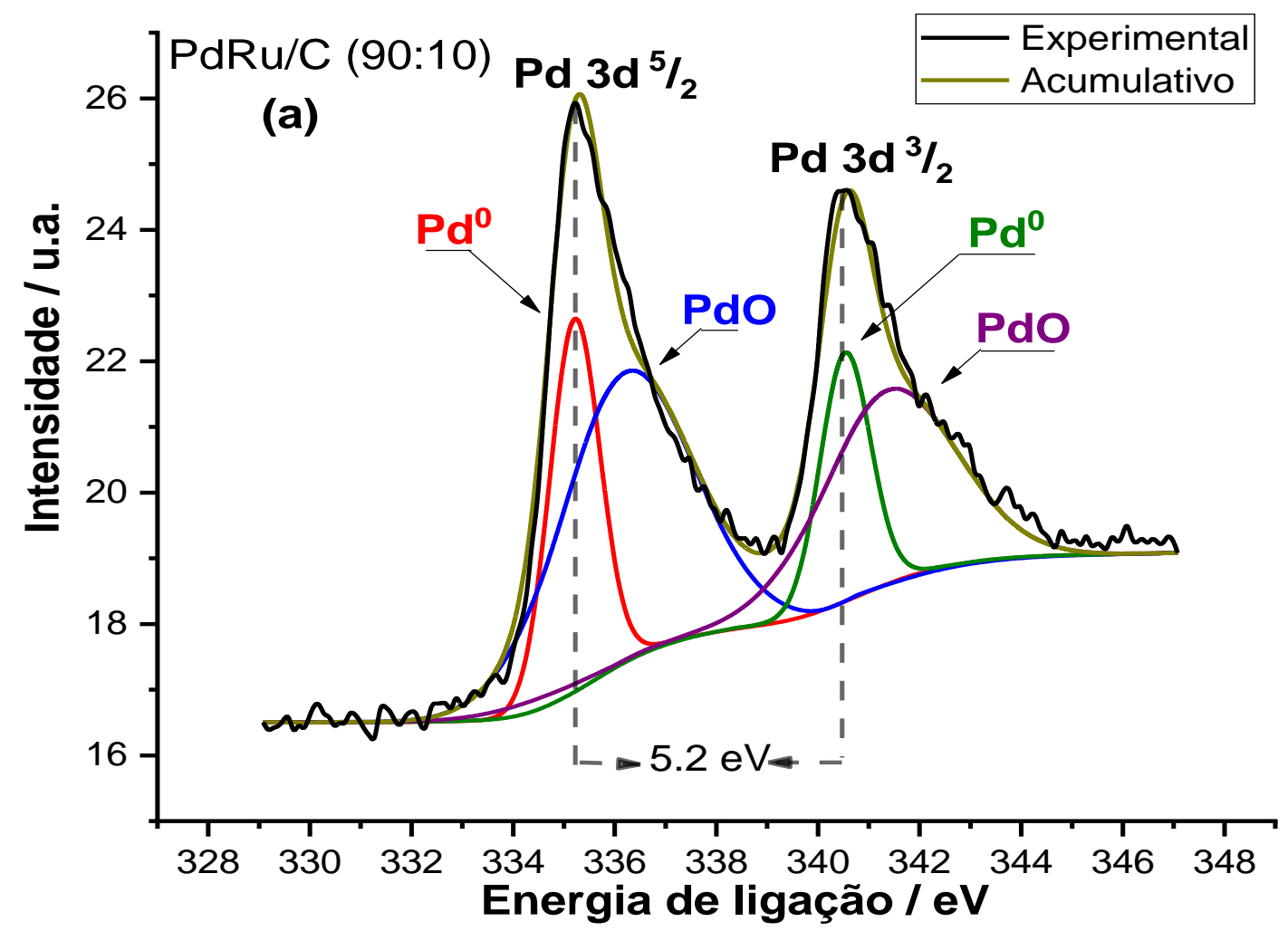

Fonte: Próprio autor 
FIGURA 10: Espectros de XPS Pd3d da superfície do eletrocatalisador (a) PdRu/C 90:10 (b) $\mathrm{PdRu} / \mathrm{C}$ (70:30) e (c) PdRu/C (50:50).
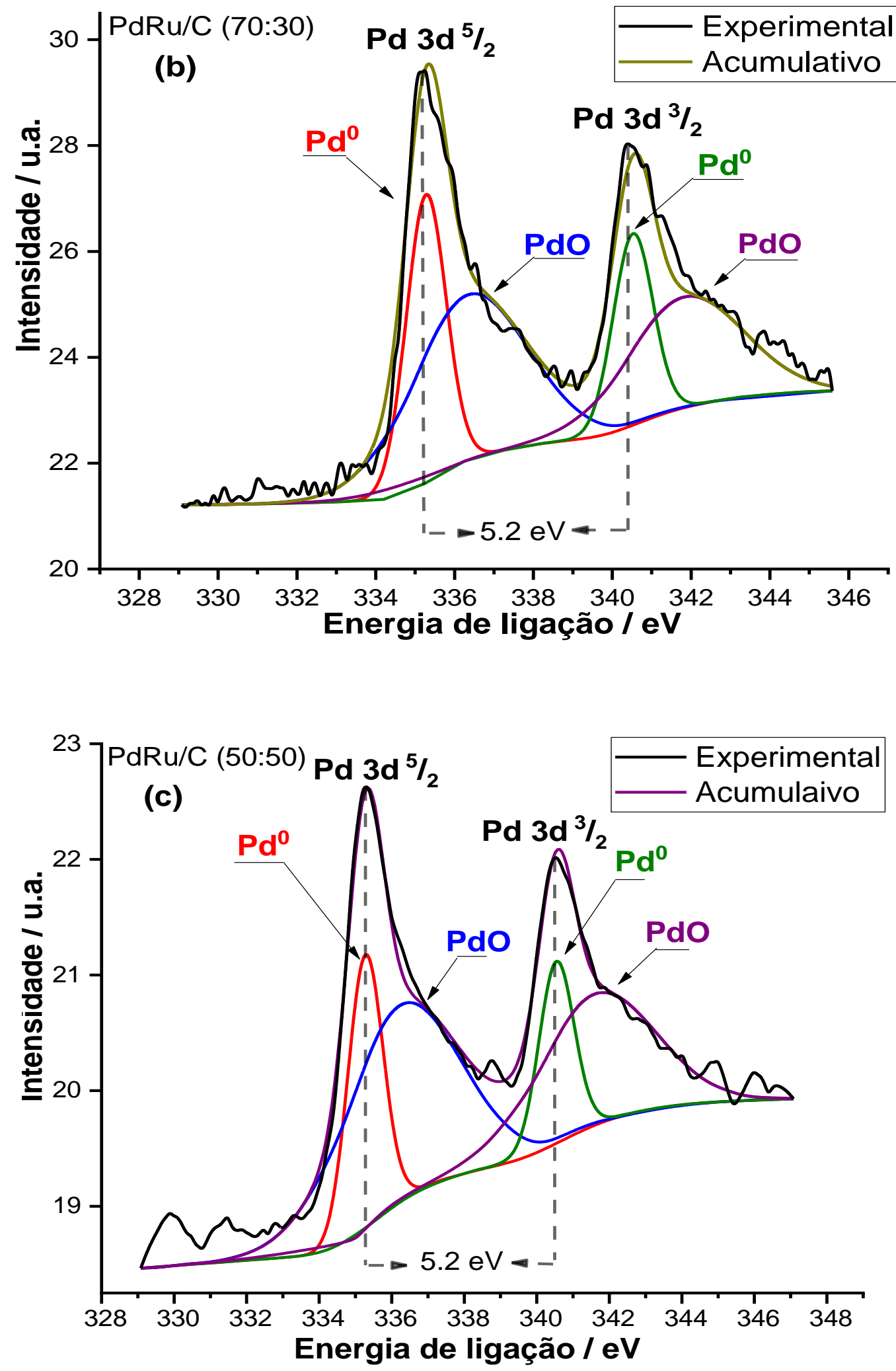

Fonte: Próprio autor 
De acordo com os espectros de XPS do paládio apresentados na figura 10, é observado a presença de um dubleto em forma de dois picos, característicos dos estados $\mathrm{Pd}_{3} \mathrm{~d}_{5 / 2}$ e Pd3 $\mathrm{d}_{3 / 2}$ do paládio. A distância medida entre os picos foi de 5,2 eV, Moulder [169] relata esta distância sendo de 5,25 eV, portanto, o ajuste da curva empregada é condizente com a teoria de XPS descrita na literatura. Em aproximadamente $335,3 \mathrm{eV}$ e $336,3 \mathrm{eV}$ foi observado a presença de $\mathrm{Pd}^{0}$ e $\mathrm{PdO}$ respectivamente, sendo atribuído à interação do oxigênio com os metais e/ou devido ao processo de síntese empregado (redução dos sais metálicos) [163; 170]. Estudos $[151 ; 171]$ comunica estes valores aproximadamente em $335,3 \mathrm{eV}$ e $337 \mathrm{eV}$, podemos afirmar que $\mathrm{Pd}^{0}$ e $\mathrm{PdO}$ está presente nos eletrocatalisadores.

A figura 11 apresenta os espectros de XPS relativos aos estados Ru3p do rutênio para os eletrocatalisadores PdRu/C (90:10; 70:30 e 50:50).

FIGURA 11: Espectros de XPS Ru3p da superfície do eletrocatalisador (a) PdRu/C 90:10, (b) $\mathrm{PdRu} / \mathrm{C}(70: 30)$ e (c) PdRu/C (50:50).

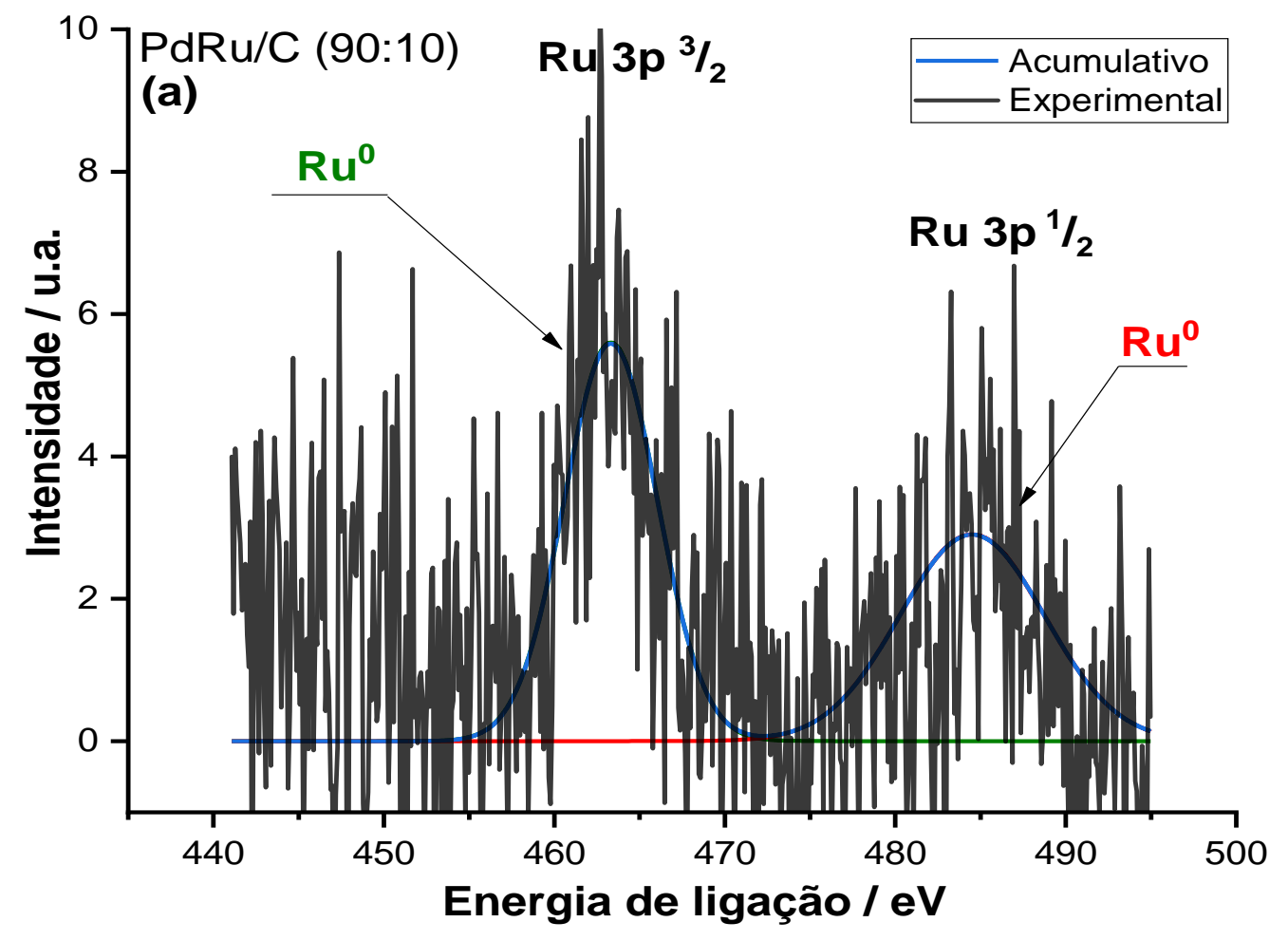

Fonte: Próprio autor 
FIGURA 11: Espectros de XPS Ru3p da superfície do eletrocatalisador (a) PdRu/C 90:10, (b) $\mathrm{PdRu} / \mathrm{C}(70: 30)$ e (c) PdRu/C (50:50).
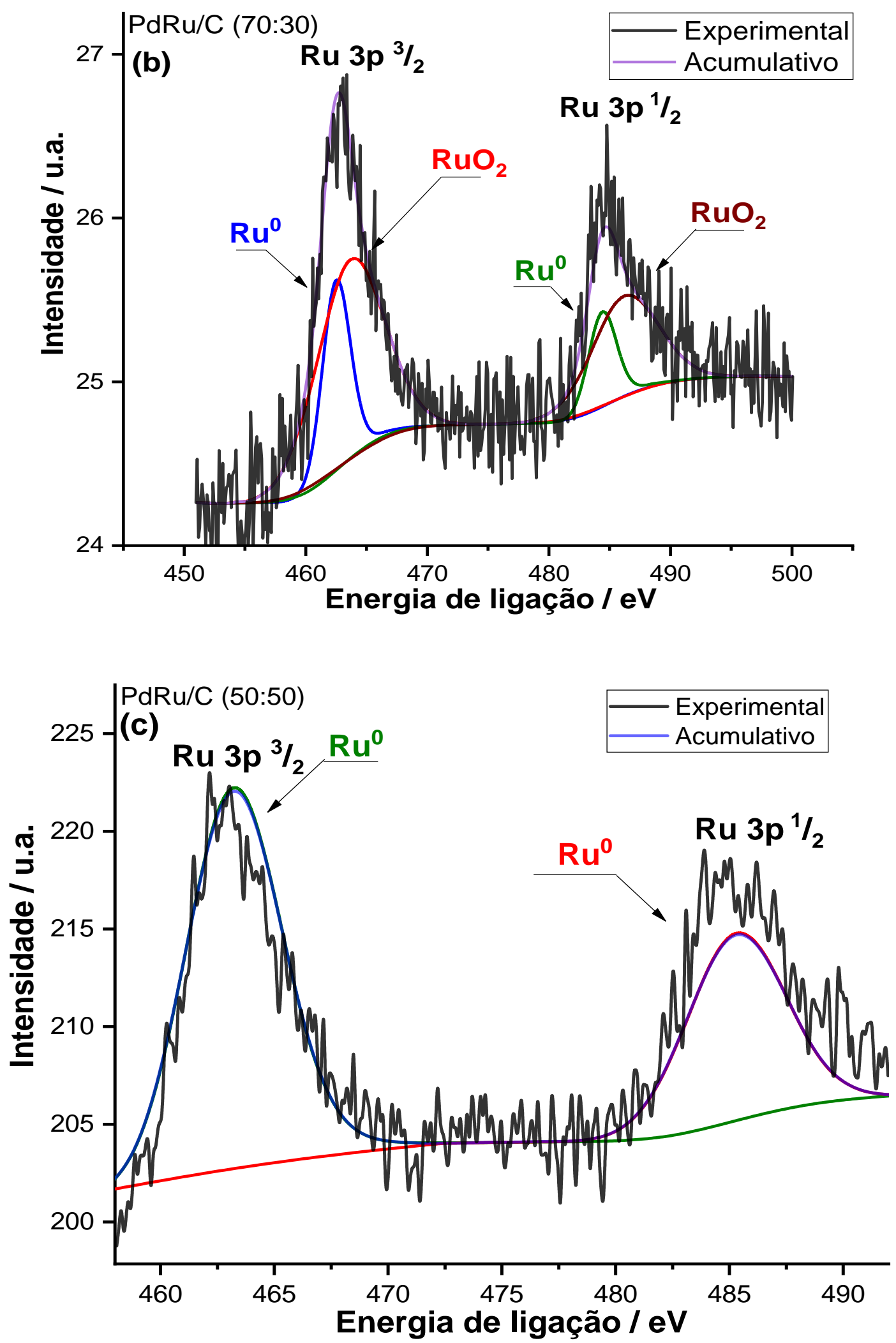

Fonte: Próprio autor 
Quanto ao espectro de XPS do $R u$ 3d, o pico do $R u 3_{3 / 2}$ quase se sobrepõe ao do carbono C1s, dificultando sua interpretação e análise [172], sendo necessário observar os espectros de rutênio em Ru3p conforme exibido na figura 4. Foi observado no espectro de XPS da banda Ru3p, para os eletrocatalisadores PdRu/C (90:10) e $\mathrm{PdRu} / \mathrm{C}$ (50:50), dois picos de 463,3 eV e aproximadamente 485,1 eV, atribuídos a $R u 3 p_{3 / 2}$ e $R u 3 p_{1 / 2}$, associados ao rutênio $R u^{0}[165]$. Para o eletrocatalisador $\mathrm{PdRu} / \mathrm{C}$ (70:30), os picos presentes em 462,6 eV e 484,4 eV, são atribuídos ao $\mathrm{Ru}^{0}$, enquanto que os picos em aproximadamente 463,8 eV e 486,4 eV são associados às espécies de $\mathrm{RuO}_{2}$ [154], essas espécies de $\mathrm{RuO}_{2}$ podem ser formadas devido as condições ambientes usadas no preparo da síntese em que os átomos de $\mathrm{Ru}$ assumem o estado de oxidação (IV) e (VI) por reações espontâneas de oxidação e redução, se apresentando em forma oxidada, como espécies hidratadas $\mathrm{Ru}^{4+}$ ou $\mathrm{RuCl}_{\mathrm{x}}$ [159]. Também foi possível observar que com o acréscimo de rutênio no eletrocatalisador se tem uma melhor resolução do espectro, sendo possível identificar os diferentes estados de oxidação.

A tabela 3 apresenta a quantificação em porcentagem de carga metálica e óxidos formados na superfície (2 $\mathrm{nm}$ ) dos eletrocatalisadores $\mathrm{Ru} / \mathrm{C}, \mathrm{Pd} / \mathrm{C}$ e $\mathrm{PdRu} / \mathrm{C}$ (50:50; 70:30 e 90:10) sintetizados pelo método de redução via borohidreto de sódio.

TABELA 3: Determinação da composição atômica dos eletrocatalisadores considerando os diferentes estados de oxidação formados na superfície dos eletrocatalisadores $\mathrm{Ru} / \mathrm{C}, \mathrm{Pd} / \mathrm{C}$ e PdRu/C (50:50; 70:30 e 90:10) sintetizados pelo método de redução via borohidreto de sódio.

\begin{tabular}{|c|c|c|c|c|}
\hline Eletrocatalisador & $\% \mathbf{P d}$ & $\% \mathbf{P d O}$ & $\% \mathbf{R u}$ & $\% \mathbf{R u O}$ \\
\hline $\mathrm{Pd} / \mathrm{C}$ & $43,83 \%$ & $56,17 \%$ & $0,00 \%$ & $0,00 \%$ \\
\hline $\mathrm{Ru} / \mathrm{C}$ & $0,00 \%$ & $0,00 \%$ & $33,00 \%$ & $67,00 \%$ \\
\hline $\mathrm{PdRu} / \mathrm{C}(50: 50)$ & $26,69 \%$ & $63,37 \%$ & $9,93 \%$ & $0,00 \%$ \\
\hline $\mathrm{PdRu} / \mathrm{C}(70: 30)$ & $22,53 \%$ & $37,83 \%$ & $11,29 \%$ & $28,33 \%$ \\
\hline $\mathrm{PdRu} / \mathrm{C}(90: 10)$ & $10,26 \%$ & $21,06 \%$ & $68,66 \%$ & $0,00 \%$ \\
\hline
\end{tabular}

Fonte: Próprio autor 
Os resultados obtidos por EDX são complementares aos resultados de XPS, a análise feita por EDX tem uma profundidade de resolução de 1 a $3 \mu \mathrm{m}$, enquanto que por fotoelétrons de raios $X$ se tem uma resolução de $2 \mathrm{~nm}$ [151].

A distância entre os dubletos $\mathrm{Pd} 3 d$ do $\mathrm{Pd} / \mathrm{C}$ (puro) foi de $5.39 \mathrm{eV}$ enquanto que os eletrocatalisadores binários apresentaram uma distância de $5.2 \mathrm{eV}$, essa variação de energia significa que houve interação entre os metais, esses resultados também são complementares aos obtidos por DRX, no qual se observa um deslocamento dos planos para maiores ângulos de Bragg com o acréscimo de rutênio, indicando possível formação de liga metálica. 


\section{CARACTERIZAÇÃO ELETROQUÍMICA ETANOL}

\subsection{Voltametria cíclica}

A figura 12 apresenta os voltamogramas cíclicos dos eletrocatalisadores $\mathrm{Ru} / \mathrm{C}$, $\mathrm{Pd} / \mathrm{C}$ e PdRu/C (50:50; 70:30 e 90:10) em solução de $\mathrm{KOH} \mathrm{1,0} \mathrm{M} \mathrm{na} \mathrm{ausência} \mathrm{de}$ etanol. A taxa de varredura é de $10 \mathrm{mV} \cdot \mathrm{s}^{-1}$ na faixa de potencial de $-0,85 \mathrm{~V}$ a 0,2 V. O eletrocatalisador $\mathrm{Ru} / \mathrm{C}$ não apresenta boa definição na região de adsorção e dessorção de hidrogênio $(-0,85 \mathrm{~V}$ a $-0,5 \mathrm{~V})$. O eletrocatalisador $\mathrm{Pd} / \mathrm{C}$ exibe um pico em aproximadamente -0,4 V atribuído ao processo de formação de PdO [147; 173174], enquanto que na varredura catódica é observado um pico em aproximadamente $-0,25$ V atribuído à redução de óxidos de $\mathrm{Pd}[147 ; 153 ; 175]$. De acordo com a literatura [147; 173], o mecanismo de formação de óxidos de paládio na superfície do eletrocatalisador deve-se a quimissorção de íons $\mathrm{OH}^{-}$provenientes da solução alcalina a qual poderá ser útil na oxidação de intermediários adsorvidos.

FIGURA 12: Voltamogramas cíclicos dos eletrocatalisadores $\mathrm{Ru} / \mathrm{C}, \mathrm{Pd} / \mathrm{C}$ e $\mathrm{PdRu} / \mathrm{C}$ (50:50; 70:30 e 90:10) em solução de $\mathrm{KOH}$ 1,0 M na ausência de etanol com uma velocidade de varredura de $10 \mathrm{mV} . \mathrm{s}^{-1}$.

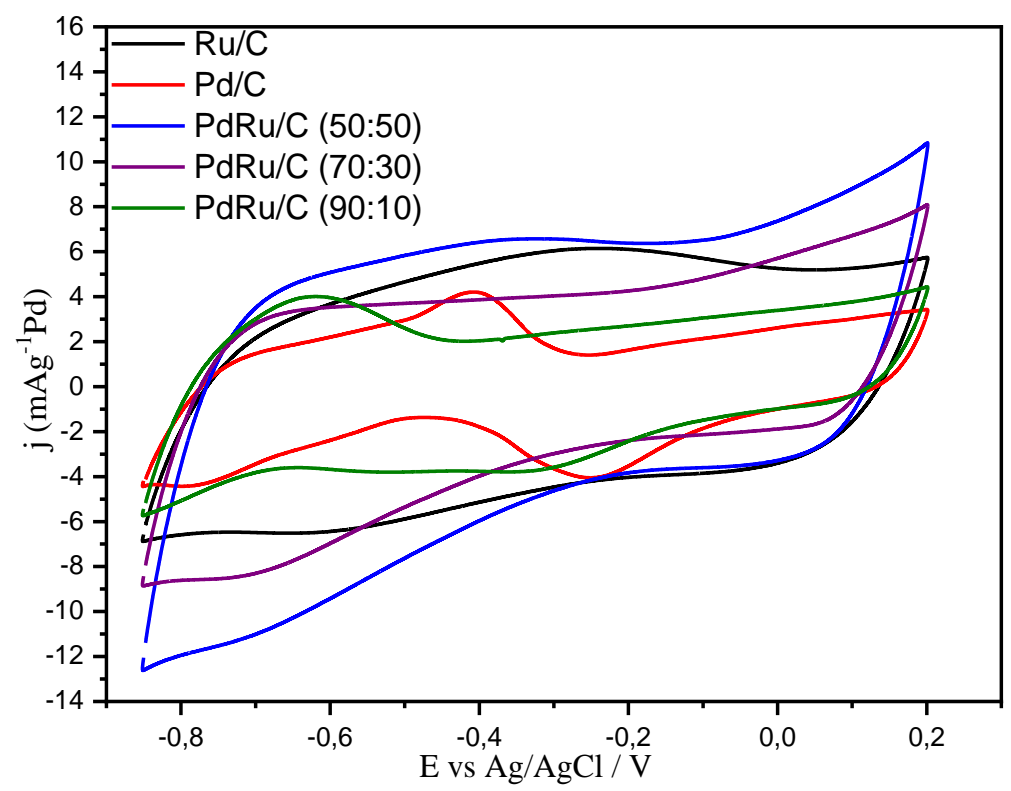

Fonte: Próprio autor 
Os voltamogramas dos eletrocatalisadores $\mathrm{PdRu} / \mathrm{C}$ e suas respectivas razões atômicas apresentaram perfis diferentes em comparação ao Pd/C. É observado um aumento na densidade de corrente (alargamento) na região da dupla camada elétrica entre os potenciais de $-0,5 \mathrm{~V}$ a $-0,1 \mathrm{~V}$ com o acréscimo de rutênio. Esse efeito é uma contribuição pseudo-capacitiva do rutênio para o carregamento da dupla camada indicando a presença de rutênio na superfície dos eletrocatalisadores [153]. Também não é observado uma boa definição na região de adsorção e dessorção de hidrogênio. Para o eletrocatalisador PdRu/C (90:10) é observado em sua varredura catódica um pico aproximadamente em $-0,35 \mathrm{~V}$ deslocado para potenciais mais negativos em comparação com o $\mathrm{Pd} / \mathrm{C}$, este efeito é associado a contribuição pseudo-capacitiva do $\mathrm{Ru}$ ao se fundir com o processo de redução de PdO [153; 173]. Para os demais eletrocatalisadores binários o mesmo efeito não é observado devido a maior concentração de rutênio, sendo observado apenas o efeito capacitivo.

Com o acréscimo de rutênio na composição do catalisador é possível notar a atenuação dos picos de adsorção e dessorção de hidrogênio assim como o aumento da capacitância da dupla camada elétrica característicos dos óxidos de rutênio.

\subsection{Desempenho Eletrocatalítico para a Oxidação Eletroquímica do Etanol}

A figura 13 apresenta os voltamogramas cíclicos obtidos a temperatura ambiente dos eletrocatalisadores $\mathrm{Ru} / \mathrm{C}, \mathrm{Pd} / \mathrm{C}$ e $\mathrm{PdRu} / \mathrm{C}(50: 50 ; 70: 30$ e 90:10) em solução de $\mathrm{KOH}$ 1,0 M na presença de 1,0 M EtOH com velocidade de varredura de $10 \mathrm{mV} \mathrm{s}^{-1}$. Todas as correntes foram normalizadas por massa de Pd (mA por mg de metal nobre).

É observado na figura 13 que o eletrocatalisador Ru/C é inativo para oxidação do etanol em meio alcalino em toda faixa de potencial estudado. O mesmo perfil do eletrocatalisador Ru/C foi observado por Ma e colaboradores [148]. Em relação aos eletrocatalisadores $\mathrm{PdRu} / \mathrm{C}$ (50:50 e 70:30), também foi observado uma baixa atividade para a oxidação do etanol em comparação ao $\mathrm{Pd} / \mathrm{C}$, indicando que a superfície ativa do Pd é envenenada por intermediários adsorvidos [148]. Esse efeito pode estar relacionado com a dificuldade do Ru na reação de oxidação do acetaldeído e acetato quando utilizado em maiores proporções [153], esses subprodutos são 
produzidos devido à dificuldade em quebrar a ligação C-C na oxidação do etanol. Outro fato importante a ser mencionado é atribuído as quantidades excessivas de $\mathrm{Ru}$ no eletrocatalisador de $\mathrm{PdRu} / \mathrm{C}$, o que leva a inibição da oxidação do etanol sobre o eletrocatalisador [40], podendo estar associado a recoberta dos sítios ativos do paládio por óxidos de rutênio.

FIGURA 13: Voltamogramas lineares obtidos a temperatura ambiente dos eletrocatalisadores $\mathrm{Ru} / \mathrm{C}, \mathrm{Pd} / \mathrm{C}$ e PdRu/C (50:50; 70:30 e 90:10) em solução de $\mathrm{KOH} \mathrm{1,0} \mathrm{M} \mathrm{na} \mathrm{presença} \mathrm{de}$ $1,0 \mathrm{M} \mathrm{EtOH}$ com uma taxa de varredura de $10 \mathrm{mV} . \mathrm{s}^{-1}$.

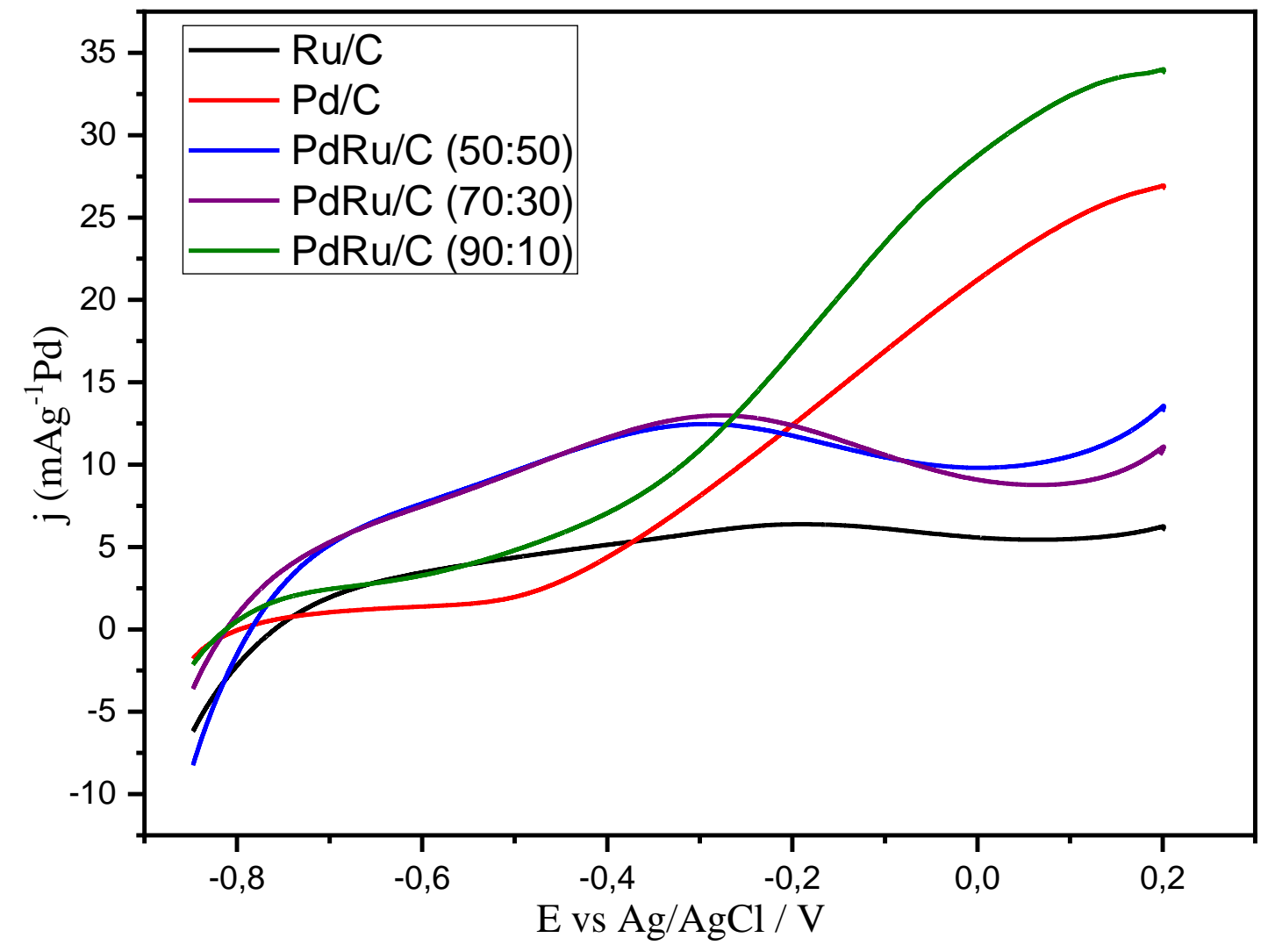

Fonte: Próprio autor

Em relação ao eletrocatalisador $\mathrm{PdRu} / \mathrm{C}$ (90:10), foi observado um pico de corrente superior em comparação ao eletrocatalisador $\mathrm{Pd} / \mathrm{C}$ bem como um início de oxidação do etanol deslocado para valores de potenciais mais baixos. Foi relatado por Cárrion-Satorre e colaboradores [40] que pequenas quantidades de rutênio introduzido ao eletrocatalisador altera o potencial de início de oxidação para potenciais mais baixos. Monyoncho e colaboradores [159] também observaram que a adição de 
$1 \%$ de $\mathrm{Ru}$ reduz o potencial de início de oxidação e aumenta significativamente a densidade de corrente. Um deslocamento na oxidação do etanol para potenciais mais baixos indica uma oxidação do combustível mais fácil nas mesmas condições [149]. Como foi observado nos resultados complementares de XPS, a superfície do rutênio se apresentou em estado metálico bem como na forma de óxidos, podendo contribuir com o mecanismo bifuncional, em que o rutênio ativa a água em potenciais inferiores em relação ao paládio, e a água ativada contribui com a oxidação dos intermediários adsorvidos no eletrocatalisador, liberando os sítios ativos do Pd [176]. Também é importante ressaltar que $\mathrm{RuO}$ facilita a formação de espécies $\mathrm{Ru}-\mathrm{OH}$ na superfície do catalisador favorecendo a oxidação de CO também através do mecanismo bifuncional [152], [177], sendo representado pelas equações 7 e 8 [152].

$\mathrm{Ru}+\mathrm{OH}^{-} \rightarrow \mathrm{Ru}-\mathrm{OH}+\mathrm{e}^{-}$

$\mathrm{Ru}-\mathrm{OH}+\mathrm{Pd}(\mathrm{CO}) \rightarrow \mathrm{Ru}+\mathrm{Pd}+\mathrm{CO}_{2}+\mathrm{H}^{+}+\mathrm{e}^{-}$

Assim, a oxidação do etanol no eletrocatalisador PdRu/C (90:10) pode ser apresentada nas equações 9, 10, 11 e 12 [173].

$\mathrm{PdRu}+\mathrm{CH}_{3} \mathrm{CH}_{2} \mathrm{OH}+3 \mathrm{OH}^{-} \rightarrow \mathrm{PdRu}-\mathrm{CH}_{3} \mathrm{CO}_{\mathrm{ad}}+3 \mathrm{H}_{2} \mathrm{O}+3 \mathrm{e}^{-}$

$\mathrm{PdRu}+\mathrm{OH}^{-} \rightarrow \mathrm{PdRu}-\mathrm{OH}_{\mathrm{ad}}+3 \mathrm{e}^{-}$

$\mathrm{PdRu}-\mathrm{CH}_{3} \mathrm{CO}_{\mathrm{ad}}+\mathrm{PdRu}-\mathrm{OH}_{\mathrm{ad}} \rightarrow 2 \mathrm{PdRu}+\mathrm{CH}_{3} \mathrm{COOH}$

$\mathrm{CH}_{3} \mathrm{COOH}+\mathrm{OH}^{-} \rightarrow \mathrm{CH}_{3} \mathrm{COO}^{-}+\mathrm{H}_{2} \mathrm{O}$

Pela equação 9, o etanol é adsorvido nos sítios ativos do catalisador formando etoxi, posteriormente, equação 10, o $\mathrm{Ru}$ adsorve os radicais $\mathrm{OH}$ em menores potenciais fornecendo $\mathrm{OH}$ adsorvido, pela equação 11 e 12, as espécies adsorvidas 
nos sítios do eletrocatalisador $\mathrm{PdRu} / \mathrm{C}(90: 10)$ transformam-se formando acetato [173].

Todos os eletrocatalisadores em estudo também foram caracterizados pela análise de cronoamperometria, a fim de observar sua estabilidade catalítica na oxidação do etanol. Para realização das mediadas manteve-se as mesmas condições experimentais realizadas nas voltametrias cíclicas com a presença de etanol. Foi determinado um período de 30 minutos a fim de observar a estabilidade do eletrocatalisador em função da corrente no período determinado.

A figura 14 exibe as curvas de cronoamperometria para os eletrocatalisadores $\mathrm{Ru} / \mathrm{C}, \mathrm{Pd} / \mathrm{C}$ e PdRu/C (50:50; 70:30 e 90:10) em temperatura ambiente, com um potencial aplicado de $-0,35 \mathrm{~V}$ no período de 1800 segundos.

FIGURA 14: Curvas de cronoamperometria obtidos a temperatura ambiente dos eletrocatalisadores $\mathrm{Ru} / \mathrm{C}, \mathrm{Pd} / \mathrm{C}$ e PdRu/C (50:50; 70:30 e 90:10) em solução de $\mathrm{KOH} 1,0 \mathrm{M}$ na presença de 1,0 M EtOH. Potencial aplicado de $-0,35 \mathrm{~V}$ durante 1800 segundos.

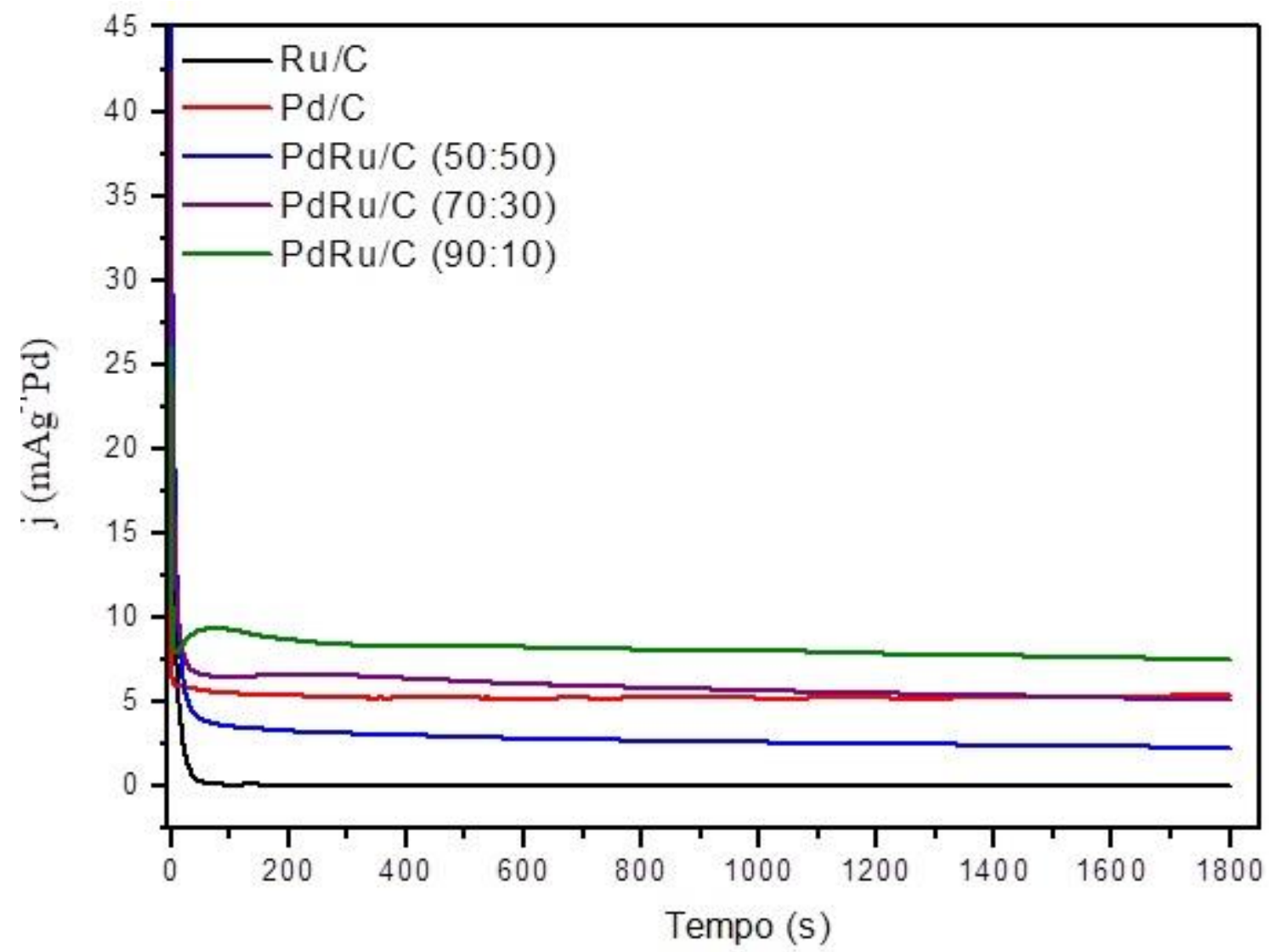

Fonte: Próprio autor 
O eletrocatalisador PdRu/C (90:10) exibe maiores valores de corrente para oxidação do etanol sendo superior aos demais eletrocatalisadores, complementando os resultados obtidos por voltametria cíclica, em que demonstrou maior atividade catalítica atribuído ao mecanismo bifuncional. O pico evidente nos primeiros 200 segundos pode ser associado a adsorção dissociativa simultânea de etanol ou as correntes pseudo-capacitivas proveniente do rutênio [148].

O eletrocatalisador PdRu/C (70:30) apresenta valores de corrente superior ao $\mathrm{Pd} / \mathrm{C}$, após 1500 segundos, é observado uma atenuação em sua curva notando um decréscimo mínimo de corrente até seu término de operação, enquanto que o eletrocatalisador $\mathrm{Pd} / \mathrm{C}$ se mantém constante em sua atividade, por fim, estas se invertem em aproximadamente em 1500 segundos. De acordo com a literatura [148; 178-179], este fato pode ser atribuído ao etanol oxidado em PdRu/C, ocorrendo um acúmulo de espécies fortemente adsorvidas em sua superfície, acarretando ao decaimento gradual de corrente.

A queda acentuada do eletrocatalisador PdRu/C (50:50) e os menores valores de corrente pode ser atribuída a rápida formação de espécies $\mathrm{OH}_{\mathrm{ad}}$ e formação de óxidos de rutênio na superfície do eletrocatalisador, bloqueando os sítios ativos do paládio para adsorção e oxidação do etanol [180]. O eletrocatalisador Ru/C não demonstra nenhuma atividade e/ou estabilidade catalítica para oxidação do etanol, resultados semelhantes são observados por Ma e colaboradores [148].

\subsection{Espectroscopia no infravermelho com reflectância total atenuada (ATR-FTIR)}

Na figura 15 são apresentados os espectros no infravermelho in-situ obtidos durante a oxidação do etanol sobre materiais baseados em PdRu em diferentes potenciais, nesses espectros foi possível observar uma banda próxima a $1710 \mathrm{~cm}^{-1}$ correspondente a ligação $\mathrm{C}=\mathrm{O}$ [181], acoplada a banda de $1750 \mathrm{~cm}^{-1}$, que assim como a banda de $1640 \mathrm{~cm}^{-1}$ correspondem a deformação da água interfacial [182]. Que no caso do material Ru/C estão sobrepostas. Para todos os materiais foram encontradas bandas referentes ao acetato de potássio, em $1410 \mathrm{~cm}^{-1}$ [183]. No entanto as bandas relativas a um produto de oxidação total do álcool em meio alcalino que é o carbonato 
de potássio em $1373 \mathrm{~cm}^{-1}$ [183] foi observada apenas em materiais mais ricos em $\mathrm{Pd}$ (Pd/C, PdRu/C 90:10, PdRu 70:30), e apenas para a composição PdRu/C 70:30 a banda em $2343 \mathrm{~cm}^{-1}$ [145] correspondente ao $\mathrm{CO}_{2}$ foi observado. Indicando que a quebra da ligação C-C exige a presença de um sítio de adsorção como o Pd.

FIGURA 15: Espectros no infravermelho obtidos durante a reação de oxidação de etanol (1 mol.L-1) em diferentes potenciais, com eletrólito de $\mathrm{KOH} 1 \mathrm{~mol} . \mathrm{L}^{-1}$ sobre eletrocatalisadores baseados em PdRu/C

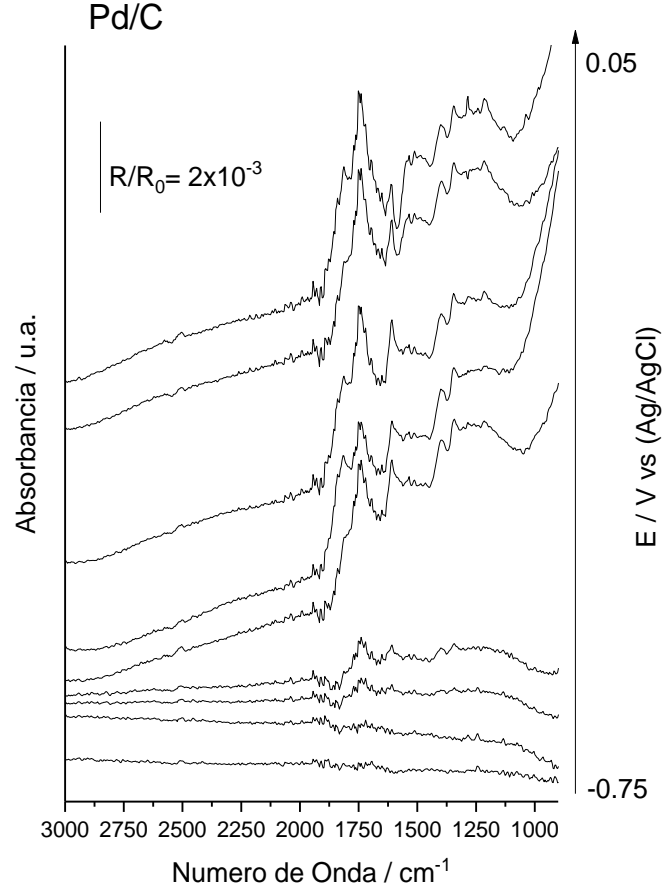

$\mathrm{PdRu} / \mathrm{C}(70: 30)$

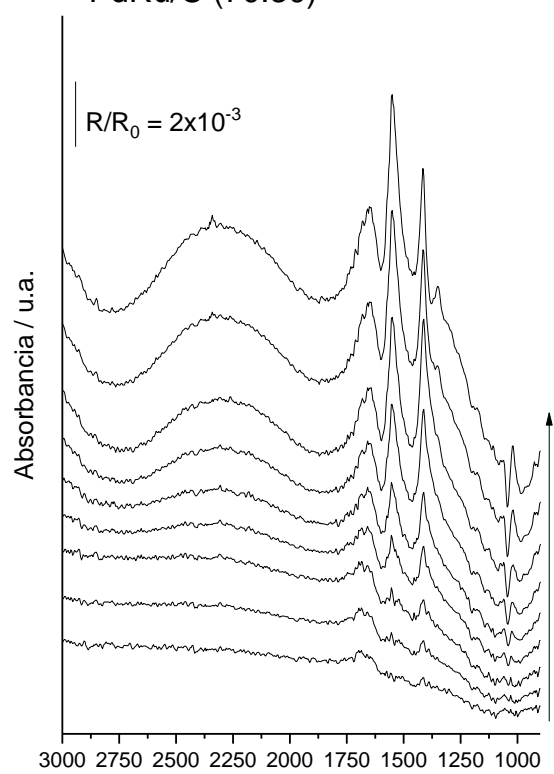

Numero de Onda / $\mathrm{cm}^{-1}$

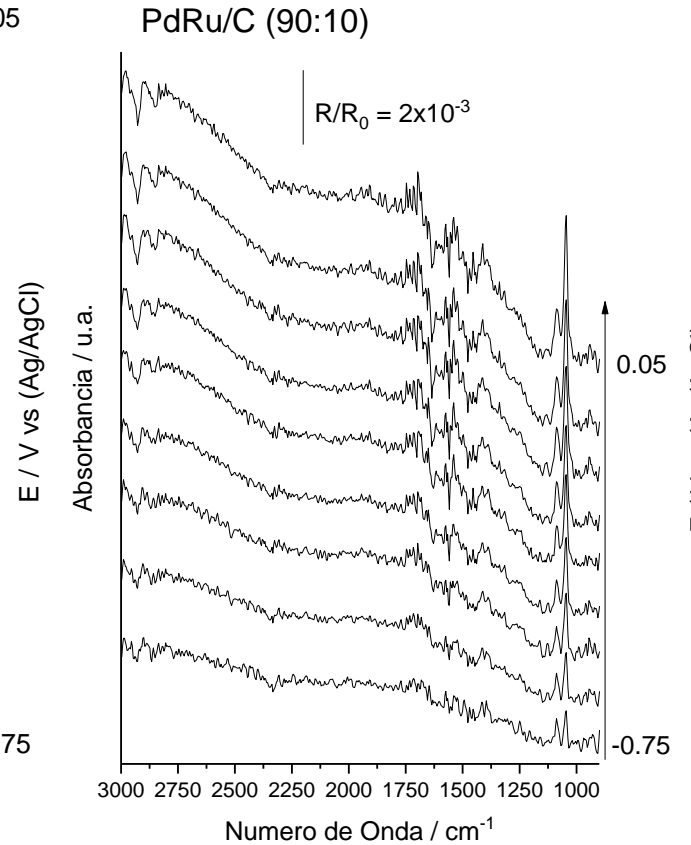

$\mathrm{PdRu} / \mathrm{C}(50: 50)$

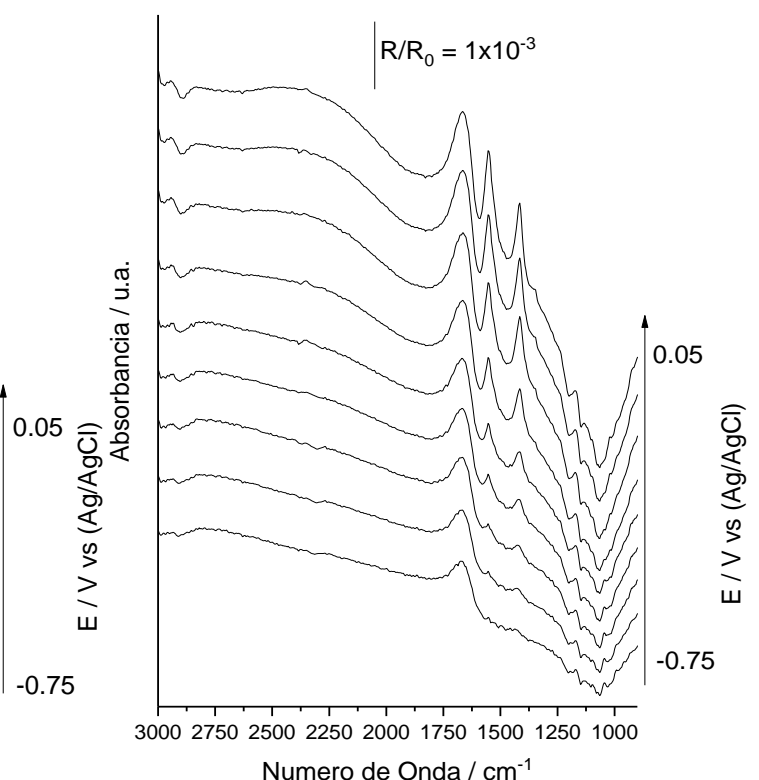

Fonte: Próprio autor 
FIGURA 15: Espectros no infravermelho obtidos durante a reação de oxidação de etanol (1 mol. $\mathrm{L}^{-1}$ ) em diferentes potenciais, com eletrólito de $\mathrm{KOH} 1 \mathrm{~mol} . \mathrm{L}^{-1}$ sobre eletrocatalisadores baseados em $\mathrm{PdRu} / \mathrm{C}$

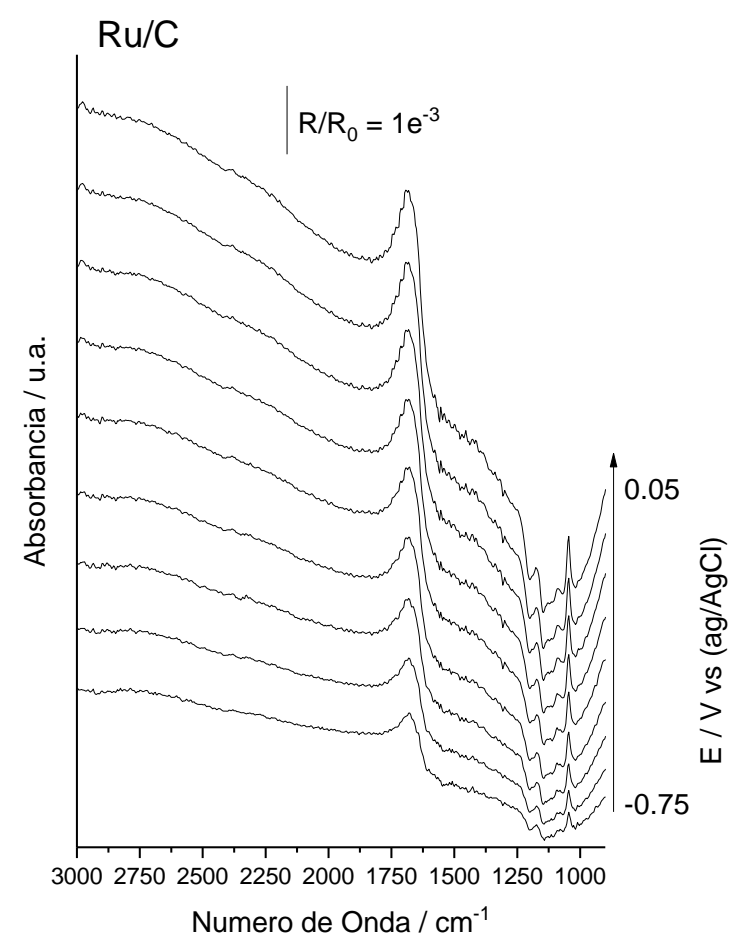

Fonte: Próprio autor

Para melhor entender a evolução da produção de espécies oriundas da oxidação do etanol, as bandas relativas a $\mathrm{CO}_{2}$, carbonato e acetato foram deconvoluídas em funções Lorentzianas e o resultado das áreas obtidas pela deconvolução graficadas na figura 16. 
FIGURA 16: Produção de espécies oriundas da oxidação do etanol, as bandas relativas a $\mathrm{CO}_{2}$, carbonato e acetato.

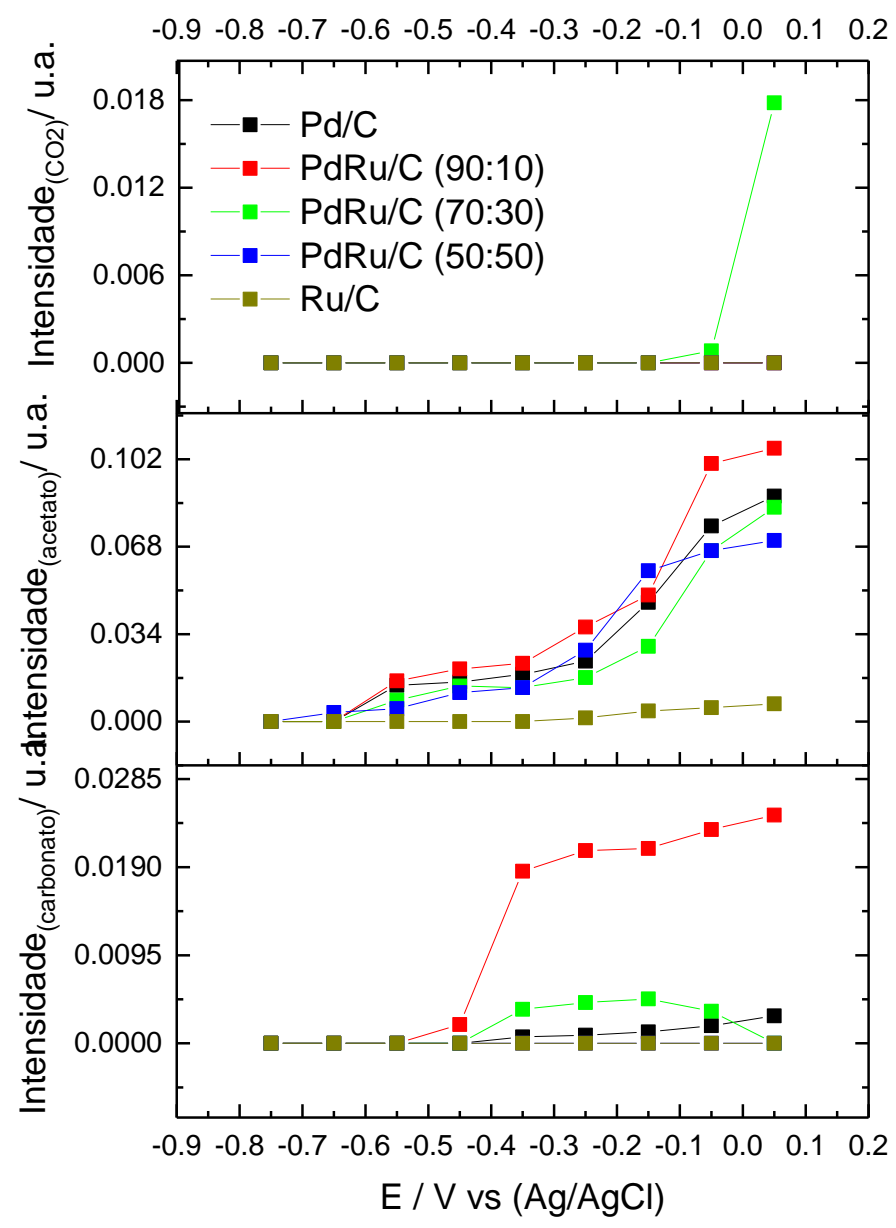

Fonte: Próprio autor

O potencial de produção de acetato é ligeiramente mais negativo do que o potencial de início de oxidação observado nas voltametrias, provavelmente pelas espécies de rutênio presentes ativarem água em potenciais mais negativos do que o $\mathrm{Pd}$, como desejado para que ocorra o mecanismo bifuncional, e essas espécies estejam fazendo parte do etanol por meio de não se aproveitar os elétrons. No entanto se observa um incremento na geração de acetato acompanhando o perfil voltametrico, indicando que a partir do potencial de início de oxidação de etanol a corrente proveniente está atrelada a produção de acetato. Exceção observada para o material $\mathrm{Ru} / \mathrm{C}$ que produz acetato mesmo sem possuir sítios de adsorção e apresentar corrente próximo de $0 \mu \mathrm{A}$, e confirmando a produção de acetato pela ativação de água. 
O carbonato sendo o produto de oxidação total do álcool, tem perfil crescente para o material mais ativo na cronoamperometria (PdRu/C 90:10), para o segundo material mais ativo em experimento potenciostático (PdRu/C 70:30) o potencial de formação é deslocado para $100 \mathrm{mV}$ menos negativo $(-0.45 \mathrm{~V})$ e com intensidade muito menor, mas crescente até próximo a $0 \mathrm{~V}$, quando a banda começa a apresentar perfil de consumo, coincidindo com o aparecimento da banda de $\mathrm{CO}_{2}$. Para $\mathrm{Pd} / \mathrm{C}$ também é possível observar essa banda, mas em valores muito mais discretos que os materiais contendo $\mathrm{Ru}$, indicando que os óxidos de rutênio presente têm papel importante na quebra da ligação C-C.

\subsection{Experimento em Célula a Combustível de etanol direto}

A figura 17 apresenta as curvas de polarização obtidas em uma célula a combustível unitária de etanol direto (DEFC) utilizando eletrocatalisadores $\mathrm{Ru} / \mathrm{C}, \mathrm{Pd} / \mathrm{C}$ e $\mathrm{PdRu} / \mathrm{C}(50: 50 ; 70: 30$ e 90:10) no anodo a uma temperatura de $80 \stackrel{\circ}{ } \mathrm{C}$.

É observado que os eletrocatalisadores binários PdRu/C (50:50 e 90:10) apresentaram um potencial de circuito aberto superior ao $\mathrm{Pd} / \mathrm{C}$, porém o eletrocatalisador $\mathrm{PdRu} / \mathrm{C}(70: 30)$ exibiu um potencial de circuito aberto próximo ao $\mathrm{Pd} / \mathrm{C}$. Em relação ao eletrocatalisador $\mathrm{Ru} / \mathrm{C}$, é observado um potencial de circuito aberto de aproximadamente $0,8 \mathrm{~V}$, exibindo atividade catalítica nas condições experimentais em uma DEFC. 
Figura 17: Curvas de polarização de uma DEFC utilizando eletrocatalisadores $\mathrm{Ru} / \mathrm{C}, \mathrm{Pd} / \mathrm{C}$ e $\mathrm{PdRu} / \mathrm{C}$ (50:50; 70:30 e 90:10) no ânodo, com uma carga metálica de $1 \mathrm{mg}$ $\mathrm{Pd} \mathrm{cm}{ }^{-2}$, em temperatura de operação de $80 \stackrel{\circ}{\circ}$, com fluxo contínuo de etanol de $2 \mathrm{M} \mathrm{KOH}+$ $\mathrm{EtOH}$.

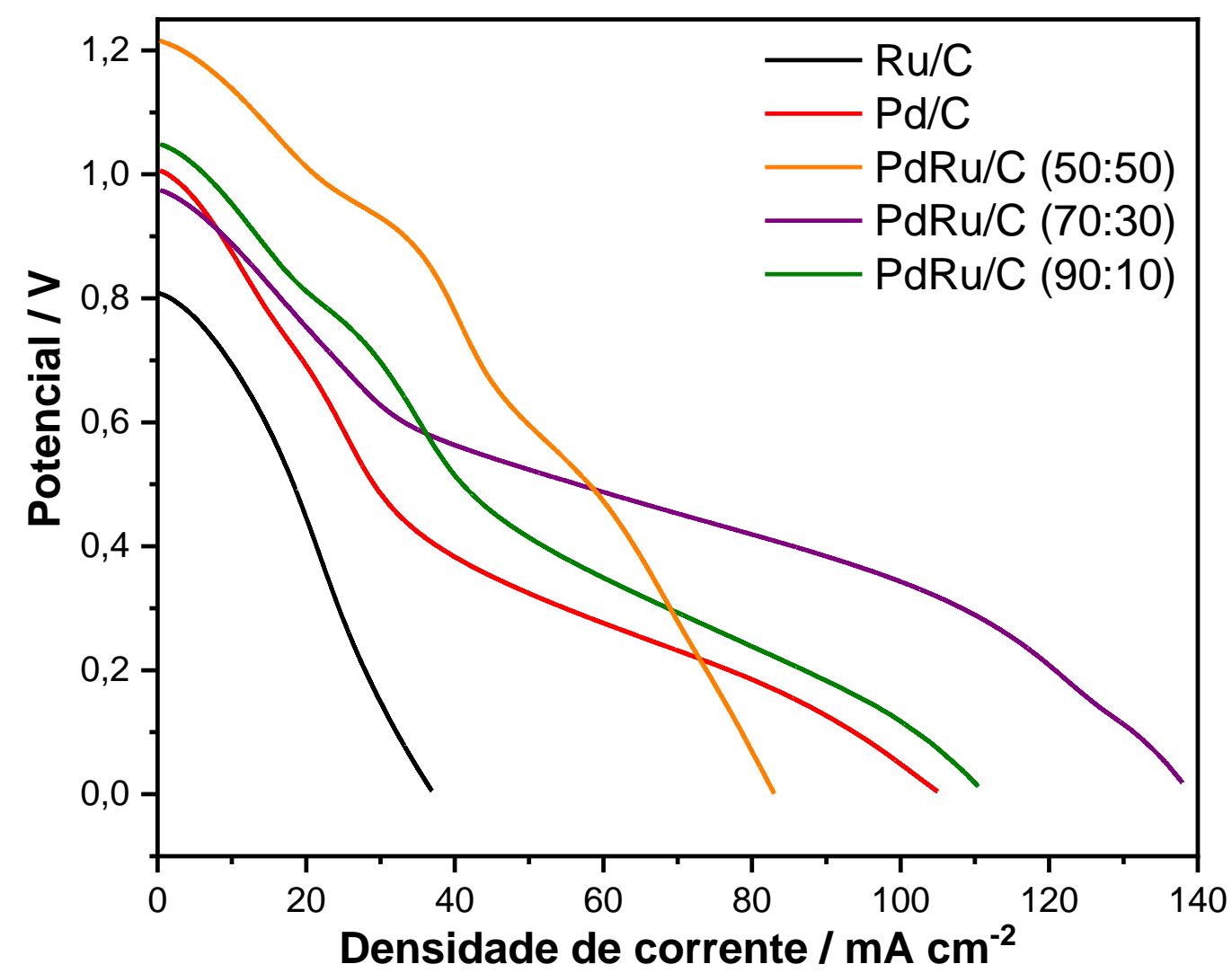

Fonte: Próprio autor

A figura 18 apresenta as curvas de densidade de potência dos eletrocatalisadores $\mathrm{Ru} / \mathrm{C}, \mathrm{Pd} / \mathrm{C}$ e PdRu/C (50:50; 70:30 e 90:10). É observado que o eletrocatalisador $\mathrm{PdRu} / \mathrm{C}(70: 30)$ apresentou maior densidade de potência em comparação aos demais eletrocatalisadores preparados, seguido do eletrocatalisador $\mathrm{PdRu} / \mathrm{C}$ (50:50) e (90:10). Esses resultados revelam a influência do rutênio e da temperatura no processo de oxidação do etanol em uma DEFC [40; 148; 153]. 
FIGURA 18: Curvas de densidade de potência de uma DEFC utilizando eletrocatalisadores $\mathrm{Ru} / \mathrm{C}, \mathrm{Pd} / \mathrm{C}$ e $\mathrm{PdRu} / \mathrm{C}(50: 50 ; 70: 30$ e 90:10) no ânodo, com uma carga metálica de $1 \mathrm{mg} \mathrm{Pd} \mathrm{cm}{ }^{-2}$, em temperatura de operação de $80 \stackrel{\circ}{ } \mathrm{C}$, com fluxo contínuo de etanol de $2 \mathrm{M} \mathrm{KOH}+\mathrm{EtOH}$.

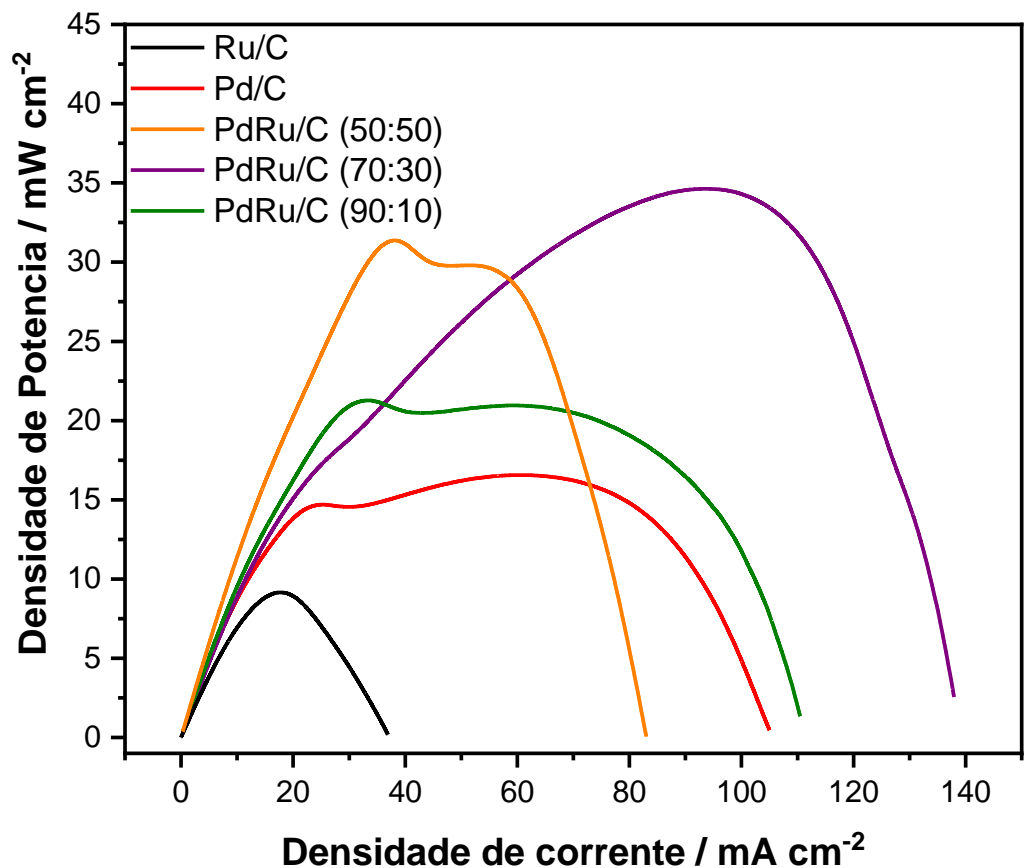

Fonte: Próprio autor

A partir dos resultados apresentados na figura 18, foi feita a elaboração da tabela 4, exibindo os valores da densidade de potência máxima dos eletrocatalisadores em estudo.

TABELA 4: Experimentos em DEFC utilizando eletrocatalisadores $\mathrm{Ru} / \mathrm{C}, \mathrm{Pd} / \mathrm{C}$ e $\mathrm{PdRu} / \mathrm{C}$ (50:50; 70:30 e 90:10), destaque para o potencial de circuito aberto em $\mathrm{V}$ e densidade de potência em mW.

\begin{tabular}{|c|c|c|}
\hline Eletrocalisador & $\begin{array}{c}\text { Potencial de circuito } \\
\text { aberto em V }\end{array}$ & $\begin{array}{c}\text { Densidade de potência } \\
\text { em } \mathbf{~ m W ~ c m - 2}\end{array}$ \\
\hline $\mathrm{Ru} / \mathrm{C}$ & 0,80 & 9,15 \\
\hline $\mathrm{Pd} / \mathrm{C}$ & 1,00 & 16,51 \\
\hline $\mathrm{PdRu} / \mathrm{C}(50: 50)$ & 1,21 & 31,36 \\
\hline $\mathrm{PdRu} / \mathrm{C}(70: 30)$ & 0,97 & 34,36 \\
\hline $\mathrm{PdRu} / \mathrm{C}(90: 10)$ & 1,01 & 21,19 \\
\hline
\end{tabular}

Fonte: Próprio autor 
A partir da tabela 4, é observado que o eletrocatalisador $\mathrm{PdRu} / \mathrm{C}$ (70:30) apresentou maior eficiência catalítica para oxidação do etanol em uma DEFC, exibindo uma densidade de potência de $34,62 \mathrm{~mW} \mathrm{~cm}^{-2}$, seguido por $\mathrm{PdRu} / \mathrm{C}$ (50:50) e PdRu/C (90:10) que apresentou uma densidade de potência de $31,36 \mathrm{~mW} . \mathrm{cm}^{-2}$ e 21,19 $\mathrm{mW} \mathrm{cm}^{-2}$ respectivamente. Todos os eletrocatalisadores binários exibiram uma atividade catalítica superior ao eletrocatalisador $\mathrm{Pd} / \mathrm{C}$ para oxidação do etanol em uma DEFC, resultados semelhantes foram observados por Ma e colaboradores [184] fazendo a mesma variação na composição do rutênio.

Em conformidade aos resultados obtidos pela caracterização eletroquímica é observado uma divergência em comparação aos resultados obtidos pelos ensaios em célula a combustível. Esse fato pode estar relacionado com a utilização da temperatura, pois os testes em célula foram realizados a $80^{\circ} \mathrm{C}$ enquanto que os experimentos eletroquímicos foram realizados a temperatura ambiente. Outro aspecto a ser mencionado que também pode ter influenciado nos resultados pode ser associado a confecção do MEA, em que influencia nos efeitos difusionais e de transporte de massa.

\section{CARACTERIZAÇÃO ELETROQUÍMICA GLICEROL}

\subsection{Voltametria cíclica}

A figura 19 apresenta os voltamogramas cíclicos dos eletrocatalisadores $\mathrm{Ru} / \mathrm{C}$, $\mathrm{Pd} / \mathrm{C}$ e PdRu/C (50:50; 70:30 e 90:10) em solução de $\mathrm{KOH} \mathrm{1,0} \mathrm{M} \mathrm{na} \mathrm{ausência} \mathrm{de}$ glicerol. A taxa de varredura é de $10 \mathrm{mV} \mathrm{s}^{-1}$ na faixa de potencial de $-0,85 \mathrm{~V}$ a $0,2 \mathrm{~V}$. $\mathrm{O}$ eletrocatalisador $\mathrm{Pd} / \mathrm{C}$ exibe um pico em aproximadamente $-0,5 \mathrm{~V}$ atribuído ao processo de formação de $\mathrm{PdO}$ [147; 173-174], enquanto que na varredura catódica é observado um pico em aproximadamente $-0,35 \mathrm{~V}$ atribuído à redução de óxidos de $\mathrm{Pd}$ [147; 153; 175]. O eletrocatalisador Ru/C não apresenta uma definição na região de adsorção e dessorção de hidrogênio, sendo observado apenas o efeito capacitivo. 
FIGURA 19: Voltamogramas cíclicos dos eletrocatalisadores $\mathrm{Ru} / \mathrm{C}, \mathrm{Pd} / \mathrm{C}$ e $\mathrm{PdRu} / \mathrm{C}$ (50:50; 70:30 e 90:10) em solução de $\mathrm{KOH}$ 1,0 M na ausência de glicerol com uma taxa de varredura de $10 \mathrm{mV} . \mathrm{s}^{-1}$.

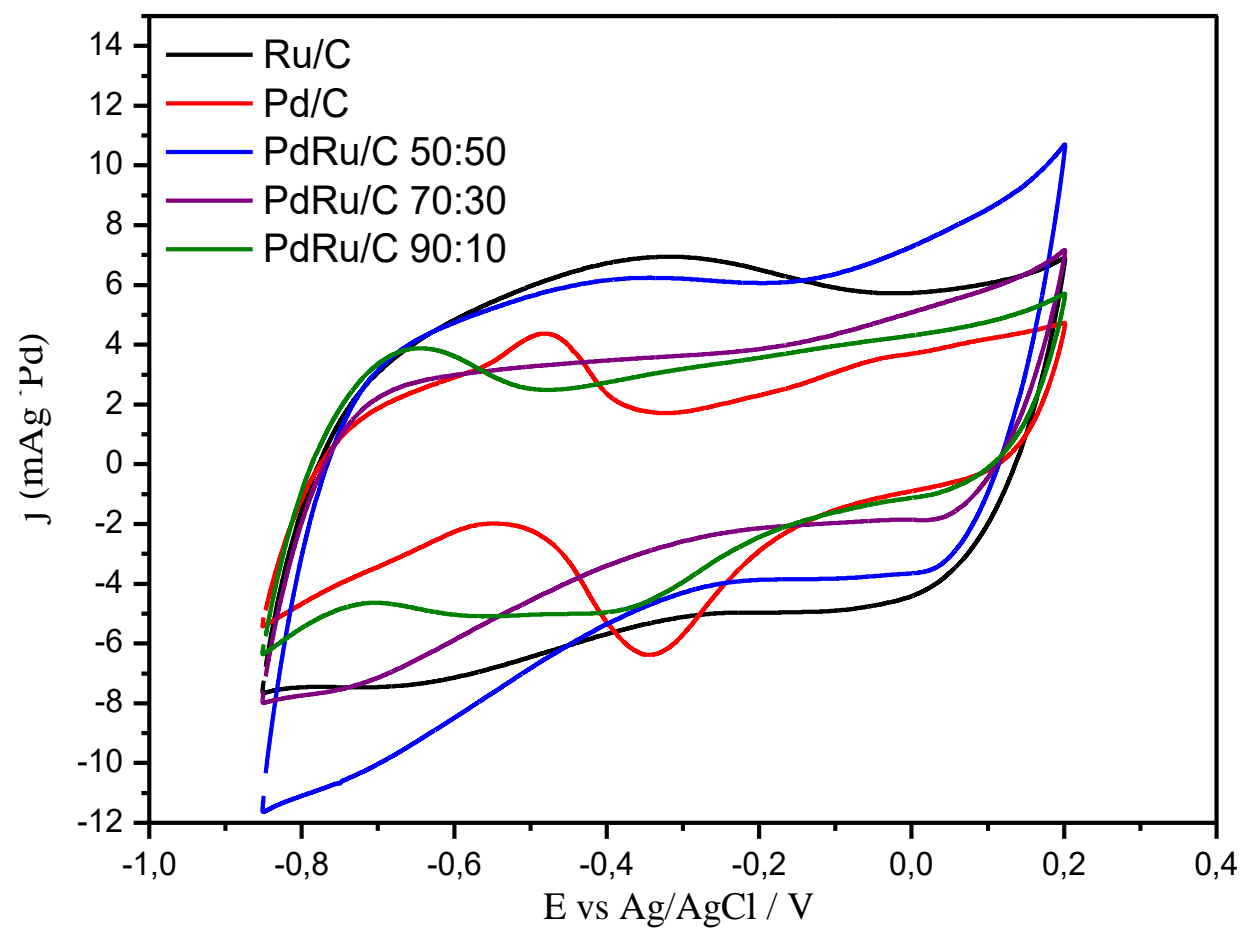

Fonte: Próprio autor

É observado nos voltamogramas cíclicos que os eletrocatalisadores binários apresentaram perfis diferentes em comparação ao Pd/C como já mencionado seção 5.1 na ausência do combustível. É percebido que com o acréscimo de rutênio aumenta a densidade de corrente entre os potencias de $-0,5 \mathrm{~V}$ a $-0,1 \mathrm{~V}$, sendo um efeito associado a contribuição pseudo-capacitiva do rutênio [153] já mencionado na seção 5.1, bem como não é observado uma boa definição na região de adsorção e dessorção de hidrogênio em comparação ao eletrocatalisador $\mathrm{Pd} / \mathrm{C}$.

O eletrocatalisador PdRu/C (90:10) apresentou em sua varredura catódica um pico em aproximadamente $-0,4 \mathrm{~V}$, relacionado a um efeito promovido pelo rutênio ao se fundir com o processo de redução de PdO [153], o mesmo efeito foi observado na seção 5.1. Em comparação aos resultados obtidos nas voltametrias apresentadas seção 5.1, na ausência do combustível, também é observado uma atenuação dos picos na região de adsorção e dessorção de hidrogênio assim como o aumento da capacitância da dupla camada elétrica característicos dos óxidos de rutênio. 


\subsection{Desempenho eletrocatalítico para a oxidação eletroquímica do glicerol}

A figura 20 apresenta as curvas voltamétricas de oxidação eletroquímica de glicerol com os eletrocatalisadores Ru/C, Pd/C e PdRu/C (50:50; 70:30 e 90:10) em solução de $\mathrm{KOH}$ 1,0 M na presença de 1,0 M glicerol com uma taxa de varredura de $10 \mathrm{mV} . \mathrm{s}^{-1}$ em temperatura ambiente. Na presente figura as densidades de correntes foram normalizadas por massa de Pd (mA por mg de metal nobre).

É observado que o eletrocatalisador Ru/C é inativo para oxidação eletroquímica do glicerol. Sua inatividade para oxidação do glicerol também foi observada por Dash e colaboradores [42]. Na seção 5.1, também é observado a inatividade do eletrocatalisador Ru/C para oxidação do etanol. Em relação aos eletrocatalisadores PdRu/C (50:50 e 70:30), também é observado uma baixa atividade para oxidação do glicerol em comparação ao $\mathrm{Pd} / \mathrm{C}$, resultados semelhantes foram observados na seção 5.1 para eletro-oxidação do etanol. Como já mencionado, este efeito pode estar relacionado a superfície do catalisador estar recoberta por óxidos inibindo a oxidação eletroquímica do glicerol [42]. Benipal e colaboradores [89] prepararam eletrocatalisadores de PdAg/CNT e observaram que a adição do teor de $\mathrm{Ag}$ a densidade de corrente baixava para a oxidação do glicerol, associando este efeito ao bloqueio dos sítios ativos do Pd com o acréscimo de Ag.

Os resultados de densidade de corrente de pico e potencial de início de oxidação de glicerol obtidos para os eletrocatalisadores Pd/C e PdRu/C (90:10) são apresentados na tabela 5 . 
FIGURA 20: Voltamogramas lineares obtidos a temperatura ambiente dos eletrocatalisadores $\mathrm{Ru} / \mathrm{C}, \mathrm{Pd} / \mathrm{C}$ e PdRu/C (50:50; 70:30 e 90:10) em solução de $\mathrm{KOH}$ 1,0 M na presença de $1,0 \mathrm{M}$ glicerol com uma taxa de varredura de $10 \mathrm{mV} \cdot \mathrm{s}^{-1}$.

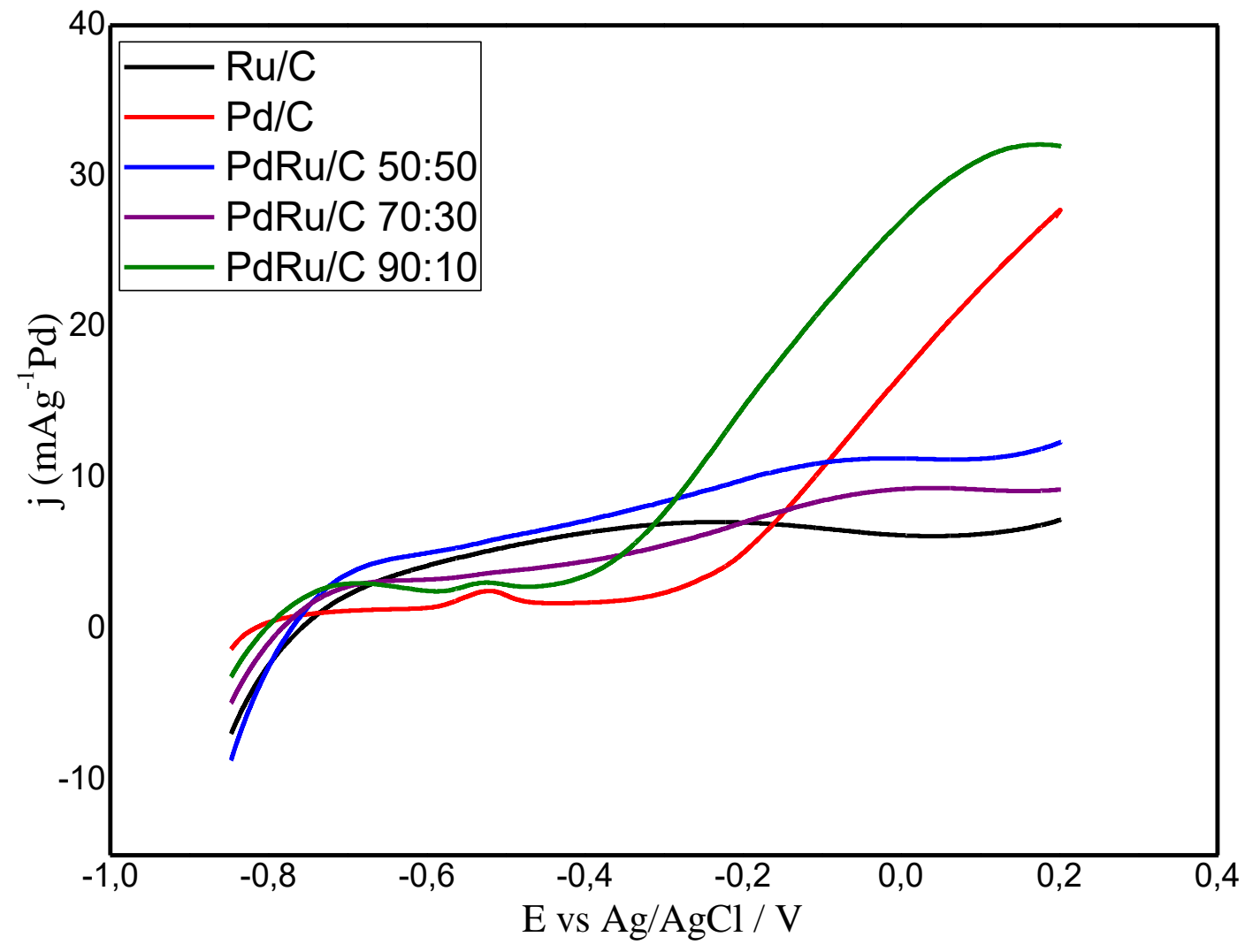

Fonte: Próprio autor

TABELA 5: Potenciais de início de oxidação eletroquímica do glicerol e densidades de corrente de pico para os eletrocatalisadores $\mathrm{Pd} / \mathrm{C}$ e PdRu/C (90:10).

\begin{tabular}{|c|c|c|}
\hline Eletrocalisador & $\begin{array}{c}\text { Potencial de início de oxidação } \\
\text { (V vs Ag/ClAg) }\end{array}$ & $\begin{array}{c}\text { Densidade de corrente de pico } \\
\text { (mA mg }^{-1} \text { Pd) }\end{array}$ \\
\hline $\mathrm{Pd} / \mathrm{C}$ & $-0,21$ & 27,64 \\
\hline $\mathrm{PdRu} / \mathrm{C}(90: 10)$ & $-0,36$ & 32,1 \\
\hline
\end{tabular}

Fonte: Próprio autor

A partir dos resultados apresentados na Figura 20 e da Tabela 5, pode-se observar que o eletrocatalisador $\mathrm{PdRu} / \mathrm{C}$ (90:10) exibe uma densidade de corrente superior ao eletrocatalisador $\mathrm{Pd} / \mathrm{C}$, também é possível notar que o inicio da oxidação 
do glicerol utilizando-se $\mathrm{PdRu} / \mathrm{C}(90: 10)$ é deslocado para potenciais mais baixos quando comparada com $\mathrm{Pd} / \mathrm{C}$. Autores [42; 185] relata que o acréscimo de rutênio em pequenas quantidades melhora a atividade eletrocatalítica de catalisadores a base de Paládio, aumentando significativamente a densidade de corrente na eletrooxidação do glicerol, enquanto que para maiores proporções de $R u$, a densidade diminui.

Esta melhora na atividade eletrocatalítica do eletrocatalisador $\mathrm{PdRu} / \mathrm{C}(90: 10)$ pode estar relacionado ao mecanismo bifuncional ou efeito eletrônico [42; 176; 186]. As nanopartículas de rutênio levam a um aumento da concentração de íons hidroxila na superfície do eletrocatalisador, favorecendo o mecanismo bifuncional, e consequentemente, diminuindo o envenenamento por intermediários adsorvidos [42; 187]. Para maiores informações sobre a adsorção das espécies de $\mathrm{CO}$ e gliceraldeído foi realizado o estudo de FTIR apresentado seção 6.3.

A fim de confirmar os resultados obtidos nos experimentos de voltametria cíclica na presença de glicerol, foram realizadas cronoamperometrias sob as mesmas condições experimentais em que foram realizadas as voltametrias aplicando-se um potencial de $-0,35 \vee$ no período de 1800 segundos, observando a estabilidade catalítica na oxidação do glicerol.

A figura 21 a seguir exibe as curvas de cronoamperometria para os eletrocatalisadores $\mathrm{Ru} / \mathrm{C}, \mathrm{Pd} / \mathrm{C}$ e $\mathrm{PdRu} / \mathrm{C}$ (50:50; 70:30 e 90:10) em temperatura ambiente, com um potencial aplicado de $-0,35 \mathrm{~V}$ no período de 1800 segundos. 
FIGURA 21: Curvas de cronoamperometria obtidos a temperatura ambiente dos eletrocatalisadores $\mathrm{Ru} / \mathrm{C}, \mathrm{Pd} / \mathrm{C}$ e PdRu/C (50:50; 70:30 e 90:10) em solução de $\mathrm{KOH}$ 1,0 M na presença de 1,0 M de glicerol. Potencial aplicado de -0,35 V no período de 1800 segundos.

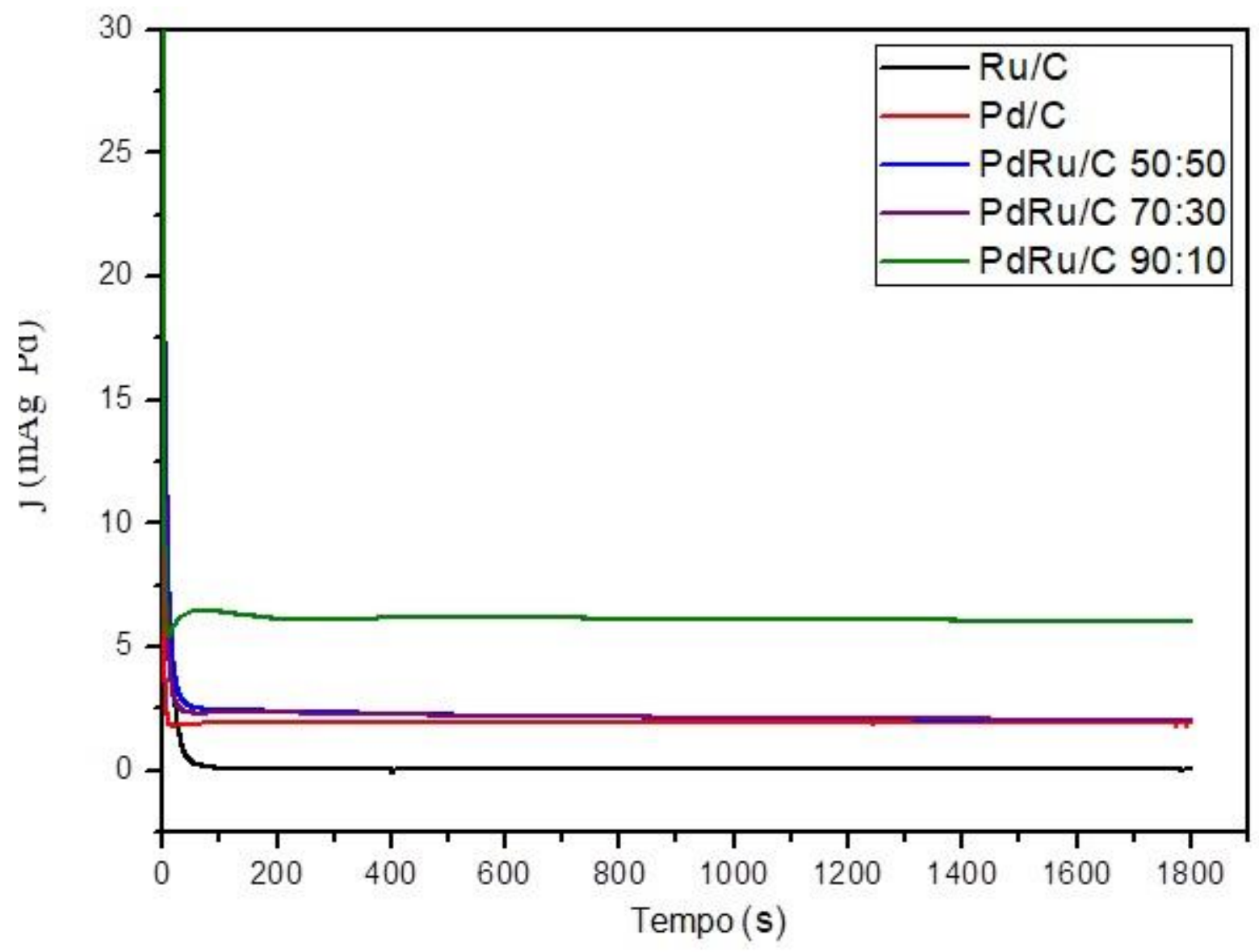

Fonte: Próprio autor

É observado uma queda inicial brusca de corrente nos primeiros segundos de operação para todos os eletrocatalisadores estudados no presente trabalho, seguido de suas respectivas estabilidades catalíticas.

O eletrocatalisador PdRu/C (90:10) apresenta maiores valores de corrente para oxidação do glicerol em comparação aos demais eletrocatalisadores em estudo, também é observado um pico nos primeiros 200 segundos de operação. O mesmo resultado é observado por Dash e colaboradores [42].

Os eletrocatalisadores PdRu/C (50:50 e 70:30) apresentam correntes semelhantes, sendo superior ao Pd/C. Após 1200 segundos, é observado uma atenuação em sua curva notando um decréscimo mínimo de corrente até seu término 
de operação, enquanto que o eletrocatalisador $\mathrm{Pd} / \mathrm{C}$ se mantém constante em sua atividade, por fim, estas se invertem em aproximadamente em 1500 segundos.

Em comparação aos resultados cronoamperometricos obtidos na seção 5.1, o eletrocatalisador PdRu/C (50:50) exibe uma atividade catalítica superior para oxidação eletroquímica do glicerol em relação a oxidação do etanol. Assim como observado na seção 5.1, o eletrocatalisador Ru/C também não demonstra nenhuma atividade catalítica para oxidação eletroquímica de glicerol.

Os valores de densidade de correntes observados para o eletrocatalisador de $\mathrm{PdRu} / \mathrm{C}(90: 10)$ são maiores para a oxidação do etanol em comparação com a oxidação do glicerol, estes resultados indicam a complexidade da reação de oxidação do glicerol em comparação ao do etanol, que talvez essa reação não seja tão interessante para a geração de energia e sim para a produção de produtos com maior valor agregado, onde essa maior contribuição poderia ser comprovada pelos resultados de FTIR.

\subsection{Espectroscopia no infravermelho com reflectância total atenuada (ATR-FTIR)}

Nos espectros de ATR-FTIR in-situ apresentados na figura 22, é possível observar bandas relacionadas ao glicerol em 1004, 1041 e $1094 \mathrm{~cm}^{-1}$ [188-189], que aparecem sendo consumidas para os materiais $\mathrm{Pd} / \mathrm{C}$ e $\mathrm{PdRu} / \mathrm{C}$ (90:10), que também foram os materiais que se apresentaram ativas nas medidas de voltametria cíclica para a oxidação do glicerol. No entanto para os demais materiais o comportamento foi no sentido inverso, indicando que o álcool está sendo atraído pelo campo elétrico do eletrodo. A banda em $\sim 1665 \mathrm{~cm}^{-1}$ [188; 190], relacionada a grupos carbonil e carboxil, produtos da oxidação do glicerol, também é observada somente para os catalisadores $\mathrm{Pd} / \mathrm{C}$ e PdRu/C (90:10). A banda correspondente a $\mathrm{CO}_{2}\left(2343 \mathrm{~cm}^{-1}\right)$ [191] não foi observada para nenhum material estudado. 
FIGURA 22: Espectros no infravermelho obtidos durante a reação de oxidação de etanol ( $\left.1 \mathrm{~mol} . \mathrm{L}^{-1}\right)$ em diferentes potenciais, com eletrólito de $\mathrm{KOH} 1 \mathrm{~mol} . \mathrm{L}^{-1}$ sobre eletrocatalisadores $\mathrm{PdRu} / \mathrm{C}$.
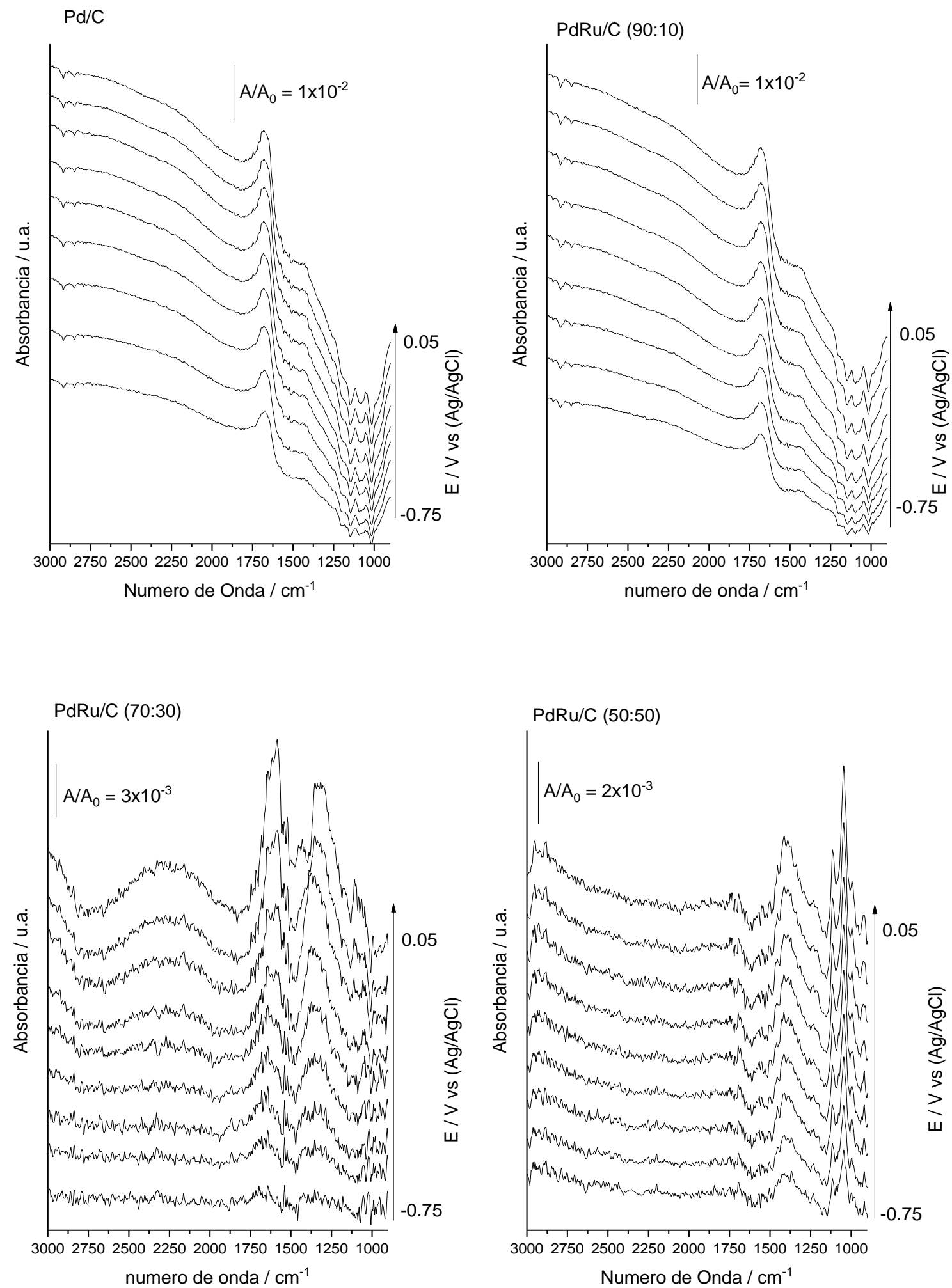

Fonte: Próprio autor 
FIGURA 22: Espectros no infravermelho obtidos durante a reação de oxidação de glicerol (1 mol. $\left.\mathrm{L}^{-1}\right)$ em diferentes potenciais, com eletrólito de $\mathrm{KOH} 1 \mathrm{~mol} . \mathrm{L}^{-1}$ sobre eletrocatalisadores baseados em $\mathrm{PdRu} / \mathrm{C}$

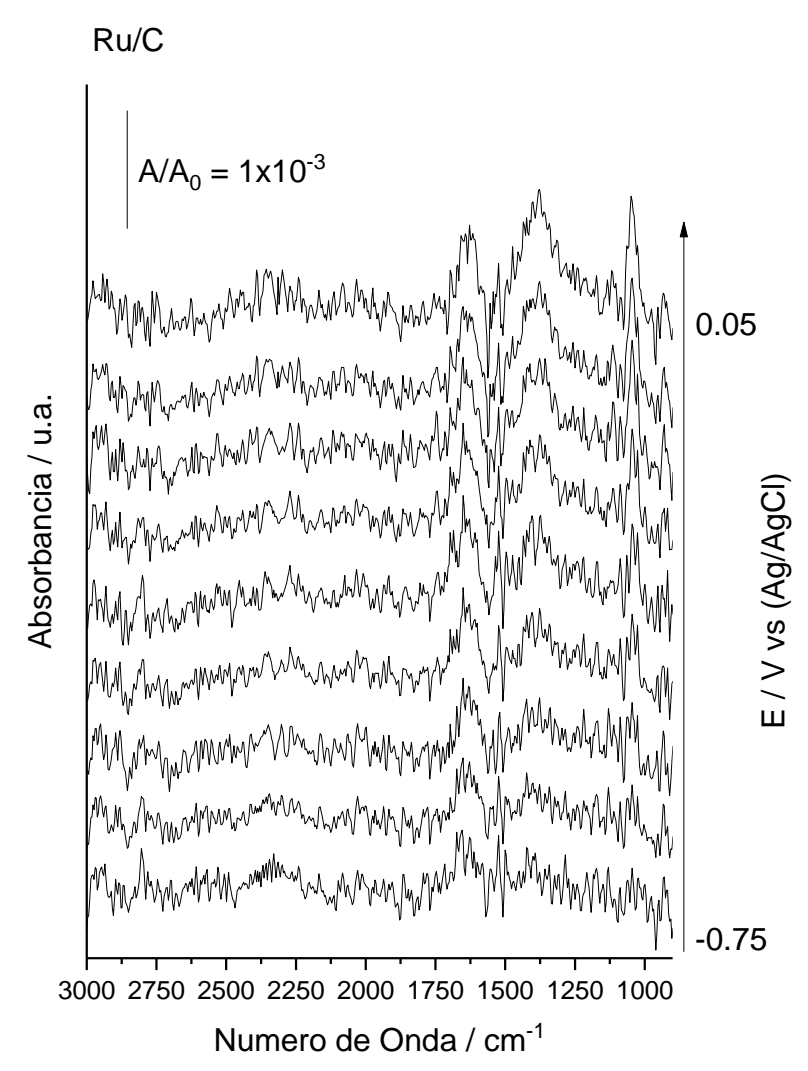

Fonte: Próprio autor

Também são observadas as bandas de produtos de oxidação do glicerol como a $1411 \mathrm{~cm}^{-1}$ correspondente ao carbonato [188], $1377 \mathrm{~cm}^{-1}$ atribuída ao glicerato [190; 192-193], $1355 \mathrm{~cm}^{-1}$ para hidroxipiruvato [188-189], $1339 \mathrm{~cm}^{-1}$ para tartronato [194] e $1225 \mathrm{~cm}^{-1}$ para formiato [195]. Essas bandas apresentam comportamentos distintos, mas de extrema importância para compreender a atividade catalítica, desta forma foram deconvoluídos em funções lorenzianas e apresentadas na figura 23. 
FIGURA 23: Produtos de oxidação do glicerol como a $1411 \mathrm{~cm}^{-1}$ correspondente ao carbonato, $1377 \mathrm{~cm}^{-1}$ atribuída ao glicerato, $1355 \mathrm{~cm}^{-1}$ para hidroxipiruvato, $1339 \mathrm{~cm}^{-1}$ para tartronato e $1225 \mathrm{~cm}^{-1}$ para formiato.

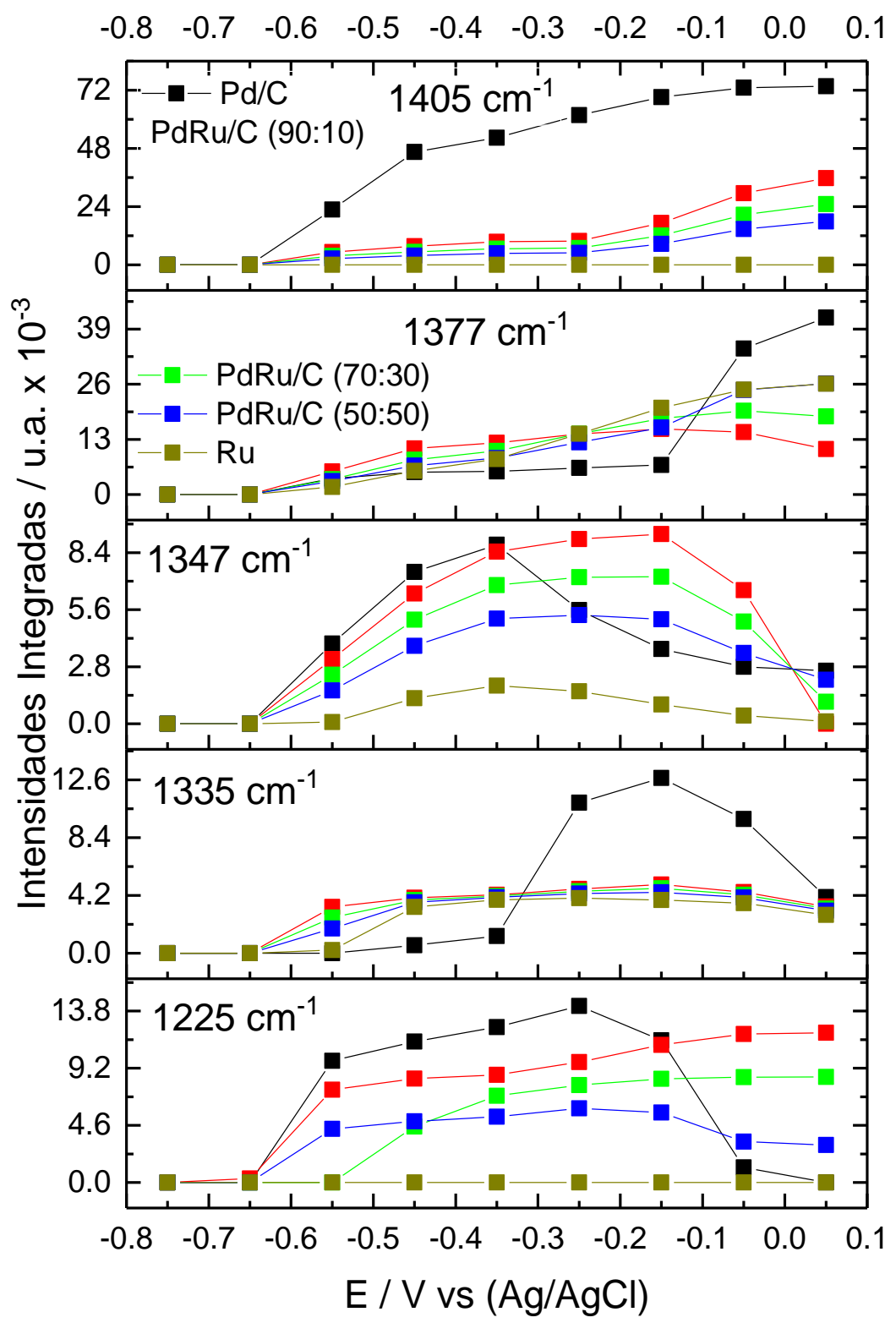

Fonte: Próprio autor

É possível observar que para $\mathrm{Pd} / \mathrm{C}$ a atividade está ligada a formação de carbonato, que se deposita sobre a camada catalítica fazendo com que a atividade do catalisador fique comparável aos demais materiais menos ativos. O material mais ativo pelos experimentos eletroquímicos é o $\mathrm{PdRu} / \mathrm{C}(90: 10)$ que apresenta baixos 
potenciais de início de formação de produtos mais oxigenados, principalmente formiato e hidroxipiruvato. Também se nota que as bandas 1345 e $1377 \mathrm{~cm}^{-1}$ descrevem comportamento descendente em - $0,25 \mathrm{~V}$ o que coincide com o incremento na produção de carbonato. Para Ru/C observa-se a ausência das bandas de carbonato e formiato sendo destacada a produção de glicolato crescente em todos os potenciais a partir de $-0,65 \mathrm{~V}$. Os materiais $\mathrm{PdRu} / \mathrm{C}$ de composição 70:30 e 50:50 não se destacam pelo comportamento de qualquer dos compostos.

\subsection{Experimentos em Célula a Combustível}

As curvas de polarização e densidade de potência utilizando os eletrocatalisadores $\mathrm{Ru} / \mathrm{C}, \mathrm{Pd} / \mathrm{C}$ e $\mathrm{PdRu} / \mathrm{C}$ (50:50; 70:30 e 90:10) para oxidação do glicerol são exibidas na figura 24 e 25 respectivamente.

Figura 24: Curvas de polarização de uma DGFC utilizando eletrocatalisadores $\mathrm{Ru} / \mathrm{C}, \mathrm{Pd} / \mathrm{C}$ e $\mathrm{PdRu} / \mathrm{C} \quad(50: 50 ; \quad 70: 30$ e 90:10) no ânodo, com uma carga metálica de

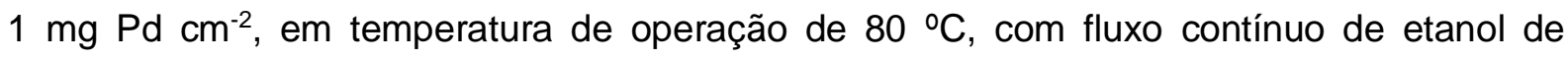
$2 \mathrm{M} \mathrm{KOH}+$ Glicerol

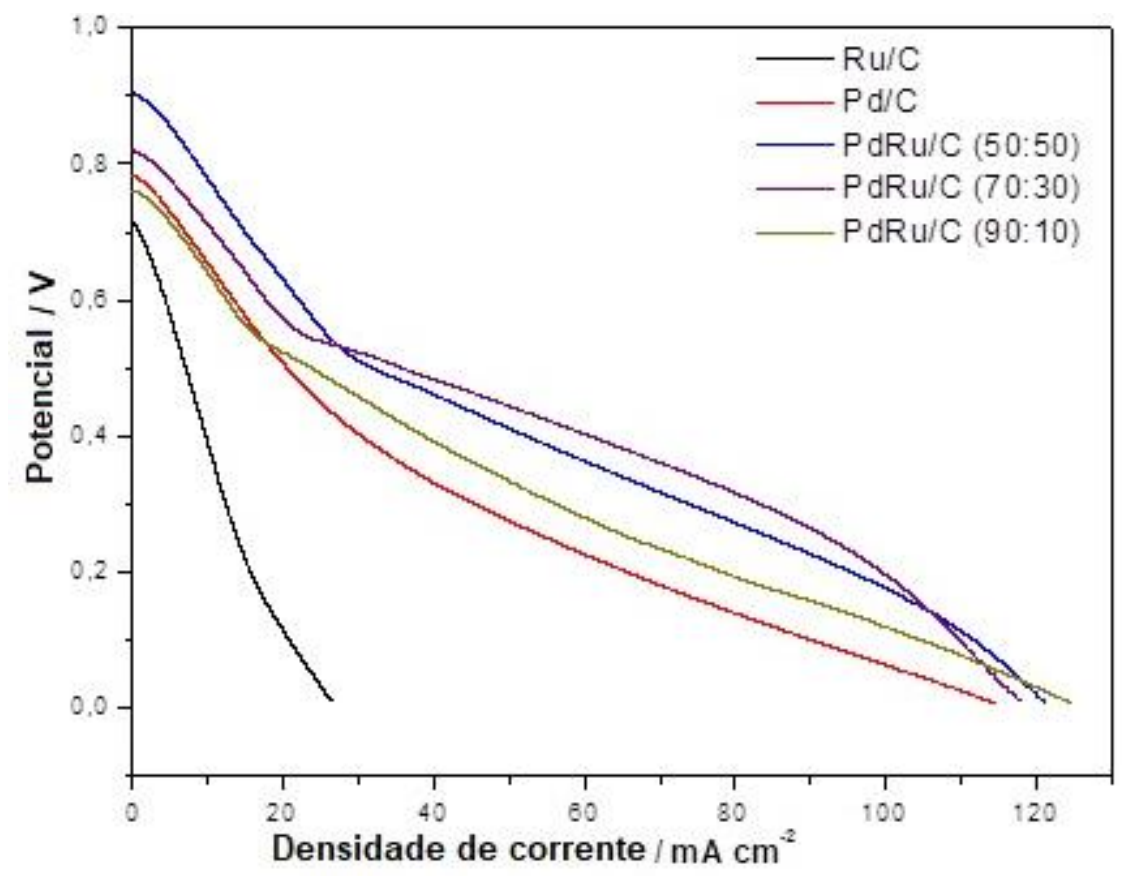

Fonte: Próprio autor 
FIGURA 25: Curvas de densidade de potência de uma DGFC utilizando eletrocatalisadores $\mathrm{Ru} / \mathrm{C}, \mathrm{Pd} / \mathrm{C}$ e $\mathrm{PdRu} / \mathrm{C}(50: 50 ; 70: 30$ e 90:10) no ânodo, com uma carga metálica de $1 \mathrm{mg} \mathrm{Pd} \mathrm{cm}{ }^{-2}$, em temperatura de operação de $80 \stackrel{\circ}{ } \mathrm{C}$, com fluxo contínuo de etanol de $2 \mathrm{M} \mathrm{KOH}+$ Glicerol

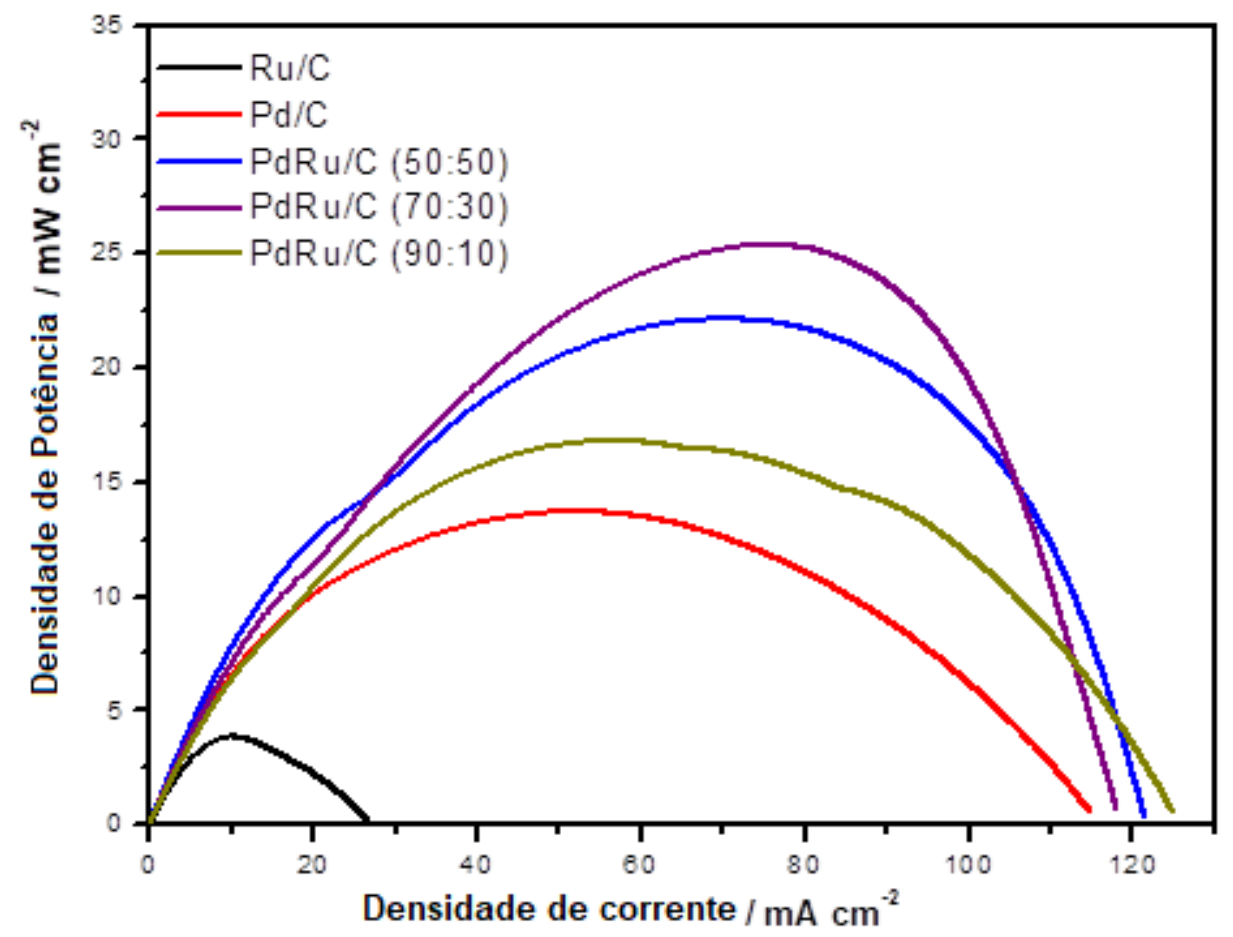

Fonte: Próprio autor

O potencial de circuito aberto para PdRu/C (50:50) foi superior aos demais eletrocatalisadores em estudo, porém a densidade de potência máxima foi observada para o eletrocatalisador PdRu/C (70:30) seguido por PdRu/C (50:50), PdRu/C (90:10), $\mathrm{Pd} / \mathrm{C}$ e Ru/C. É importante mencionar que diferente dos estudos por voltametria cíclica e cronoamperometria, o eletrocatalisador $\mathrm{Ru} / \mathrm{C}$ neste estudo apresentou atividade catalítica, este efeito pode estar relacionado com os fatores de operação da célula a combustível. Zhang e colaboradores [88] observaram que com o aumento de temperatura o desempenho das células DGFC é melhorado, relatando que a cinética de oxidação do glicerol é aprimorada de acordo com a temperatura de operação.

A tabela 6 a seguir apresenta os resultados obtidos nos ensaios em célula a combustível de glicerol direto de acordo com as figuras 24 e 25. 
TABELA 6: Experimentos em DGFC utilizando eletrocatalisadores $\mathrm{Ru} / \mathrm{C}, \mathrm{Pd} / \mathrm{C}$ e $\mathrm{PdRu} / \mathrm{C}$ (50:50; 70:30 e 90:10), destaque para o potencial de circuito aberto em $\mathrm{V}$ e densidade de potência em $\mathrm{mW}$.

\begin{tabular}{|c|c|c|}
\hline Eletrocalisador & $\begin{array}{c}\text { Potencial de circuito } \\
\text { aberto em } \mathbf{~}\end{array}$ & $\begin{array}{c}\text { Densidade de potência } \\
\text { em } \mathbf{~ m W ~} \mathbf{~ c m}-\mathbf{2}\end{array}$ \\
\hline $\mathrm{Ru} / \mathrm{C}$ & 0,71 & 3,75 \\
\hline $\mathrm{Pd} / \mathrm{C}$ & 0,79 & 13,75 \\
\hline $\mathrm{PdRu} / \mathrm{C}(50: 50)$ & 0,90 & 22,00 \\
\hline $\mathrm{PdRu} / \mathrm{C}(70: 30)$ & 0,82 & 25,30 \\
\hline $\mathrm{PdRu} / \mathrm{C}(90: 10)$ & 0,77 & 16,25 \\
\hline
\end{tabular}

Fonte: Próprio autor

A partir da tabela 6, é observado que o eletrocatalisador PdRu/C (70:30) apresentou maior eficiência catalítica para oxidação do glicerol, exibindo uma densidade de potência de 25,3 $\mathrm{mW} \mathrm{cm}^{-2}$, seguido por $\mathrm{PdRu} / \mathrm{C}$ (50:50) e $\mathrm{PdRu} / \mathrm{C}$ (90:10) que apresentou uma densidade de potência de $22,0 \mathrm{~mW} \cdot \mathrm{cm}^{-2}$ e $16,25 \mathrm{~mW} \cdot \mathrm{cm}^{-2}$ respectivamente. Todos os eletrocatalisadores binários exibiram uma atividade catalítica superior ao eletrocatalisador $\mathrm{Pd} / \mathrm{C}$ para oxidação do glicerol.

Em conformidade aos resultados obtidos pela caracterização eletroquímica é observado uma divergência em comparação aos resultados obtidos pelos ensaios em célula a combustível. Esse fato pode estar relacionado com a utilização da temperatura, que foi realizado a $90^{\circ} \mathrm{C}$ enquanto que os experimentos eletroquímicos foram realizados a temperatura ambiente. Outro aspecto a ser mencionado que também pode ter influenciado nos resultados pode ser associado a confecção do MEA, em que influencia nos efeitos difusionais e de transporte de massa. 


\section{CONCLUSÕES}

Com base no trabalho realizado conclui-se que o método de redução por borohidreto de sódio foi efetivo para preparação dos eletrocatalisadores em estudo para eletro-oxidação do etanol e glicerol em meio alcalino.

Os resultados obtidos pela análise de EDX para todos os eletrocatalisadores sintetizados mostraram que os valores das razões atômicas obtidos $(\mathrm{Pd} / \mathrm{C} ; \mathrm{Ru} / \mathrm{C}$; $\mathrm{PdRu} / \mathrm{C}$ 50:50; 70:30 e 90:10) são próximas aos valores nominais de partida indicando a efetividade do método de síntese proposto.

Os difratogramas de raios $\mathrm{X}$ mostraram a presença da estrutura cúbica de face centrada do paládio e a estrutura hexagonal compacta do rutênio. Os eletrocatalisadores de $\mathrm{PdRu} / \mathrm{C}$ apresentaram um deslocamento dos valores $2 \theta=68^{\circ}$ para maiores se comparados com o eletrocatalisador de $\mathrm{Pd} / \mathrm{C}$, indicando uma formação de liga metálica para estes materiais, ou seja, há inserção de rutênio na estrutura cristalina do paládio.

As micrografias obtidas pela técnica de MET mostraram para todos os eletrocatalisadores que as nanopartículas metálicas foram ancoradas e distribuídas homogeneamente sobre o suporte de carbono, com exceção ao eletrocatalisador $\mathrm{Ru} / \mathrm{C}$ que apresentou aglomeração entre as nanopartículas.

Os resultados de XPS evidenciaram que o eletrocatalisador $\mathrm{PdRu} / \mathrm{C}$ (70:30) foi o único a apresentar uma mistura de espécies de rutênio de diferentes estados de oxidação ( $\mathrm{RuO}$ e RuO2) , que de certa forma poderia contribuir para a ocorrência do mecanismo bifuncional para oxidação das espécies intermediárias adsorvidas da reação de oxidação do etanol e glicerol.

Os estudos de caracterização eletroquímica (voltametria cíclica e cronoamperometria) mostraram que o eletrocatalisador $\mathrm{PdRu} / \mathrm{C}(90: 10)$ foi o mais ativo para oxidação do etanol e glicerol em comparação aos demais eletrocatalisadores em estudo. Os resultados podem ser explicados pelos maiores valores de densidade de corrente observados nos experimentos eletroquímicos considerando os potenciais de interesse tecnológico.

Os ensaios em célula a combustível unitária alimentadas diretamente com etanol e glicerol mostraram que o eletrocatalisador PdRu/C (70:30) exibiu maior valor 
de densidade de potência máxima em comparação aos demais eletrocatalisadores. Este fato pode estar relacionado ao aumento da quebra da ligação C-C na oxidação do etanol devido a adição de rutênio sendo observado nos experimentos de ATR-FTIR in situ a maior produção de $\mathrm{CO}_{2}$ para este material, no entanto é importante ressaltar que os ensaios em célula a combustível têm-se o efeito da temperatura e do fluxo contínuo do combustível que podem resultar em divergências quando comparado aos estudos eletroquímicos convencionais. Os diferentes produtos observados para a reação de oxidação do etanol ou glicerol mostra a complexidade dos mecanismos de reação para estes combustíveis.

O melhor desempenho dos eletrocatalisadores de $\mathrm{PdRu} / \mathrm{C}$ em relação ao $\mathrm{Pd} / \mathrm{C}$ tem sido atribuído aos mecanismos eletrônico e bifuncional, como também a sinergia entre os componentes presentes na composição destes eletrocatalisadores. 


\section{TRABALHOS PUBLICADOS}

NANDENHA, J.; RAMOS, C. E. D.; DE SOUZA, R. F. B.; OTTONI, C. A.; NETO, A. O.; PdIn/C electrocatalysts synthesis enhancement for effective glycerol electrooxidation under alkaline condition. Ionics, 2020. No prelo.

FONTES, ERIC H.; RAMOS, CARLOS EDUARDO D.; NANDENHA, JÚLIO; PIASENTIN, RICARDO M. ; NETO, ALMIR O. ; LANDERS, RICHARD . Structural analysis of $\mathrm{PdRh} / \mathrm{C}$ and $\mathrm{PdSn} / \mathrm{C}$ and its use as electrocatalysts for ethanol oxidation in alkaline medium. International Journal of Hydrogen Energy. v. 44, p. 937-951, 2019.

OTTONI, CRISTIANE, A.; RAMOS, C. E. D. ; SOUZA, R. F. B. ; SILVA, SIRLANE GOMES DA ; SPINACE, E. V. ; OLIVEIRA NETO, A. . Glycerol and Ethanol Oxidation in Alkaline Medium Using $\mathrm{PtCu} / \mathrm{C}$ Electrocatalysts. International Journal of Electrochemical Science. v. 13, p. 1893-1904, 2018.

OTTONI, CRISTIANE, A.; RAMOS, C. E. D. ; DA SILVA, SIRLANE G. ; SPINACE, E. V. ; DE SOUZA, RODRIGO F. B. ; NETO, ALMIR OLIVEIRA . Glycerol and Methanol Electro-oxidation at Pt/C-ITO under Alkaline Condition. Electroanalysis. v. 28, p. 2552-2558, 2016. 


\section{REFERÊNCIAIS BIBLIOGRÁFICAS}

[1] SAUPSOR, J.; KASEMPREMCHIT, N.; BUMROONGSAKULSAWAT, P.; LOHSOONTORN, P.; WONGSAKULPHASATVH, S.; KIATKITTIPONG, W.; LAOSIRIPOJANA, N.; GONG, J. ASSABUMRUNGRAT, S. Performance comparison among different multifunctional reactors operated under energy self-sufficiency for sustainable hydrogen production from ethanol. International Journal Hydrogen Energy, no. xxxx, p.xxxx, 2019.

doi: 10.1016/j.ijhydene.2019.03.090

[2] DAWSON, I. G. J.; JONHSON, J. E. V. Does Size Matter ? A Study of Risk Perceptions of Global Population Growth. Risk Analysis. v. 37, p. 65-81, 2017. doi: 10.1111/risa.12576.

[3] STRONG, M. F. ECO 92: Critical Challenges and Global Solutions. Jounal of Interbational Affairs. v. 44, p. 287-300, 1991.

[4] MARCO, B. A. de.; RECHELO, B. S.; tÓtOLI, E. G.; KOGAWA, A. C.; SALGADO, H. R. N. Evolution of green chemistry and its multidimensional impacts: A review. Saudi Pharmaceutical Journal. v. 27, p. 1-8, 2019.

doi: 10.1016/j.jsps.2018.07.011.

[5] CLARK, W. C.; KERKHOFF, L. Van; LEBEL, L.; GALLOPIN, G. C. Crafting usable knowledge for sustainable development. Proceedind of the National Academy of Sciences. v.113, n. 17, p. 4570-4578, 2016.

doi: 10.1073/pnas.1601266113.

[6] HUEMANN, M.; SILVIUS, G. Projects to create the future: Managing projects meets sustainable development. International Journal Project Management. v. 35, n. 6, p. 1066-1070, 2017.

doi: 10.1016/j.jproman.2017.04.014.

[7] BIZON, N.; THOUNTHONG, P. Fuel economy using the global optimization of the Fuel Cell Hybrid Power Systems. Energy Conversion Management. v. 173, p. $665-678,2018$.

doi: 10.1016/j.enconman.2018.08.015.

[8] KIM, M.; LEE, C.; KO, S. M.; NAM, J. M. Metal alloy hybrid nanoparticles with enhanced catalytic activities in fuel cell applications. Journal Solid State Chemistry. v. 270, p. 295-303, 2019.

doi: $10.1016 / j . j s s c .2018 .11 .014$.

[9] LIU, L.; LIN, X. X.; ZOU, S. Y.; WANG, A. J.; CHEN, J. R.; FENG, J. J. One-pot wet-chemical synthesis of PtPd@Pt nanocrystals supported on reduced graphene oxide with highly electrocatalytic performance for ethylene glycol oxidation. Electrochimica Acta. v. 187, p. 576-583, 2016.

doi: 10.1016/j.electacta.2015.11.089. 
[10] ZHIANI, M.; MAJIDI, S.; ROSTAMI, H.; TAGHABADI, M. M. Comparative study of aliphatic alcohols electrooxidation on zero-valent palladium complex for direct alcohol fuel cells. Inernational Journal of Hydrogen Energy. v. 40, p. 568-576, 2015.

doi: 10.1016/j.jhydene.2014.10.144.

[11] FATHIRAD, F.; MOSTAFAVI, A.; AFZALI, D. Bimetallic Pd-Mo nanoalloys supported on Vulcan XC-72R carbon as anode catalysts for direct alcohol fuel cell. International Journal of Hydrogen Energy. v. 42, p. 3215-3221, 2017. doi: 10.1016/j.jhydene.2016.09.138.

[12] HE, Q.; SHEN, Y.; XIAO, K.; XI, J.; QIU, X. Alcohol electro-oxidation on platinum-ceria/graphene nanosheet in alkaline solutions. International Journal of Hydrogen Energy. v. 41, n. 45, p. 20709-20719, 2016.

doi: 10.1016/j.ijhydene.2016.07.205.

[13] SUN, C. L.; TANG, J. S.; BRAZEAU, N.; WU, J. J.; NTAIS, S.; YIN, W. C.; CHOU, H. L.; BARANOVA, E. A. Particle size effects of sulfonated graphene supported Pt nanoparticles on ethanol electrooxidation. Electrochimica Acta. v. 162, p. 282-289, 2015.

doi: 10.1016/j.electacta.2014.12.099.

[14] NETO, A. O; DIAS, R. R.; RIBEIRO, V. A.; SPINACÉ, E. V.; LINARDI, M. Eletrooxidação de etanol sobre eletrocatalisadores $\mathrm{PtRh} / \mathrm{C}, \mathrm{PtSn} / \mathrm{C}$ e $\mathrm{PtSnRh} / \mathrm{C}$ preparados pelo método da redução por álcool. Eclética Química. v. 31, n. 1, p. 81-88, 2006.

doi: $10.1590 / \mathrm{s} 0100-46702006000100010$.

[15] ANTOLINI, E.; GONZALEZ, E. R. Alkaline direct alcohol fuel cells. Journal Power Sources. v. 195, no. 11, p. 3431-3450, 2010.

doi: 10.1016/j.jpowsour.2009.11.145.

[16] WANG, H.; THIA, L.; LI, N.; GE, X.; LIU, Z.; . WANG, X; Pd nanoparticles on carbon nitride-graphene for the selective electro-oxidation of glycerol in alkaline solution. Catalysis. vol. 5, no. 6, pp. 3174-3180, 2015,

doi: 10.1021/acscatal.5b00183.

[17] COUTO, R. N.; LINARES, J. J. KOH-doped polybenzimidazole for alkaline direct glycerol fuel cells. Journal Membrane Science. v.486, p. 239-247, 2015. doi: 10.1016/j.memsci.2015.03.031.

[18] OTTONI, C. A.; SOUZA, R. de; SILVA, S. G. da; SPINACÉ, E. V.; SOUZA, R. F. B. de.; NETO, A. O. Performance of Pd Electrocatalyst Supported on a Physical Mixture Indium Tin Oxide-carbon for Glycerol Electro-oxidation in Alkaline Media. Electroanalysis. v. 29, n. 4, p. 960-964, 2017 doi: 10.1002/elan.201600569. 
[19] ZANATA, C. R.; FERNÁNDEZ, P. S.; TROIANI, H. E.; SOLDATI, A. L.; LANDERS, R. CAMARA, G. A.; CARVALHO, A. E. MARTINS, C. A. Rh-decorated PtIrOx nanoparticles for glycerol electrooxidation: Searching for a stable and active catalyst. Applied Catalysis B: Environmental. v. 181, p. $445-455,2016$.

doi: 10.1016/j.apcatb.2015.08.021.

[20] OTTONI, C. A.; RAMOS, C. E. D.; SOUZA, R. F. B. de; SILVA, S. G. da; SPINACE, E. V.; NETO, A. O. Glycerol and ethanol oxidation in alkaline medium using $\mathrm{PtCu} / \mathrm{C}$ electrocatalysts. International Journal of Electrochemical Science. v. 13, n. 2, p. 1893-1904, 2018

doi: $10.20964 / 2018.02 .58$.

[21] MARSHALL, A. T.; GOLOVKO, V.; PADAYACHEE, D. Influence of gold nanoparticle loading in $\mathrm{Au} / \mathrm{C}$ on the activity towards electrocatalytic glycerol oxidation. Electrochimica Acta. v. 153, p. 370-378, 2015.

doi: 10.1016/j.electacta.2014.11.186.

[22] OTTONI, C. A.; RAMOS, C. E. D.; SILVA, S. G. da.; SPINACÉ, E. V.; SOUZA, R. F. B. de.; NETO, A. O. Glycerol and Methanol Electro-oxidation at Pt/C-ITO under Alkaline Condition. Electroanalysis. v. 28, n. 10, p. 2552-2558, 2016.

doi: 10.1002/elan.201600090.

[23] MUKHERJEE, P.; ROY, P. S.; MANDAL, K.; BHATTACHARJEE, D.; DASGUPTA, S.; BHATTACHARYA, S. K. Improved catalysis of room temperature synthesized $\mathrm{Pd}-\mathrm{Cu}$ alloy nanoparticles for anodic oxidation of ethanol in alkaline media. Electrochimica Acta. v. 154, p. 447-455, 2015 doi: 10.1016/j.electacta.2014.12.054.

[24] LIU, L.; LIN, X. X.; ZOU, S. Y.; WANG, A. J.; CHEN, J. R.; FENG, J. J. One-pot wet-chemical synthesis of PtPd@Pt nanocrystals supported on reduced graphene oxide with highly electrocatalytic performance for ethylene glycol oxidation. Electrochimica Acta. v. 187,pp. 576-583, 2016

doi: 10.1016/j.electacta.2015.11.089.

[25] KIM, M.; LE, C.; KO, S. M.; NAM, J. M. Metal alloy hybrid nanoparticles with enhanced catalytic activities in fuel cell applications. Journal Solid State Chemistry. v. 270, p. 295-303, 2019.

doi: 10.1016/j.jssc.2018.11.014.

[26] MORAES, L. P. R.; MATOS, B. R.; RADTKE, C.; SANTIAGO, E. I.; FONSECA, F. C.; AMICO, S. C.; MALFATTI, C. F. Synthesis and performance of palladiumbased electrocatalysts in alkaline direct ethanol fuel cell. International Journal of Hydrogen Energy. v. 41, n. 15, p. 6457-6468, 2016.

doi: 10.1016/j.ijhydene.2016.02.150. 
[27] ROSTAMI, H.; OMRANI, A.; ROSTAMI, A. A. On the role of electrodeposited nanostructured $\mathrm{Pd}$-Co alloy on Au for the electrocatalytic oxidation of glycerol in alkaline media. International Journal of Hydrogen Energy. v. 40, n. 30, p. 9444-9451, 2015.

doi: 10.1016/j.jhydene.2015.05.154.

[28] FASHEDEMI, O. O.; OZOEMENA, K. I. Comparative electrocatalytic oxidation of ethanol, ethylene glycol and glycerol in alkaline medium at Pd-decorated FeCo@Fe/C core-shell nanocatalysts. Electrochimica Acta. v. 128, p. 279-286, 2014.

doi: 10.1016/j.electacta.2013.10.194.

[29] MA, L.; CHU, D.; CHEN, R. Comparison of ethanol electro-oxidation on Pt/C and $\mathrm{Pd} / \mathrm{C}$ catalysts in alkaline media. International Journal of Hydrogen Energy. v. 37, n. 15, p. 11185-11194, 2012.

doi: 10.1016/j.jhydene.2012.04.132.

[30] BLOXHAM, L et. al. Platinum 2013: Interim Review. Hertfordshire: Johnson Matthey. v. 57, n. 3, p. 215-216, 2013.

doi: $10.1595 / 147106713 \times 668974$.

[31] KABIR, S.; SEROV, A.; ARTYUSHKOVA, K.; ATANASSOV, P. Design of Novel Graphene Materials as a Support for Palladium Nanoparticles: Highly Active Catalysts towards Ethanol Electrooxidation. Electrochimica Acta. v. 203, p. 144-153, 2016.

doi: 10.1016/j.electacta.2016.04.026.

[32] HU, G.; NITZE, F.; BARZEGAR, H. R.; SHARIFI, T. Palladium nanocrystals supported on helical carbon nanofibers for highly efficient electro-oxidation of formic acid, methanol and ethanol in alkaline electrolytes. Journal of Power Sources. v. 209, p. 236-242, 2012

doi: 10.1016/j.jpowsour.2012.02.080.

[33] ZHANG, X. J.; ZHANG, J. M.; ZHANG, P. Y.; LI, Y.; XIANG, S.; TANG, H. G.; FAN, Y. J. Highly active carbon nanotube-supported Ru@Pd core-shell nanostructure as an efficient electrocatalyst toward ethanol and formic acid oxidation. Molecular Catalysis. v. 436, p. 138-144, 2017.

doi: 10.1016/j.mcat.2017.04.015.

[34] OTTONI, C. A.; SILVA, S. G. da; SOUZA, R. F. B. de; NETO, A. O. Glycerol oxidation reaction using $\mathrm{PdAu} / \mathrm{C}$ electrocatalysts. Ionics. v. $22, \mathrm{n} .7$, p. 1167-1175, 2016.

doi: 10.1007/s11581-015-1631-8.

[35] CHEN, Y.; ZHUANG, L.; LU, J. Non-Pt Anode Catalysts for Alkaline Direct Alcohol Fuel Cells. Chinese Journal of Catalysis. v. 28, p. 870-874, 2007. doi: 10.1016/S1872-2067(07)60073-4. 
[36] SHEN, S. Y.; ZHAO, T. S.; XU, J. B.; LI, Y. S. Synthesis of PdNi catalysts for the oxidation of ethanol in alkaline direct ethanol fuel cells. Journal of Power Sources. v. 195, n. 4, p. 1001-1006, 2010.

doi: 10.1016/j.jpowsour.2009.08.079.

[37] HE, Q.; CHEN, W.; MUKERJEE, S.; CHEN, S.; LAUFEK, F. Carbon-supported $\mathrm{PdM}(\mathrm{M}=\mathrm{Au}$ and $\mathrm{Sn})$ nanocatalysts for the electrooxidation of ethanol in high pH media. Journal of Power Sources. v. 187, n. 2, p. 298-304, 2009. doi: 10.1016/j.jpowsour.2008.11.065.

[38] LI, G.; JIANG, L.; JIANG, Q.; WANG, S.; SUN, G. Preparation and characterization of $\mathrm{PdxAgy/C}$ electrocatalysts for ethanol electrooxidation reaction in alkaline media. Electrochimica Acta. v. 56, p. 7703-7711, 2011. doi: 10.1016/j.electacta.2011.06.036.

[39] KANG, W. da; WEI, Y. C.; LIU, C. W.; WANG, K. W. Enhancement of electrochemical properties on $\mathrm{Pd}-\mathrm{Cu} / \mathrm{C}$ electrocatalysts toward ethanol oxidation by atmosphere induced surface and structural alteration. Electrochemistry communications. v. 13, n. 2, p. 162-165, 2011. doi: 10.1016/j.elecom.2010.12.003.

[40] CARRIÓN-SATORRE, S.; MONTIEL, M.; ESCUDERO, R.; FIERRO, J. L. G.; FATÁS, E.; OCÓN, P. Performance of carbon-supported palladium and palladium-ruthenium catalysts for alkaline membrane direct ethanol fuel cells. International Journal of Hydrogen Energy. v. 41, n. 21, p. 8954-8962, 2016. doi: 10.1016/j.ijhydene.2016.04.053.

[41] XU, H.; YAN, B.; ZHANG. K.; LI, S.; WANG, C.; SHIRAISHI, Y.; DU, Y.; YANG, $P$. Facile fabrication of novel PdRu nanoflowers as highly active catalysts for the electrooxidation of methanol. Journal Colloid and Interface Science. v. 505, p. 1-8, 2017.

doi: 10.1016/j.jcis.2017.05.067.

[42] DASH. S.; MUNICHANDRAIAH, N. Nanoflowers of PdRu on PEDOT for Electrooxidation of Glycerol and Its Analysis. Electrochimica Acta. v. 180 , p. 339-352, 2015.

doi: 10.1016/j.electacta.2015.07.020.

[43] BARBIR, F.; GÓMEZ, T. Efficiency and economics of proton exchange membrane (PEM) fuel cells. International Journal of Hydrogen Energy. v. 22, n. 10-11, p. 1027-1037, 1997.

doi: 10.1016/s0360-3199(96)00175-9.

[44] MOHAMAD, N. A.; NAKAO, H.; JAAFAR, J.; KIM, J. D. Crosslinked carbon nanodots with highly sulfonated polyphenylsulfone as proton exchange membrane for fuel cell applications. International Journal of Hydrogen Energy. v. 45, n. 16, p. 9979-9988, 2020.

doi: $10.1016 / j . i j h y d e n e .2020 .01 .142$. 
[45] SIWAL, S. S.; THAKUR, S.; ZHANG, Q. B.; THAKUR, V. K. Electrocatalysts for electrooxidation of direct alcohol fuel cell: chemistry and applications. Materials Today Chemistry. v. 14, p. 100182, 2019.

doi: 10.1016/j.mtchem.2019.06.004.

[46] COUTURE, G.; ALAAEDdine, A.; BOSCHET, F.; AMEDURI, B. Polymeric materials as anion-exchange membranes for alkaline fuel cells. Progress Polymer Science. v. 36, n. 11, p. 1521-1557, 2011.

doi: 10.1016/j.progpolymsci.2011.04.004.

[47] STEELE, B. C. H.; HEINZEL, A. Materials for fuel-cell technologies. Nature. v. 414, n. 6861, p. 345-352, 2001.

doi: $10.1038 / 35104620$.

[48] KIM, Y. S.; KIM, H. J.; KIM, W. B. Composited hybrid electrocatalysts of Ptbased nanoparticles and nanowires for low temperature polymer electrolyte fuel cells. Electrochemistry communications. v. 11, n. 5, p. 1026-1029, 2009. doi: 10.1016/j.elecom.2009.03.003.

[49] FOUDA-ONANA, F.; BAH, S.; SAVADOGO, O. Palladium-copper alloys as catalysts for the oxygen reduction reaction in an acidic media I: Correlation between the ORR kinetic parameters and intrinsic physical properties of the alloys. Journal Electroanalytical Chemistry. v. 636, n. 1-2, p. 1-9, 2009.

doi: 10.1016/j.jelechem.2009.06.023.

[50] NOTO, V. di; NEGRO, E. Development of nano-electrocatalysts based on carbon nitride supports for the ORR processes in PEM fuel cells. Electrochimica Acta. v. 55, n. 26, p. 7564-7574, 2010.

doi: 10.1016/j.electacta.2009.11.032.

[51] GONG, K. et al. Platinum-monolayer electrocatalysts: Palladium interlayer on IrCo alloy core improves activity in oxygen-reduction reaction. Journal Electroanalytical Chemistry. v. 649, n. 1-2, p. 232-237, 2010.

doi: 10.1016/j.jelechem.2010.04.011.

[52] AHMADI, N.; KÕRGESAAR, M. Analytical approach to investigate the effect of gas channel draft angle on the performance of PEMFC and species distribution. International Journal Heat and Mass Transfer. v. 152, p. 119529, 2020. doi: 10.1016/j.ijheatmasstransfer.2020.119529.

[53] PENG, F.; REN, L.; ZHAO, Y.; LI, L. Hybrid dynamic modeling-based membrane hydration analysis for the commercial high-power integrated PEMFC systems considering water transport equivalent. Energy Conversion Management. v. 205, p. $112385,2020$.

doi: 10.1016/j.enconman.2019.112385.

[54] LINARDI, M. Introdução à Ciência e Tecnologia de Células a Combustível. 1. Ed. São Paulo.: Artiliber, 2010. 
[55] EG\&G TECHNICAL SERVICES IC.; SCIENCE APPLICATIONS INTERNATIONAL CORPORATION. Fuel Cell Handbook. 6 ed. Morgantown: U.S Department of Energy, 2002. 11. 2002.

[56] WANG, Y.; CHEN, K. S.; MISHLER, J.; S. CHO, C.; ADROHER, X. C.; A review of polymer electrolyte membrane fuel cells: Technology, applications, and needs on fundamental research. Applied Energy. v. 88, p. 981-1007, 2011. doi: 10.1016/j.apenergy.2010.09.030.

[57] PAPAGEORGOPOULOS, D. DOE fuel cell technology program overview and introduction to the $\mathbf{2 0 1 0}$ fuel cell pre-solicitation workshop in DOE fuel cell pre-solicitation workshop. Department of Energy, Lakewood, Colorado: 2010.

[58] WENDT, H.; GOTZ, M.; LINARDI, M. Tecnologia de células a combustível. Química Nova, v. 23, n. 4, p. 538-546, 2000.

doi: $10.1590 / \mathrm{s} 0100-40422000000400018$.

[59] TICIANELLI, E. A.; GONZALEZ, E. R. Eletroquímica . 2.ed. São Paulo.: Editora da Universidade de São Paulo: EDUSP, 2013.

[60] SORENSEN, B. Renewable Energy: Its physics, engineering, use, environmental impacts, economy and planning aspects. 3.ed. Roskilde, Denmark, 2004.

[61] ANDÚJAR. J. M.; SEGURA, F. Fuel cells: History and updating. A walk along two centuries. Renewable Sustainable Energy Reviews. v. 13, n. 9, p. 2309-2322, 2009.

doi: 10.1016/j.rser.2009.03.015.

[62] ZHU, M.; SUN, G.; XIN, Q. Effect of alloying degree in PtSn catalyst on the catalytic behavior for ethanol electro-oxidation. Electrochimica Acta. v. 54, n. 5, p. 1511-1518, 2009.

doi: 10.1016/j.electacta.2008.09.035.

[63] GODOI, D. R. M.; PEREZ, J.; VILLULLAS, H. M. Alloys and oxides on carbonsupported Pt-Sn electrocatalysts for ethanol oxidation. Journal of Power Sources. v. 195, n. 11, p. 3394-3401, 2010.

doi: 10.1016/j.jpowsour.2009.12.037.

[64] SILVA, D .F.; GERALDES, A. N.; NETO, A. O.; PINO, E. S.; LINARDI, M.; SPINACÉ, E. V.; MACEDO, W. A. A.; ARDISSON. Preparation of PtSnO2/C electrocatalysts using electron beam irradiation. Materials Science and Engineering: B. v. 175, n. 3, p. 261-265, 2010.

doi: 10.1016/j.mseb.2010.08.002. 
[65] DE SOUZA, R. F. B.; PARREIRA, L. S.; SILVA, J. C. M.; SIMÕES, F.C.; CALEGARO, M. L.; GIZ, M. J.; CAMARA, G. A.; NETO, A. O.; SANTOS, M. C. $\mathrm{PtSnCe} / \mathrm{C}$ electrocatalysts for ethanol oxidation: DEFC and FTIR 'in-situ' studies. International Journal of Hydrogen Energy. v.36, n. 18, p.11519-11527, 2011.

doi: 10.1016/j.jijhydene.2011.05.016.

[66] SILVA, J. C. M.; PAREIRA, L. S.; DE SOUZA, R. F. B.; CALEGARO, M. L.; SPINACÉ, E. V.; NETO, A. O.; SANTOS, M. C. PtSn/C alloyed and non-alloyed materials: Differences in the ethanol electro-oxidation reaction pathways. Applied Catalysis B: Environmental. v. 110, p. 141-147, 2011. doi: 10.1016/j.apcatb.2011.08.036.

[67] FADZILLAH, D. M.; KAMARUDIN, S. K.; ZAINOODIN, M. A.; MASDAR, M. S. Critical challenges in the system development of direct alcohol fuel cells as portable power supplies: An overview. International Journal of Hydrogen Energy. v. 44, no. 5, pp. 3031-3054, 2019.

doi: $10.1016 /$ j.ijhydene.2018.11.089.

[68] JURZINSKY, T.; CREMERS, C.; JUNG, F.; PINKWARD, K.; TUBKE, J. Development of materials for anion-exchange membrane direct alcohol fuel cells. International Journal of Hydrogen Energy. v. 40, n. 35, p. 11569-11576, 2015.

doi: 10.1016/j.ijhydene.2015.02.056.

[69] ZAKIL, F. A.; KAMARUDIN, S. K.; BASRI, S.; Modified Nafion membranes for direct alcohol fuel cells: An overview. Renewable Sustainable Energy Reviews. v. 65, p. 841-852, 2016.

doi: $10.1016 / j . r s e r .2016 .07 .040$.

[70] CHOUDHARY, A. K.; PRAMANIK, H. Enhancement of ethanol electrooxidation in half cell and single direct ethanol fuel cell (DEFC) using post-treated polyol synthesized Pt-Ru nano electrocatalysts supported on HNO3-functionalized acetylene black carbon. International Journal of Hydrogen Energy. v. 45, n. 1, p. 574-594, 2020.

doi: 10.1016/j.ijhydene.2019.10.243.

[71] AKHAIRI, M. A. F.; KAMARUDIN, S. K.; Catalysts in direct ethanol fuel cell (DEFC): An overview. International Journal of Hydrogen Energy. v. 41, n. 7, p. 4214-4228, 2016.

doi: 10.1016/j.ijhydene.2015.12.145.

[72] BENNERTZ, R.; RIP, A. The evolving Brazilian automotive-energy infrastructure: Entanglements of national developmentalism, sugar and ethanol production, automobility and gasoline. Energy Research \& Social Science. v. 41 , n. p. $109-117,2018$.

doi: 10.1016/j.erss.2018.04.022. 
[73] SÁNCHEZ-MONREAL, J.; P. GARCÍA-SALABERRI, A.; VERA, M. A mathematical model for direct ethanol fuel cells based on detailed ethanol electro-oxidation kinetics. Applied Energy. v. 251, p. 113264, 2019.

doi: 10.1016/j.apenergy.2019.05.067.

[74] BRAUNCHWEIG, B.; HIBBITTS, D.; NEUROCK, M.; WIECKOWSKI, A. Electrocatalysis: A direct alcohol fuel cell and surface science perspective. Catalysis Today. v. 202, n. 1, p. 197-209, 2013.

doi: 10.1016/j.cattod.2012.08.013.

[75] TAYAL, J.; RAWAT, B.; BASU, S.; Bi-metallic and tri-metallic Pt-Sn/C, Pt-Ir/C, Pt-Ir-Sn/C catalysts for electro-oxidation of ethanol in direct ethanol fuel cel. Inernational Journal of Hydrogen Energy. v. 36, p. 14884-14897, 2011. doi: 10.1016/j.ijhydene.2011.03.035.

[76] WANG, Q.; LU, X.; XIN, Q.; SUN, G. Polyol-synthesized Pt2.6Sn1Ru0.4/C as a high-performance anode catalyst for direct ethanol fuel cells. Chinese Journal of Catalysis. v. 35, n. 8, p. 1394-1401, 2014.

doi: 10.1016/S1872-2067(14)60063-2.

[77] ABDULLAH, S.; KAMARUDIN, S. K.; HASRAN, U. A.; MASDAR, M. S.; DAUD, W. R. W. Development of a conceptual design model of a direct ethanol fuel cell (DEFC). International Journal of Hydrogen Energy. v. 40, n. 35, p. 11943-11948, 2015.

doi: 10.1016/j.jhydene.2015.06.070.

[78] PEREIRA, J. P.; FAlCÃO, D. S.; OliveiRA, V. B.; PINTO, A. M. F. R. Performance of a passive direct ethanol fuel cell. Journal of Power Sources. v. 256, p. 14-19, 2014,

doi: 10.1016/j.jpowsour.2013.12.036.

[79] SOUZA, F. M.; NANDENHA, J.; BATISTA, B. L.; OLIVEIRA, V. H. A.; PINHEIRO, V. S.; PARREIRA, L. S.; NETO, A. O.; SANTOS, M. C.; PdxNby electrocatalysts for DEFC in alkaline medium: Stability, selectivity and mechanism for EOR. International Journal of Hydrogen Energy. v. 43, n. 9, p. 4505-4516, 2018.

doi: 10.1016/j.ijhydene.2018.01.058.

[80] AZAM, A. M. I. N.; LEE, S. H.; MASDAR, M. S.; ZAINOODIN, A. M.; KAMARUDIN, S. K. Parametric study on direct ethanol fuel cell (DEFC) performance and fuel crossover. International Journal of Hydrogen Energy. p. 8566-8574, 2019.

doi: 10.1016/j.jhydene.2018.08.121.

[81] TRIPKOVI ,A. V.; POPOVI, K. D.; GRGUR, B. N.; BLIZANAC B.; ROSS, P. N.; MARKOVI, N. M. Methanol electrooxidation on supported Pt and PtRu catalysts in acid and alkaline solutions. Electrochimica Acta. v. 47, p. 3707-3714, 2002. doi: 10.1016/S0013-4686(02)00340-7. 
[82] FANG, X.; WANG, L.; SHEN, P. K.; CUI, G.; BIANCHINI, C. An in situ Fourier transform infrared spectroelectrochemical study on ethanol electrooxidation on Pd in alkaline solution. Journal of Power Sources. v. 195, p. 1375-1378, 2010. doi: 10.1016/j.jpowsour.2009.09.025.

[83] ZHOU, Z. Y.; WANG, Q.; LIN, J. L.; TIAN, N.; SUN, S. G. In situ FTIR spectroscopic studies of electrooxidation of ethanol on $\mathrm{Pd}$ electrode in alkaline media. Electrochimica Acta. v. 55, n. 27, p. 7995-7999, 2010.

doi: 10.1016/j.electacta.2010.02.071.

[84] FANG, X.; SHEN, P. K. Mechanism of ethanolelectrooxidation on Pd electrode. Acta Physuco-Chimica Sinica. v. 9, p. 1933-1938, 2009.

[85] OH, Y.; KIM, S. K.; PECK, D. H.; JANG, J. S.; KIM, J.; JUNG, D. H. Improved performance using tungsten carbide/carbon nanofiber based anode catalysts for alkaline direct ethanol fuel cells. International Journal of Hydrogen Energy. v. 39, n. 28, p. 15907-15912, 2014.

doi: 10.1016/j.ijhydene.2014.02.010.

[86] GERALDES, A. N.; SILVA, D. F.; DE SOUZA, R. F. B.; NETO, A. O.; LINARDI, M.; SANTOS, M. C. L. Glycerol electrooxidation in alkaline Medium Using $\mathrm{Pd} / \mathrm{C}$, $\mathrm{Au} / \mathrm{C}$ and PdAuC/C," vol. 25, no. 5, pp. 831-840, 2014.

doi: 10.5935/0103-5053.20140044.

[87] BANJONG, J.; THERDTHIANWONG, A.; THERDTHIANWONG, S.; YONGPRAPAT, S.; WONGYAO, N. High performance alkaline-acid direct glycerol fuel cells for portable power supplies via electrode structure design. International Journal of Hydrogen Energy. n. xxxx, p.xxxx, 2019. doi: 10.1016/j.ijhydene.2019.11.041.

[88] ZHANG, Z.; XIN, L.; LI, W. Supported gold nanoparticles as anode catalyst for anion-exchange membrane-direct glycerol fuel cell (AEM-DGFC). International Journal of Hydrogen Energy. v. 37, n. 11, p. 9393-9401, 2012.

doi: 10.1016/j.ijhydene.2012.03.019.

[89] BENIPAL, N.; QI, J.; LIU, Q.; LI, W. Carbon nanotube supported PdAg nanoparticles for electrocatalytic oxidation of glycerol in anion exchange membrane fuel cells. Applied Catalysis B: Environmental. v. 210, p. 121-130, 2017.

doi: 10.1016/j.apcatb.2017.02.082.

[90] BADWAL, S. P. S.; GIDDEY, S.; KULKARNI, A.; GOEL, J.; BASU, S. Direct ethanol fuel cells for transport and stationary applications - A comprehensive review. Applied Energy. v. 145, p. 80-103, 2015.

doi: 10.1016/j.apenergy.2015.02.002.

[91] XU, C.; ZENG, R.; SHEN, P. K.; WEI, Z. Synergistic effect of CeO2 modified $\mathrm{Pt} / \mathrm{C}$ catalysts on the alcohols oxidation. Electrochimica Acta. v. 51, n. 6, 
p. 1031-1035, 2005.

doi: 10.1016/j.electacta.2005.05.041.

[92] ANTOLINI, E. Catalysts for direct ethanol fuel cells. Journal of Power Sources. v. 170, n. 1, p. 1-12, 2007.

doi: 10.1016/j.jpowsour.2007.04.009.

[93] XU, J. B.; ZHAO, T. S.; SHEN, S. Y.; LI, Y. S. Stabilization of the palladium electrocatalyst with alloyed gold for ethanol oxidation. International Journal of Hydrogen Energy. v. 35, n. 13, p. 6490-6500, 2010.

doi: 10.1016/j.ijhydene.2010.04.016.

[94] NGUYEN, S. T.; LIANG TAN, D. S.; LEE, J. M.; CHAN, S. H.; WANG, J. Y.; WANG, $X$. Tb promoted Pd/C catalysts for the electrooxidation of ethanol in alkaline media. International Journal of Hydrogen Energy. v. 36, n. 16, p. 9645-9652, 2011.

doi: 10.1016/j.ijhydene.2011.05.049.

[95] NGUYEN, S. T.; LAW, H. M.; NGUYEN, H. T.; KRISTIAN, N.; WANG, S.; HWA, S.; WANG, C. X. Enhancement effect of Ag for Pd/C towards the ethanol electrooxidation in alkaline media. Applied Catalysis B: Environmental. v. 91, n. 1-2, p. 507-515, 2009.

doi: 10.1016/j.apcatb.2009.06.021.

[96] GERALDES, A. N.; DA SILVA, D. F.; DA SILVA, J. C. M.; DE SÁ, O. A.; SPINACÉ, E. V.; NETO, A. O.; SANTOS, M. C. Palladium and palladium-tin supported on multi wall carbon nanotubes or carbon for alkaline direct ethanol fuel cell. Journal of Power Sources. v. 275, p. 189-199, 2015.

doi: 10.1016/j.jpowsour.2014.11.024.

[97] MAO, H.; GAO, H.; ZHANG, X.; KUMI, F. Nondestructive measurement of total nitrogen in lettuce by integrating spectroscopy and computer vision. Scientia Horticulturae. v. 184, p. 1-7, 2015.

doi: 10.1016/j.scienta.2014.12.027.

[98] M. Z. F. Kamarudin, S. K. Kamarudin, M. S. Masdar, and W. R. W. Daud, "Review: Direct ethanol fuel cells," Int. J. Hydrogen Energy, vol. 38, no. 22, pp. 9438-9453, 2013.

doi: 10.1016/j.ijhydene.2012.07.059.

[99] ROH, G.; LEE, H.; JEONG, Y.; KIM, J. H.; KIM, H. Preparation of carbonsupported $\mathrm{Pt}-\mathrm{Ru}$ core-shell nanoparticles using carbonized polydopamine and ozone for a CO tolerant electrocatalyst. International Journal of Hydrogen Energy. v. 44, n. 39, p. 21588-21596, 2019.

doi: 10.1016/j.ijhydene.2019.06.079.

[100] ABDEL HAMEED, R. M.; Facile preparation of Pd-metal oxide/C electrocatalysts and their application in the electrocatalytic oxidation of ethanol. Applied Surface Science. v. 411, p. 91-104, 2017. doi: 10.1016/j.apsusc.2017.03.108. 
[101] SHIEH, D. T. Kinetics for Electro-oxidation of Ethanol on Thermally Prepared Ruthenium Oxide in Alkaline Solution. Journal of the Electrochemical Society. v. 142, n. 3, p. 816, 1995.

doi: $10.1149 / 1.2048541$.

[102] Q. Q. Xia, L. Y. Zhang, Z. L. Zhao, and C. M. Li, "Growing Platinum-RutheniumTin ternary alloy nanoparticles on reduced graphene oxide for strong ligand effect toward enhanced ethanol oxidation reaction," J. Colloid Interface Sci., vol. 506, pp. 135-143, 2017, doi: 10.1016/j.jcis.2017.06.098.

[103] SHEN, Y.; XIAO, K.; XI, J.; QIU, X. Comparison study of few-layered graphene supported platinum and platinum alloys for methanol and ethanol electrooxidation. Journal of Power Sources. v. 278, p. 235-244, 2015.

doi: 10.1016/j.jpowsour.2014.12.062.

[104] ROSSMEISL, J.; FERRIN, P.; TRITSARIS, G. A.; NILEKAR, A. U.; KOH, S.; BAE, S. E.; BRANKOVIC, S. R.; STRASSER, P.; MAVRIKAKIS, M. Bifunctional anode catalysts for direct methanol fuel cells. Energy \& Environmental Science. vol. 5, n. 8, p. 8335-8342, 2012.

doi: $10.1039 /$ c2ee21455e.

[105] ZHOU, W.; LEE, J. Y. Particle size effects in Pd-catalyzed electrooxidation of formic acid. Journal of Physical Chemistry C. v. 112, n. 10, p. 3789-3793, 2008.

doi: $10.1021 / j p 077068 m$.

[106] ALMEIDA, T. S.; PALMA, L. M.; LEONELLO, P. H.; MORAIS, C.; KOKOH, K. B.; DE ANDRADE, A. R. An optimization study of PtSn/C catalysts applied to direct ethanol fuel cell: Effect of the preparation method on the electrocatalytic activity of the catalysts. Journal of Power Sources. v. 215, p. 53-62, 2012. doi: 10.1016/j.jpowsour.2012.04.061.

[107] LIM, D. H.; CHOI, D. H.; LEE, W. D.; LEE, H. I. A new synthesis of a highly dispersed and $\mathrm{CO}$ tolerant $\mathrm{PtSn} / \mathrm{C}$ electrocatalyst for low-temperature fuel cell; its electrocatalytic activity and long-term durability. Applied Catalysis B: Environmental. v. 89, n. 3-4, p. 484-493, 2009.

doi: 10.1016/j.apcatb.2009.01.011.

[108] VIDAL-IGLESIAS, F. J.; AI-AKL, A.; WATSON, D. J.; ATTARD, G. A. A new method for the preparation of PtPd alloy single crystal surfaces," Electrochemistry communications. v. 8, n. 7, p. 1147-1150, 2006. doi: 10.1016/j.elecom.2006.05.008.

[109] FENG, R.; LI, M.; LIU, J. Synthesis of core-shell Au@Pt nanoparticles supported on Vulcan XC-72 carbon and their electrocatalytic activities for methanol oxidation. Colloids Surfaces A: Physicochemical and Engineering Aspects. v. 406, p. 6-12, 2012. 
doi: 10.1016/j.colsurfa.2012.04.030.

[110] SUN, Z. P.; ZHANG, X. G.; LIU, R. L.; LIANG, Y. Y.; LI, H. L. A simple approach towards sulfonated multi-walled carbon nanotubes supported by $\mathrm{Pd}$ catalysts for methanol electro-oxidation. Journal of Power Sources. v. 185, n. 2, p. 801-806, 2008.

doi: 10.1016/j.jpowsour.2008.07.026.

[111] ARMSTRONG, K. J.; ELBAZ, L.; BAUER, E.; BURRELL, A. K.; McCLESKEY, T. M.; BROSHA, E. L. Nanoscale titania ceramic composite supports for PEM fuel cells. Journal of Materials Research. v. 27, n. 15, p. 2046-2054, 2012. doi: 10.1557/jmr.2012.169.

[112] BLACKMORE, K. J.; ELBAZ, L.; BAUER, E.; MORE, K.; McCLESKEY, T. M.; BURRLL, A. K. High Surface Area Molybdenum Nitride Support for Fuel Cell Electrodes. Journal of the Electrochemical Socirty. v.158, n.10, p.B1255, 2011.

doi:10.1149/1.3625580.

[113] SHANMUGAM, S.; GEDANKEN, A. Synthesis and electrochemical oxygen reduction of platinum nanoparticles supported on mesoporous TiO2. Journal of Physical Chemistry C. v. 113, n. 43, p. 18707-18712, 2009.

doi: 10.1021/jp908322h.

[114] MORALES-ACOSTA, D.; RODRÍGUEZ-VARELA, F. J.; BENAVIDES, R. Template-free synthesis of ordered mesoporous carbon: Application as support of highly active Pt nanoparticles for the oxidation of organic fuels. International Journal of Hydrogen Energy. v.41, p. 3387-3398, 2016. doi: 10.1016/j.ijhydene.2015.10.114.

[115] CHIANG, Y. C.; LIANG, C. C.; C. CHUNG, P. Characterization of platinum nanoparticles deposited on functionalized graphene sheets. Materials. v. 8, n. 9, p. 6484-6497, 2015.

doi: $10.3390 / \mathrm{ma} 8095318$.

[116] YOLA, M. L.; EREN, T.; ATAR, N.; SARAL, H.; ERMIS, I. Direct-methanol Fuel Cell Based on Functionalized Graphene Oxide with Mono-metallic and Bimetallic Nanoparticles: Electrochemical Performances of Nanomaterials for Methanol Oxidation. Electroanalysis. v. 28, n. 3, p. 570-579, 2016.

doi: 10.1002/elan.201500381.

[117] ŞENER, T.; KAYHAN, E.; SEVIM, M.; METIN, Ö. Monodisperse CoFe2O4 nanoparticles supported on Vulcan XC-72: High performance electrode materials for lithium-air and lithium-ion batteries. Journal of Power Sources. v. 288, p. 36-41, 2015.

doi: 10.1016/j.jpowsour.2015.04.120.

[118] PÉREZ-RODRÍGUEZ, S.; PASTOR, E.; LÁZARO, M. J. Electrochemical behavior of the carbon black Vulcan XC-72R: Influence of the surface chemistry. International Journal of Hydrogen Energy. v. 43, n. 16, 
p. 7911-7922, 2018.

doi: $10.1016 / j . j$ hydene.2018.03.040.

[119] MA, Y.; WANG, H.; JI, S.; GOH, J.; FENG, H.; WANG, R. Highly active Vulcan carbon composite for oxygen reduction reaction in alkaline medium. Electrochimica Acta. v. 133, p. 391-398, 2014.

doi:10.1016/j.electacta.2014.04.080.

[120] EI KHATIB, K. M.; ABDEL HAMEED, R. M. Development of Cu2O/Carbon Vulcan XC-72 as non-enzymatic sensor for glucose determination. Biosensors Bioelectronics. v. 26, n. 8, p. 3542-3548, 2011.

doi: 10.1016/j.bios.2011.01.042.

[121] SPINACÉ, E. V.; NETO, A. O.; FRANCO, E. G.; LINARDI, M.; GONZALEZ, E. $R$. Métodos de preparação de nanopartículas metálicas suportadas em carbono de alta área superficial, como eletrocatalisadores em células a combustível com membrana trocadora de prótons. Quimica Nova. v. 27, n. 4, p.648-654, 2004. doi: 10.1590/s0100-40422004000400020.

[122] GOMES, W. S.; SILVA, U. L. V.; SOUZA, J. P. I. Influência do método de preparação de eletrocatalisadores $\mathrm{PtRu} / \mathrm{C}$ sobre a atividade catalítica frente à reação de oxidação de etanol em meio ácido. Quimica Nova. v. 36, n. 4, p. 507-512, 2013.

[123] TOSHIMA, N.; YONEZAWA, T. Bimetallic nanoparticles novel materials for chemical and physical applications. New Journal of Chemistry. v. 22, p. 11791201, 1998.

[124] KIM, S.; SONG, K.; KIM, M.; JANG, I.; OH, S. G. Preparation of Pt-TiO2 composite particles by alcohol reduction method and their photocatalytic activities. Journal of Physics and Chemistry of Solids. v. 74, n. 3, p. 524-529, 2013,

doi: 10.1016/j.jpcs.2012.12.001.

[125] LEE, J. M.; KIM, D. W.; KIM, T. H.; OH, S. G. Facile route for preparation of silica-silver heterogeneous nanocomposite particles using alcohol reduction method. Materials Letters. v. 61, n. 7, p. 1558-1562, 2007.

doi:10.1016/j.matlet.2006.07.078.

[126] SARMA, L. S.; LIN, T. D.; TSAI, Y. W.; CHEN, J. M.; HWANG, B. J.; Carbonsupported Pt-Ru catalysts prepared by the Nafion stabilized alcohol-reduction method for application in direct methanol fuel cells. Journal of Power Sources. v. 139, n. 1-2, p. 44-54, 2005.

doi: 10.1016/j.jpowsour.2004.07.016.

[127] BEYHAN, S.; ŞAHIN, N. E.; PRONIER, S.; LÉGER, J. M.; KADIRGAN, F. Comparison of oxygen reduction reaction on $\mathrm{Pt} / \mathrm{C}, \mathrm{Pt}-\mathrm{Sn} / \mathrm{C}, \mathrm{Pt}-\mathrm{Ni} / \mathrm{C}$, and $\mathrm{Pt}-\mathrm{Sn}$ $\mathrm{Ni} / \mathrm{C}$ catalysts prepared by Bönnemann method: A rotating ring disk electrode study. Electrochimica Acta. v. 151, p. 565-573, 2015.

doi: 10.1016/j.electacta.2014.11.053. 
[128] BEYHAN, S.; COUTANCEAU, C.; LÉGER, J. M.; NAPPORN, T. W.; KADIRGAN, F. Promising anode candidates for direct ethanol fuel cell: Carbon supported PtSn-based trimetallic catalysts prepared by Bönnemann method. International Journal of Hydrogen Energy. v. 38, n. 16, p. 6830-6841, 2013. doi:10.1016/j.jhydene.2013.03.058.

[129] NETO, A. O.; FRANCO, E. G.; ARICÓ, E.; LINARDI, M.; GONZALEZ, E. R. Electro-oxidation of methanol and ethanol on Pt-Ru/C and Pt-Ru-Mo/C electrocatalysts prepared by Bönnemann's method. Journal of the European Ceramic Society. v. 23, n. 15, p. 2987-2992, 2003.

doi: 10.1016/S0955-2219(03)00310-8.

[130] LIU, W.; CHENG, S.; GUO, J. Anode modification with formic acid: A simple and effective method to improve the power generation of microbial fuel cells. Applied Surface Science. v. 320, p. 281-286, 2014.

doi: 10.1016/j.apsusc.2014.09.088.

[131] BRANKOVIC, S. R.; McBREEN, J.; ADZIC, R. R. Spontaneous deposition of Pt on the $\mathrm{Ru}(0001)$ surface. Journal Electroanalysis Chemica. v. 503, n. 1-2, p. 99-104, 2001.

doi: 10.1016/S0022-0728(01)00349-7.

[132] CHANG, W. C.; NGUYEN, M. T. Investigations of a platinum-ruthenium/carbon nanotube catalyst formed by a two-step spontaneous deposition method. Journal of Power Sources. v. 196, n. 14, p. 5811-5816, 2011.

doi: 10.1016/j.jpowsour.2011.03.012.

[133] DELGADO, J. A.; CLAVER, C.; CASTILLÓN, S.; CURULLA-FERRÉ, D.; ORDOMSKY, V. V.; GODARD, C. Fischer-Tropsch synthesis catalysed by small TiO2 supported cobalt nanoparticles prepared by sodium borohydride reduction. Applied Catalysis A: General. v. 513, p. 39-46, 2016. doi: 10.1016/j.apcata.2015.12.019.

[134] SALMI, T.; RUSSO, V. Reaction engineering approach to the synthesis of sodium borohydride. Chemical Engineering Science. v. 199, p. 79-87, 2019. doi: 10.1016/j.ces.2019.01.007.

[135] HU, J.; KONG, G.; ZHU, Y.; CHE, C. Ultrafast room-temperature reduction of graphene oxide by sodium borohydride, sodium molybdate and hydrochloric acid. Chinese Chemical Letters. 2020.

doi: 10.1016/j.cclet.2020.03.045.

[136] PERIASAMY M.; THIRUMALAIKUMAR, M. Methods of enhacement of reactivity and selectivity of sodium borohydride for applications in organic syntesis. Journal of Organometallic Chemistry. v. 609, p. 137-151, 2000. doi: https://doi.org/10.1016/S0022-328X(00)00210-2 
[137] NABID, M. R.; BIDE, Y.; KAMALI, B. Hydrogen release from sodium borohydride by Fe2O3@nitrogen-doped carbon core-shell nanosheets as reasonable heterogeneous catalyst. International Journal of Hydrogen Energy. v. 44, n. 47, p. 25662-25670, 2019.

doi: 10.1016/j.jhydene.2019.08.038.

[138] LUTY-BLOCHO, M.; FITZNER, K.; LOB, P.; MASKOS, M.; WOJNICKI, M. Synthesis of gold nanoparticles in an interdigital micromixer using ascorbic acid and sodium borohydride as reducers. Chemical Engineering Journal. v. 171, n. 1, p. 279-290, 2011.

doi: 10.1016/j.cej.2011.03.104.

[139] ZENG, C.; WEN, H.; YAO, H.; SPRUNGER, P. T.; GUO, S. M.; In-situ synchrotron $\mathrm{X}$-ray diffraction data for the dynamic reaction processes between titanium and air under laser irradiation. Data in Brief. v. 29, p. 105155, 2020.

doi: 10.1016/j.dib.2020.105155.

[140] KELLOGG, R.; LAPIDUS, S.; HEDMAN, T.; KALMAN, J. Synchrotron Based Measurement of the Temperature Dependent Thermal Expansion Coefficient of Ammonium Perchlorate. Propellants, Explosives, Pyrotechnics. v. 45, n. 3, pp. 480-485, 2020.

doi: 10.1002/prep.201900257.

[141] KIRKLAND, A. I.; HUTCHISON, J. L. Nanocharacterization. 1.ed. Cambridge.: RSC Publishing, 2007. 2007.

[142] GUPTA, G. Design of Novel Catalysts by infusion of Presynthesized Nanocrystals into Mesoporous Supports. Estado: Texas, ProQest LLC., 2008.

[143] KOOG, D. A.; HOLLER, F. J.; CROUCH, S. R. Principles of instrumental analysis. Cengage learning, 2017.

[144] SKOOG, D. A.; HOLLER, F. J.; NIEMAN, T. A. Princípio de análise Instrumental. 5 ed. Porto Alegre: Bookman, 2002. 2002.

[145] FONTES, E. H.; PIASENTIN, R. M.; AYOUB, J. M. S.; DA SILVA, J. C. M.; ASSUMPÇÃO, M. H. M. T.; SPINACÉ, E. V.; NETO, A. O.; DE SOUZA, R. F. $B$. Electrochemical and in situ ATR-FTIR studies of ethanol electro-oxidation in alkaline medium using $\mathrm{PtRh} / \mathrm{C}$ electrocatalysts. Materials Renewable Sustainable Energy. v. 4, n. 1, 2015.

doi: $10.1007 /$ s40243-015-0043-z.

[146] ZHANG, J. PEM Fuel Cell Electrocatalysts and CatalystLayers: Fundamentals and Applications. Vancouver: Springer, 2008.

[147] GERALDES, A. N. et al. Ethanol electro-oxidation in an alkaline medium using $\mathrm{Pd} / \mathrm{C}, \mathrm{Au} / \mathrm{C}$ and $\mathrm{PdAu} / \mathrm{C}$ electrocatalysts prepared by electron beam irradiation. 
Electrochimica Acta. v. 111, p. 455-465, 2013.

doi: 10.1016/j.electacta.2013.08.021.

[148] MA, L.; HE, H.; HSU, A.; CHEN, R. PdRu/C catalysts for ethanol oxidation in anion-exchange membrane direct ethanol fuel cells. Journal of Power Sources. v. 241, p. 696-702, 2013.

doi: 10.1016/j.jpowsour.2013.04.051.

[149] MAO, H.; HUANG, T.; YU, A. Surface noble metal modified PdM/C (M = Ru, Pt, Au) as anode catalysts for direct ethanol fuel cells. Journal of Alloys and Compounds. v. 676, p. 390-396, 2016.

doi: 10.1016/j.jallcom.2016.03.200.

[150] BUZZO, G. S.; TEIXEIRA-NETO, E.; HOMEM-DE-MELO, P.; LOPES, A. C. G.; FRANCO-JUNIO, E.; SUFFREDINI, H. B. Effects of catalyst load in Pt and Pbbased catalysts using formic acid oxidation as a model. Journal of Power Sources. v. 199, p. 75-84, 2012.

doi: 10.1016/j.jpowsour.2011.10.044.

[151] FONTES, E. H.; RAMOS, C. E. D.; NANDENHA, J.; PIASENTIN, R. M.; NETO, A. O.; LANDERS, R. Structural analysis of PdRh/C and PdSn/C and its use as electrocatalysts for ethanol oxidation in alkaline medium. International Journal of Hydrogen Energy. v. 44, n. 2, p. 937-951, 2019.

doi: 10.1016/j.jhydene.2018.11.049.

[152] XIONG, Z.; XU, H. LI, S.; GU, Z.; YAN, B.; GUO, J.; DU, Y. Concave Pd-Ru nanocubes bounded with high active area for boosting ethylene glycol electrooxidation. Applied Surface Science. v. 427, p. 83-89, 2018.

doi: 10.1016/j.apsusc.2017.08.170.

[153] GUO, J.; CHEN, R.; ZHU, F. C.; SUN, S. G.; VILLULLAS, H. M. New understandings of ethanol oxidation reaction mechanism on $\mathrm{Pd} / \mathrm{C}$ and $\mathrm{Pd} 2 \mathrm{Ru} / \mathrm{C}$ catalysts in alkaline direct ethanol fuel cells. Applied Catalysis B Environmental. v. 224, p. 602-611, 2018.

doi: 10.1016/j.apcatb.2017.10.037.

[154] ZHANG, J.; QU, X.; HAN, Y.; SHEN, L.; YIN, S.; LI, G.; JIANG, Y.; SUN, S. Engineering PtRu bimetallic nanoparticles with adjustable alloying degree for methanol electrooxidation: Enhanced catalytic performance. Applied Catalysis B: Environmental. v. 263, p. 118345, 2020.

doi: 10.1016/j.apcatb.2019.118345.

[155] DE LA FUENTE, J. L. G.; MARTÍNEZ-HUERTA, M. V.; ROJAS, S.; TERREROS, P.; FIERRO, J. L. G.; PENA, M. A. Methanol electrooxidation on PtRu nanoparticles supported on functionalised carbon black. Catalysis Today. v. 116, n. 3, p. 422-432, 2006.

doi: $10.1016 /$ j.cattod.2006.05.083.

[156] LIU, Z.; ZHANG, X.; TAY, S. W. Nanostructured PdRu/C catalysts for formic acid oxidation. Journal of Solid State Electrochemistry. v. 16, n. 2, 
p. 545-550, 2012.

doi: 10.1007/s10008-011-1378-8.

[157] KUBLER, M.; JURZINSKY, T.; ZIEGENBALG, D.; CREMERS, C. Methanol oxidation reaction on core-shell structured Ruthenium-Palladium nanoparticles: Relationship between structure and electrochemical behavior. Journal of Power Sources. v. 375, p. 320-334, 2018.

doi: 10.1016/j.jpowsour.2017.07.114.

[158] LI, F.; SHANG, Y.; DING, Z.; WENG, H.; XIAO, J.; LIN, M. Efficient extraction and separation of palladium $(\mathrm{Pd})$ and ruthenium $(\mathrm{Ru})$ from simulated HLLW by photoreduction. Separation and Purification Technology. v. 182, p. 9-18, 2017.

doi: 10.1016/j.seppur.2017.03.029.

[159] MONYONCHO, E. A.; NTAIS, S.; SOARES, F.; WOO, T. K.; BARANOVA, E. A. Synergetic effect of palladium-ruthenium nanostructures for ethanol electrooxidation in alkaline media. Journal of Power Sources. v. 287, p. 139-149, 2015. doi: 10.1016/j.jpowsour.2015.03.186.

[160] HELLGREN, N.; HAASCH, R. T.; SCHMIDT, S.; HULTMAN, L.; PETROV, I. Interpretation of $X$-ray photoelectron spectra of carbon-nitride thin films: New insights from in situ XPS. Carbon. v. 108, p. 242-252, 2016.

doi: 10.1016/j.carbon.2016.07.017.

[161] CAO, J.; SONG, L.; TANG, J.; XU, J.; WANG, W.; CHEN, Z. Enhanced activity of $\mathrm{Pd}$ nanoparticles supported on Vulcan $\mathrm{XC72R}$ carbon pretreated via a modified Hummers method for formic acid electrooxidation. Applied Surface Science. v. 274, p. 138-143, 2013. doi: 10.1016/j.apsusc.2013.02.133.

[162] KUMAR, S. M. S.; HERRERO, J. S.; IRUSTA, S.; SCOTT, K. The effect of pretreatment of Vulcan XC-72R carbon on morphology and electrochemical oxygen reduction kinetics of supported $\mathrm{Pd}$ nano-particle in acidic electrolyte. Journal of Electroanalytical Chemistry. v. 647, n. 2, p. 211-221, 2010. doi: 10.1016/j.jelechem.2010.05.021.

[163] NANDENHA, J.; NAGAHAMA, I. H. F.; YAMASHITA, J. Y.; FONTES, E. H.; AYOUB, J. M. S.; DE SOUZA, R. F. B.; FONSECA, F. C.; NETO, A. O. Activation of methane on $\mathrm{PdZn} / \mathrm{C}$ electrocatalysts in an acidic electrolyte at low temperatures. Internaional Journal of Electrochemical Science. v. 14, n. 12, p. 10819-10834, 2019.

doi: $10.20964 / 2019.12 .76$.

[164] KUNDU, S.; WANG, Y.; XIA, W.; MUHLER, M. Thermal Stability and Reducibility of Oxygen-Containing Functional Groups on Multiwalled Carbon Nanotube Surfaces: A quantitative High-Resolution XPS and TPD/TPR Study. Journal of Physical Chemistry C. v. 481, p. 16869-16869, 2008. doi:10.1021/jp804413a 
[165] DOLGOV, A.; LOOPAEV, D.; LEE, C. J.; ZOETHOUT, E.; MEDVEDEV, V.; YAKUSHEV, O.; BIJKERK, F. Characterization of carbon contamination under ion and hot atom bombardment in a tin-plasma extreme ultraviolet light source. Applied Surface Science. v. 353, p. 708-713, 2015.

doi: 10.1016/j.apsusc.2015.06.079.

[166] HUANG, Y.; TANG, J.; GAU, L.; GONG, Y.; GUAN, H.; HE, R.; LYU, H. Different approaches for preparing a novel thiol-functionalized graphene oxide/Fe-Mn and its application for aqueous methylmercury removal. Chemical Engineering Journal. v. 319, p. 229-239, 2017.

doi: 10.1016/j.cej.2017.03.015.

[167] MEREL, P.; TABBAL, M.; CHAKER, M.; MOISA, S.; MARGOT, J. Direct evaluation of the sp 3 content in diamond-like-carbon films by XPS. Applied Surface Science. v. 136, n. 1-2, p. 105-110, 1998.

doi: 10.1016/S0169-4332(98)00319-5.

[168] ATASHBAR, M. Z.; SUN, H. T.; GONG, B.; WLODARSKI, W.; LAMB, R. XPS study of $\mathrm{Nb}$-doped oxygen sensing $\mathrm{TiO} 2$ thin films prepared by sol-gel method. Thin Solid Films. v. 326, n. 1-2, p. 238-244, 1998.

doi: 10.1016/S0040-6090(98)00534-3.

[169] MOULDER, J.; STICKLE, W. F.; SOBOL, P. E.; BOMBEN, K. D. Handbook of X-ray photoelectron spectroscopy: a reference book of standard spectra for identification and interpretation of XPS data. Physical Electronics Division, Perkin-Elmer Corporation, Minnesota (1992).

[170] LOPEZ-SUAREZ, F. E.; BUENO-LOPEZ, A.; EGUILUZ, K. I. B.; SALZARBANDA, G. R. Pt-Sn/C catalysts prepared by sodium borohydride reduction for alcohol oxidation in fuel cells: Effect of the precursor addition order. Journal of Power Sources. v. 268, p. 225-232, 2014.

doi: 10.1016/j.jpowsour.2014.06.042.

[171] LI, Y.; YU, H.; WANG, Z.; LIU, S.; XU, Y.; LI, X.; WANG, L.; WANG, H. Onestep synthesis of self-standing porous palladium-ruthenium nanosheet array on $\mathrm{Ni}$ foam for ambient electrosynthesis of ammonia. International Journal of Hydrogen Energy. v. 45, n. 11, p. 5997-6005, 2020.

doi: 10.1016/j.ijhydene.2019.12.098.

[172] ZHANG, R. L.; DUAN, J-J.; HUAN, Z.; FENG, J-J.; HUANG, H.; ZHANG, Q-L.; WANG, A-J. One-step aqueous synthesis of hierarchically multi-branched $\mathrm{PdRuCu}$ nanoassemblies with highly boosted catalytic activity for ethanol and ethylene glycol oxidation reactions. Applied Surface Science. v. 506, p. 144791, 2020.

doi: 10.1016/j.apsusc.2019.144791.

[173] YI, Q.; NIU, F.; SONG, L.; LIU, X.; NIE, H. Electrochemical activity of novel titanium-supported porous binary $\mathrm{Pd}-\mathrm{Ru}$ particles for ethanol oxidation in 
alkaline media. Electroanalysis. v. 23, n. 9, p. 2232-2240, 2011. doi: 10.1002/elan.201100148.

[174] XU, C.; CHENG, L.; SHEN, P.; LIU, Y. Methanol and ethanol electrooxidation on $\mathrm{Pt}$ and $\mathrm{Pd}$ supported on carbon microspheres in alkaline media. Electrochemistry communications. v. 9, n. 5, p. 997-1001, 2007. doi: 10.1016/j.elecom.2006.12.003.

[175] R. M. Modibedi, T. Masombuka, and M. K. Mathe, "Carbon supported Pd-Sn and Pd-Ru-Sn nanocatalysts for ethanol electro-oxidation in alkaline medium," Int. J. Hydrogen Energy, vol. 36, no. 8, pp. 4664-4672, 2011, doi: 10.1016/j.ijhydene.2011.01.028.

[176] WANG, Y.; NGUYEN, T. S.; LIU, X.; WANG, X. Novel palladium-lead (Pd-Pb/C) bimetallic catalysts for electrooxidation of ethanol in alkaline media. Journal of Power Sources. v. 195, n. 9, p. 2619-2622, 2010.

doi: 10.1016/j.jpowsour.2009.11.072.

[177] HUANG, Y.; CAI, J.; GUO, Y. Facile synthesis of a Bi-modified PtRu catalyst for methanol and ethanol electro-oxidation in alkaline medium. International Journal of Hydrogen Energy. v. 38, n. 8, p. 3250-3256, 2013. doi: 10.1016/j.ijhydene.2012.12.091.

[178] JIANG, L.; HSU, A.; CHU, D.; CHEN, R. Ethanol electro-oxidation on Pt/C and $\mathrm{PtSn} / \mathrm{C}$ catalysts in alkaline and acid solutions. International Journal of Hydrogen Energy. v. 35, n. 1, p. 365-372, 2010.

doi: 10.1016/j.ijhydene.2009.10.058.

[179] YANG, Y.; YU, S.; GAO, L.; WANG, X.; YAN, S. The properties of PdRu /C with respect to the electro-oxidation of methanol and ethanol. International Journal of Electrochemical Science. v. 14, n. 2, p. 1270-1282, 2019.

doi: $10.20964 / 2019.02 .50$.

[180] JIANG, L.; HSU, A.; CHU, D.; CHEN, R. Oxygen reduction on carbon supported $\mathrm{Pt}$ and PtRu catalysts in alkaline solutions. Journal of Electroanalytical Chemistry. v. 629, n. 1-2, p. 87-93, 2009.

doi: 10.1016/j.jelechem.2009.01.029.

[181] CAMARA, G. A.; IWASITA, T. Parallel pathways of ethanol oxidation: The effect of ethanol concentration. Journal of Electroanalytical Chemistry. v. 578, n. 2, p. 315-321, 2005.

doi: 10.1016/j.jelechem.2005.01.013.

[182] SIMÕES, F. C. et. al. Electroactivity of tin modified platinum electrodes for ethanol electrooxidation. Journal of Power Sources. v. 167, p. 1-10, 2007. doi: 10.1016/j.jpowsour.2006.12.113.

[183] FONTES, E. H.; DA SILVA, S. G.; SPINACÉ, E. V.; NETO, A. O.; DE SOUZA, R. F. B. In Situ ATR-FTIR Studies of Ethanol Electro-oxidation in Alkaline Medium on PtRh/C Electrocatalyst Prepared by an Alcohol Reduction Process. Electrocatalysis. v. 7, n. 4, p. 297-304, 2016. 
doi: 10.1007/s12678-016-0308-z.

[184] MA, L.; HSU, A.; CHEN, R. Performance of PdRu/C Anode Catalyst for AnionExchange Membrane Direct Ethanol Fuel Cell. ECS Transactions. v. 58, n. 1, p. 1321-1326, 2013.

doi: $10.1149 / 05801.1321$ ecst.

[185] XU, C.; WANG, L.; MU, X.; DING, Y. Nanoporous PtRu alloys for electrocatalysis. Langmuir. v. 26, n. 10, p. 7437-7443, 2010.

doi: $10.1021 / l a 9041474$.

[186] WATANABE, M.; MOTOO, S. Eletrocatálise por ad-átomos Parte III, Melhoria da oxidação de $\mathrm{CO}$ em Pt por Ru ad-átomos. Journal of Electroanalytical Chemistry. v.60, pp. 275 - 283, 1975.

[187] FISHER, J. M.; CABELLO-MORENO, N.; CHRISTIAN, E.; THOMPSETT, D. Methanol oxidation activity of PtRu alloy nanoparticles in direct methanol fuel cells. Electrochemical anf Solid State Letters. v. 12, n. 5, 2009.

doi: $10.1149 / 1.3095675$.

[188] FALASE, A.; MAIN, M.; GARCIA, K.; SEROV, A.; LAU, C.; ATANASSOV, P. Electrooxidation of ethylene glycol and glycerol by platinum-based binary and ternary nano-structured catalysts. Electrochimica Acta, v. 66, p. 295-301, 2012.

doi: 10.1016/j.electacta.2012.01.096.

[189] JEFFERY, D. Z.; CAMARA, G. A. The formation of carbon dioxide during glycerol electrooxidation in alkaline media: First spectroscopic evidences. Electrochemistry communications. v. 12, n. 8, p. 1129-1132, 2010. doi: 10.1016/j.elecom.2010.06.001.

[190] SCHNAIDT, J.; HEINEN, M.; DENOT, D.; JUSYS, Z.; BEHM, R. J. Electrooxidation of glycerol studied by combined in situ IR spectroscopy and online mass spectrometry under continuous flow conditions. Journal of Electroanalytical Chemistry. v. 661, n. 1, p. 250-264, 2011.

doi: 10.1016/j.jelechem.2011.08.011.

[191] NETO, A. O.; NANDENHA, J.; ASSUMPÇÃO, M. H. M. T.; LINARDI, M.; SPINACÉ, E. V.; DE SOUZA, R. F. B.; In situ spectroscopy studies of ethanol oxidation reaction using a single fuel cell/ATR-FTIR setup. International Journal of Hydrogen Energy. v. 38, n. 25, p. 10585-10591, 2013. doi: 10.1016/j.ijhydene.2013.06.026.

[192] SIMÕES, M.; BARANTON, S.; COUTANCEAU, C. Electro-oxidation of glycerol at $\mathrm{Pd}$ based nano-catalysts for an application in alkaline fuel cells for chemicals and energy cogeneration. Applied Catalysis B Environmental. v. 93, n. 3-4, p. 354-362, 2010. doi: 10.1016/j.apcatb.2009.10.008. 
[193] SIMÕES, M.; BARANTON, S.; COUTANCEAU, C. Enhancement of catalytic properties for glycerol electrooxidation on $\mathrm{Pt}$ and $\mathrm{Pd}$ nanoparticles induced by $\mathrm{Bi}$ surface modification. Applied Catalysis B: Environmental. v. 110, p. 40-49, 2011.

doi: 10.1016/j.apcatb.2011.08.020.

[194] CAI, J.; MA, H.; ZHANG, J.; DU, Z.; HUANG, Y.; GAO, J.; XU, J. Catalytic oxidation of glycerol to tartronic acid over Au/HY catalyst under mild conditions. Chinese Journal Catalysis. v. 35, n. 10, p. 1653-1660, 2014. doi: 10.1016/S1872-2067(14)60132-7.

[195] OTTONI, C. A.; DA SILVA, S. G.; DE SOUZA, R. F. B.; NETO, A. O. PtAu Electrocatalyst for Glycerol Oxidation Reaction Using a ATR-FTIR/Single Direct Alkaline Glycerol/Air Cell In Situ Study. Electrocatalysis. v. 7, p. 22-32, 2016. doi: $10.1007 / \mathrm{s} 12678-015-0277-7$. 


\section{INSTITUTO DE PESQUISAS ENERGÉTICAS E NUCLEARES}

Diretoria de Pesquisa, Desenvolvimento e Ensino

Av. Prof. Lineu Prestes, 2242 - Cidade Universitária CEP: 05508-000

Fone/Fax(0XX11) 3133-8908

SÃO PAULO - São Paulo - Brasil

http://www.ipen.br

O IPEN é uma Autarquia vinculada à Secretaria de Desenvolvimento, associada à Universidade de São Paulo e gerida técnica e administrativamente pela

Comissão Nacional de Energia Nuclear, órgão do

Ministério da Ciência, Tecnologia, Inovações e Comunicações. 